University of Tennessee Health Science Center

UTHSC Digital Commons

\title{
Dependence of Craniofacial Growth on Stages of Cervical Vertebral Maturation and Stages of Mandibular Canine Mineralization
}

Charles Allen Chance

University of Tennessee Health Science Center

Follow this and additional works at: https://dc.uthsc.edu/dissertations

Part of the Orthodontics and Orthodontology Commons

\section{Recommended Citation}

Chance, Charles Allen, "Dependence of Craniofacial Growth on Stages of Cervical Vertebral Maturation and Stages of Mandibular Canine Mineralization" (2006). Theses and Dissertations (ETD). Paper 40. http://dx.doi.org/10.21007/etd.cghs.2006.0046. 


\title{
Dependence of Craniofacial Growth on Stages of Cervical Vertebral Maturation and Stages of Mandibular Canine Mineralization
}

\author{
Abstract \\ When an individual presents for orthodontic treatment, orthodontic records are made that also include \\ demographic information. The orthodontic treatment plan is determined not only from the diagnostic \\ records but also from the relative amounts of growth the orthodontist perceives will take place during \\ treatment. The purpose of this study was to determine if pretreatment biological age, as assessed from \\ cervical vertebral (CV) maturity and/or mandibular canine mineralization, are statistically tied to the \\ amount of growth occurring during treatment, and if so, then if biological age has any predictive merit in \\ anticipating the amounts of growth occurring during treatment. The sample was narrowed from the 1,250 \\ Class II division I records at the Department of Orthodontics, University of Tennessee to 183 individuals, \\ 106 females and 77 males. Pretreatment cervical vertebral grades and canine mineralization stages were \\ analyzed via ANOVA to determine if facial growth occurring over treatment was statistically tied to the \\ pretreatment grade assessed. It was found that as individuals age, less growth occurs during treatment. \\ For all CV stages the growth was highly significant for the stage and sex of the individual. Although \\ pretreatment CV grades were highly significant in terms of growth per stage, tooth mineralization stages \\ were less significant, but did provide clinical applications of whether the individual has reached or passed \\ their growth spurt.

\section{Document Type} \\ Thesis

\section{Degree Name} \\ Master of Dental Science (MDS) \\ Program \\ Orthodontics \\ Research Advisor \\ Edward Harris, Ph.D. \\ Keywords \\ Craniofacial Growth, Stages Cervical Vertebral Maturation, Mandibular Canine \\ Subject Categories \\ Dentistry | Medicine and Health Sciences | Orthodontics and Orthodontology
}




\title{
DEPENDENCE OF CRANIOFACIAL GROWTH \\ ON STAGES OF CERVICAL VERTEBRAL MATURATION AND \\ STAGES OF MANDIBULAR CANINE MINERALIZATION
}

\author{
A Thesis \\ Presented for \\ The Graduate Studies Council \\ The University of Tennessee \\ Health Science Center

\begin{abstract}
In Partial Fulfillment
Of the Requirements for the Degree

Master of Dental Science

From the University of Tennessee
\end{abstract}

By

Charles Allen Chance

May 2006 
Copyright $\odot$ Charles Allen Chance, 2006 All rights reserved 


\section{DEDICATION}

This thesis is dedicated to my parents

Mr. Charles Hale Chance

and

Mrs. Karen Jean Chance

in recognition of their love, guidance, and support

of my education. 


\section{ACKNOWLEDGEMENTS}

I would like to thank my thesis committee for their help and support over these last three years. Dr. Chuck Robinson and Dr. William Parris guided my thoughts and contributed to my process of learning throughout the process. Dr. Edward Harris, my committee chairman and research advisor, is irreplaceable in the knowledge and guidance he has provided for the project. I would like to thank Tim Patel for his encouragement when I felt uninspired and Starbucks ${ }^{\circledR}$ for their endless supply of coffee. I would like to thank God for this opportunity and for the abilities he has given me to experience life. Lastly, I would like to thank Linda Widjaja for her unknowing contribution to drive my desire for excellence in life. 


\begin{abstract}
When an individual presents for orthodontic treatment, orthodontic records are made that also include demographic information. The orthodontic treatment plan is determined not only from the diagnostic records but also from the relative amounts of growth the orthodontist perceives will take place during treatment. The purpose of this study was to determine if pretreatment biological age, as assessed from cervical vertebral (CV) maturity and/or mandibular canine mineralization, are statistically tied to the amount of growth occurring during treatment, and if so, then if biological age has any predictive merit in anticipating the amounts of growth occurring during treatment. The sample was narrowed from the 1,250 Class II division I records at the Department of Orthodontics, University of Tennessee to 183 individuals, 106 females and 77 males. Pretreatment cervical vertebral grades and canine mineralization stages were analyzed via ANOVA to determine if facial growth occurring over treatment was statistically tied to the pretreatment grade assessed. It was found that as individuals age, less growth occurs during treatment. For all CV stages the growth was highly significant for the stage and sex of the individual. Although pretreatment $\mathrm{CV}$ grades were highly significant in terms of growth per stage, tooth mineralization stages were less significant, but did provide clinical applications of whether the individual has reached or passed their growth spurt.
\end{abstract}




\section{TABLE OF CONTENTS}

$\begin{array}{lll}\text { Chapter } & \text { Page }\end{array}$

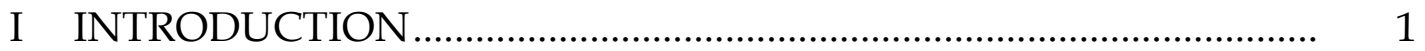

II REVIEW OF THE LITERATURE............................................................. 6

Parapubertal Growth Spurt ....................................................... 6

Sex Differences in Parapubertal Growth......................... 8

Stature and Facial Dimensions ...................................... 11

Synchronicity of Stature and Facial Growth Spurts ...... 15

Early, Average, and Late Maturers ................................ 16

Craniofacial Growth....................................................... 21

Craniofacial Growth Spurt................................... 21

Sex Differences in Facial Growth Spurt .............. 24

Nasomaxillary Complex ...................................... 25

Mandible ............................................................ 26

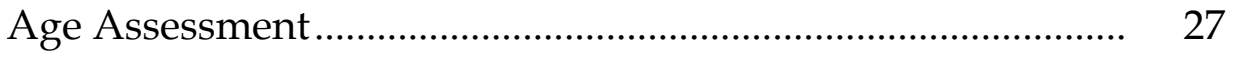

Chronological Versus Physiological Age........................ 27

Dental Age Versus Skeletal Age...................................... 28

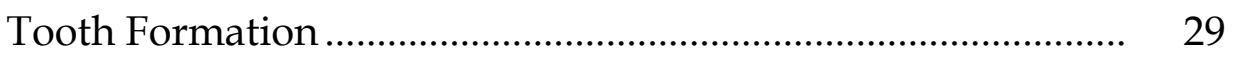

Tooth Mineralization.................................................................... 31 
Tooth Development Variability.

Tooth Classification .......................................................... 32

Sexual Dimorphism..................................................... $\quad 38$

Physiological Age Prediction ............................................ 41

Formation and Development of Cervical Vertebrae ................. 43

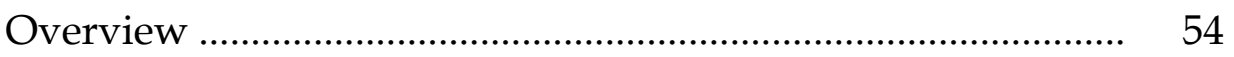

III MATERIALS AND METHODS.......................................................... 56

Sample Description ............................................................... 56

Cervical Vertebrae Maturation .................................................... 57

Tooth Mineralization.................................................................. 60

Facial Bony Growth................................................................ 62

Statistical Analysis.................................................................... 66

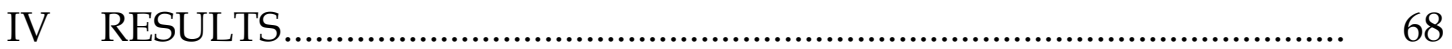

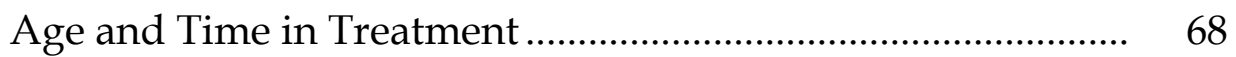

Chronological Age and Growth ................................................ 77

Sex Differences in Growth Rates ............................................... 92

Canine Apexification............................................................... 92

Second Cervical Vertebra ........................................................... 110

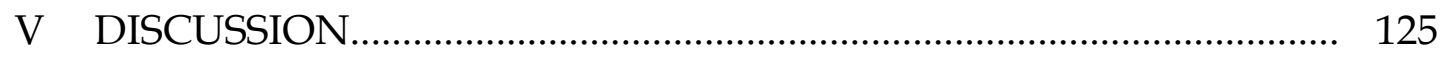

Sexual Dimorphism.................................................................. 129

Chronological Age versus Physiological Age ………………... 130 
Class II Correction .................................................................. 131

VI SUMMARY AND CONCLUSIONS........................................................ 134

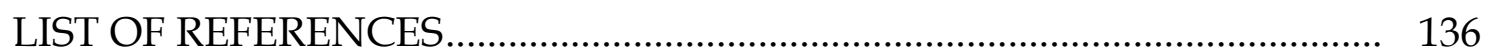

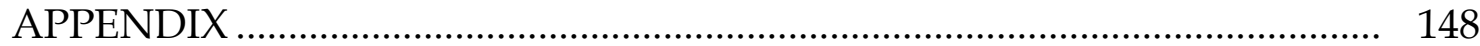

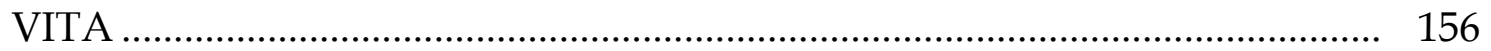




\section{LIST OF TABLES}

Table

Page

1. Definitions of the 15 stages of tooth formation used by Gleiser and Hunt (1955) to grade the mineralization of the mandibular first permanent molar

2. Definitions of the ten stages of tooth formation used by Nolla (1960) to grade the mineralization.

3. Comparative table of mineralization stages used by different authors

4. Chronological age distribution of pretreatment orthodontic subjects used in the present study

5. Subject distribution among stages of CV2 and mandibular canine

6. Results of four-way factorial ANOVA looking at sources of variation for the in-treatment change in Sella-Nasion distance.

7. Results of four-way factorial ANOVA looking at sources of variation for the in-treatment change in Sella-Gnathion distance

8. Results of four-way factorial ANOVA looking at sources of variation for the in-treatment change in Sella-Gonion distance

9. Results of four-way factorial ANOVA looking at sources of variation for the in-treatment change in Sella-A Point distance

10. Results of four-way factorial ANOVA looking at sources of variation for the in-treatment change in Sella-B Point distance. 
11. Results of regression of facial growth on

chronological age at the start of treatment, in males.

12. Results of regression of facial growth on

chronological age at the start of treatment, in females

13. Results of analysis of covariance testing whether the amount of growth differed between the sexes.

14. Descriptive statistics for chronological age at the start of treatment partitioned by sex and stage of mandibular canine root formation

15. Results of ANOVA tests of whether the amounts of growth differed between mandibular canine grade 12 and 13 assessed at the pretreatment examination

16. Descriptive statistics of the amounts of facial growth partitioned by stage of the mandibular canine at the start of treatment and sex.

17. Descriptive statistics for age at the start of treatment partitioned by sex and CV2 stage of development.

18. Results of two-way ANOVA tests of whether the amounts of growth differ by CV2 stage of development

19. Descriptive statistics for dimensions of facial growth, by sex and stage of cervical vertebral morphology

A-1. Demographic, skeletal, dental, and cephalometric data for all patients. 


\section{LIST OF FIGURES}

Figure

Page

1. Human growth velocity chart for somatic tissues partitioned into the four major intervals of postnatal growth....

2. Height velocity curve for boys and girls ....................................... 10

3. Fishman's 11-grade scheme used to assess skeletal maturity from a hand-wrist radiograph.

4. Schematic drawings of the stages of tooth mineralization used by Moorrees, Fanning and Hunt (1963)

5. Schematic drawings along with the textual cues for discriminating between Demirjian's 8 grades to tooth formation.

6. Sketches of the six morphological grades of the cervical vertebrae

7. Mandibular growth in each cervical vertebrae maturational stages

8. Six CVMI as described by Hassel and Farman (1995)

9. Diagram of CV dimensional measurements used in determining dimensional ratios of the vertebral bodies of $\mathrm{C} 2$ and $\mathrm{C} 3$.

10. Radiographic interpretation of Moorrees-FanningHunt ordinal single-rooted tooth grades

11. Five craniofacial measurements used in this study.

12. Age distributions of the total sample $(n=183)$ by sex.

13. Plot of amount of growth in Sella-Nasion against 
chronological age at the start of treatment in males

14. Plot of amount of growth in Sella-Gnathion against chronological age at the start of treatment in males

15. Plot of amount of growth in Sella-Gonion against chronological age at the start of treatment in males....

16. Plot of amount of growth in Sella-A Point against chronological age at the start of treatment in males

17. Plot of amount of growth in Sella-B Point against chronological age at the start of treatment in males.

18. Plot of amount of growth in Sella-Nasion against chronological age at the start of treatment in females

19. Plot of amount of growth in Sella-Gnathion against chronological age at the start of treatment in females

20. Plot of amount of growth in Sella-Gonion against chronological age at the start of treatment in females

21. Plot of amount of growth in Sella-A Point against chronological age at the start of treatment in females

22. Plot of amount of growth in Sella-B Point against chronological age at the start of treatment in females

23. Plot of age at the start of treatment against the amount of growth during treatment, by sex, for Sella-Nasion

24. Plot of age at the start of treatment against the amount of growth during treatment, by sex, for Sella-Gnathion.

25. Plot of age at the start of treatment against the amount of growth during treatment, by sex, for Sella-Gonion

26. Plot of age at the start of treatment against the amount of growth during treatment, by sex, for Sella-A Point 
27. Plot of age at the start of treatment against the amount of growth during treatment, by sex, for Sella-B Point

28. Mean growth in Sella-Nasion, partitioned by stage of the mandibular canine and sex

29. Mean growth in Sella-Gnathion, partitioned by stage of the mandibular canine and sex

30. Mean growth in Sella-Gonion, partitioned by stage of the mandibular canine and sex

31. Mean growth in Sella-A Point, partitioned by stage of the mandibular canine and sex

32. Mean growth in Sella-B Point, partitioned by stage of the mandibular canine and sex

33. Mean ages at each morphological stage of cervical vertebra 2

34. Plot of mean amounts of growth in Sella-Nasion achieved during treatment, based on subject's sex and cervical vertebral morphology

35. Plot of mean amounts of growth in Sella-Gnathion achieved during treatment, based on subject's sex and cervical vertebral morphology

36. Plot of mean amounts of growth in Sella-Gonion achieved during treatment, based on subject's sex and cervical vertebral morphology

37. Plot of mean amounts of growth in Sella-A Point achieved during treatment, based on subject's sex and cervical vertebral morphology

38. Plot of mean amounts of growth in Sella-B Point achieved during treatment, based on subject's sex and cervical vertebral morphology 


\section{CHAPTER I}

\section{INTRODUCTION}

When a patient presents for orthodontic treatment, the orthodontist develops a problem list and a treatment plan appropriate for that individual. In devising the treatment plan, the orthodontist considers not only dental and facial relationships but also how much jaw growth can be anticipated and whether this will aid in correcting any parasagittal discrepancies (e.g., Bergersen 1972;

Fishman 1987). Orthodontics can modulate jaw growth during treatment to improve the dentofacial outcome, but only to the extent that the patient is growing. The orthodontist seldom has the opportunity to choose when to treat a patient - that is determined primarily by parental decisions of when to take a child for treatment - but the orthodontist can assess how much facial growth might occur during the course of treatment given the patient's demographics and adjust his treatment plan accordingly.

Treatment options are, then, modulated by the patient's degree of physiological maturity. From birth until the end of growth, an individual is constantly changing in his physiological progression toward maturity. Maturity is a term used to describe the physiological progression an individual has undergone or, conversely, is yet to take place (Tanner et al. 1975). It is a 
developmental process that proceeds from being completely immature to completely mature. Size parameters such as stature do not have these same qualities. "A child who is tall for his age may be so because he is more mature than his coevals, but he may simply be a tall child of average maturity, who will eventually be a tall adult" (Tanner et al. 1975: 4). When only height is used to assess maturity, a short person with a late adolescent growth spurt would be assumed to be a short adult. After the late spurt, he could catch up to and/or bypass children of the same chronological age in height and would then be labeled as a tall adult.

A way of measuring progression toward maturity - and, thus, the patient's growth potential -is to use biological markers known as developmental "milestones" (Tanner et al. 1975: 4). These are events that occur in all normally developing individuals. Menarche and breast development for girls are two markers. Tanner et al. (1975) explain that menarche provides information to conclude that a girl who has reached this milestone is more mature than one who has not yet reached it. The more refined a grading system of maturity, the more fully a child's progress towards maturity can be described. A more refined grading system provides more information about an individual, which is especially useful to an orthodontist. It is well known that growth rates vary both within and among individuals, but with information about a patient's degree of 
maturity and tempo of growth, a treatment plan can be customized to optimize the treatment outcome.

The optimal treatment plan for orthodontic correction usually involves some type of facial growth modification. Because orthodontic treatment modifies growth and does not cause it, the best time to treat is when facial growth is most rapid (Pancherz and Hägg 1985). Many researchers have suggested by rendering treatment during the enhanced velocity of the adolescent growth spurt, the orthodontist can achieve a successful outcome in a reduced period of time (Björk 1972; Pancherz and Hägg 1985; von Bremen and Pancherz 2002).

Although chronological age (CA) commonly is used to gauge a patient's position on his growth trajectory, CA is not tied well with a person's tempo of growth. Not only does CA not address an individual's degree of biological development, it is also a weak predictor of growth rates because of appreciable variation in the tempo of children's growth (Fishman 1979). Chronological age does not address the differences in the timing, duration, and extent of adolescence between the sexes and among individuals within the same sex (e.g., Tanner 1962; van der Linden 1986; Bogin 1988). When physiological age is used instead of chronological age, the prediction of the growth potential of the patient becomes more individualized (Moorrees et al. 1963). Physiological age has been estimated using various maturational indicators, such as voice changes in boys, 
menarche and breast development in girls, and pubic hair development (e.g., Marshall and Tanner 1969, 1970; Moore et al. 1990).

One way of estimating a child's degree of biological maturity and thereby, his or her position relative to the adolescent growth spurt is by assessing the morphology of the cervical vertebrae. The predictive value of cervical vertebrae morphologies in the assessment of skeletal age has been shown to be extremely reliable (O'Reilly and Yanniello 1988; Kucukkeles et al. 1999; Chang et al. 2001; Baccetti et al. 2002; Mito et al. 2003).

Another way of estimating the growth spurt velocity is by assessing the degree of crown-root formation of permanent teeth (Moorrees et al. 1963). According to Chertkow (1980) the root and apexification of the mandibular canine occurs close to the adolescent growth spurt. Tooth mineralization often is categorized into stages ranging from the initial crown formation to apex closure (e.g., Moorrees et al. 1963; Haavikko 1974; Demirjian and Goldstein 1976). Of these stages, "complete root formation prior to apical closure coincided with the appearance of other maturational indicators of the pubertal growth spurt" (Chertkow 1980: 90).

When physiological age is used in place of chronological age, a more individualized estimate of growth potential can be obtained. The purpose of the present research is to determine if biological age, as assessed from cervical vertebral maturity and/or tooth mineralization, have any predictive merit in 
anticipating the amounts of facial growth during the course of orthodontic treatment.

The central issue is whether the amount of facial growth observed during the course of treatment is tied statistically to maturational status at the start of treatment. Prior research (McKinney and Harris 2001; Harris 2001) has shown that the amounts of facial growth are tied to chronological age at the start of treatment. Substituting bone age or dental age for chronological age should, then, improve the associations between 'age' and growth because the variability of 'age' is smaller when using a physiological instead of a chronological measure of maturity (e.g., Bergersen 1972; Grave and Brown 1976; Hägg and Taranger 1980).

There has been prior work in this area, notably the studies by O'Reilly and Yanniello (1988) and Baccetti et al. (2002). These studies evaluated untreated childrens' annualized growth in the absence of orthodontic treatment. The study design is different here: The question is how much growth can be anticipated over the course of treatment, which is on the order of $2 \frac{1 / 2}{2}$ years. This is a more clinically-relevant question, and it also avoids reliance on children whose occlusion did not warrant orthodontic treatment. 


\section{CHAPTER II}

\section{REVIEW OF THE LITERATURE}

\section{Parapubertal Growth Spurt}

Growth is a process that occurs throughout an individual's life, though the rate slows considerably after the second decade (Forsberg and Odenrick 1979). The pattern of somatic growth during the first 20 years often is categorized into four broad intervals (Fig. 1): infancy, spanning birth to approximately 3 years of age; childhood, from about 3 to 12 years of age; adolescence, from about 12 to 18 years of age; and adulthood, from 18 years onward (Tanner 1978; Bogin 1988). Although growth during infancy is very rapid, it is rapidly decelerating. The rate decreases until about age 3 where it proceeds for several years at an approximately constant rate (Smith 1977; Tanner 1978; van der Linden 1986). In the early teens, velocity accelerates, which is the well-known adolescent (parapubertal) growth spurt. After adolescence, the rate of growth decreases substantially, but does not stop (Behrents 1986). Although all of these intervals of growth occur in normally developing individuals, the adolescent growth spurt (along with the other intervals to a lesser degree) varies significantly in the initiation, duration, and amount of growth (Moore et al. 1990). Some common reasons for such diversity in the growth spurt can be contributed 


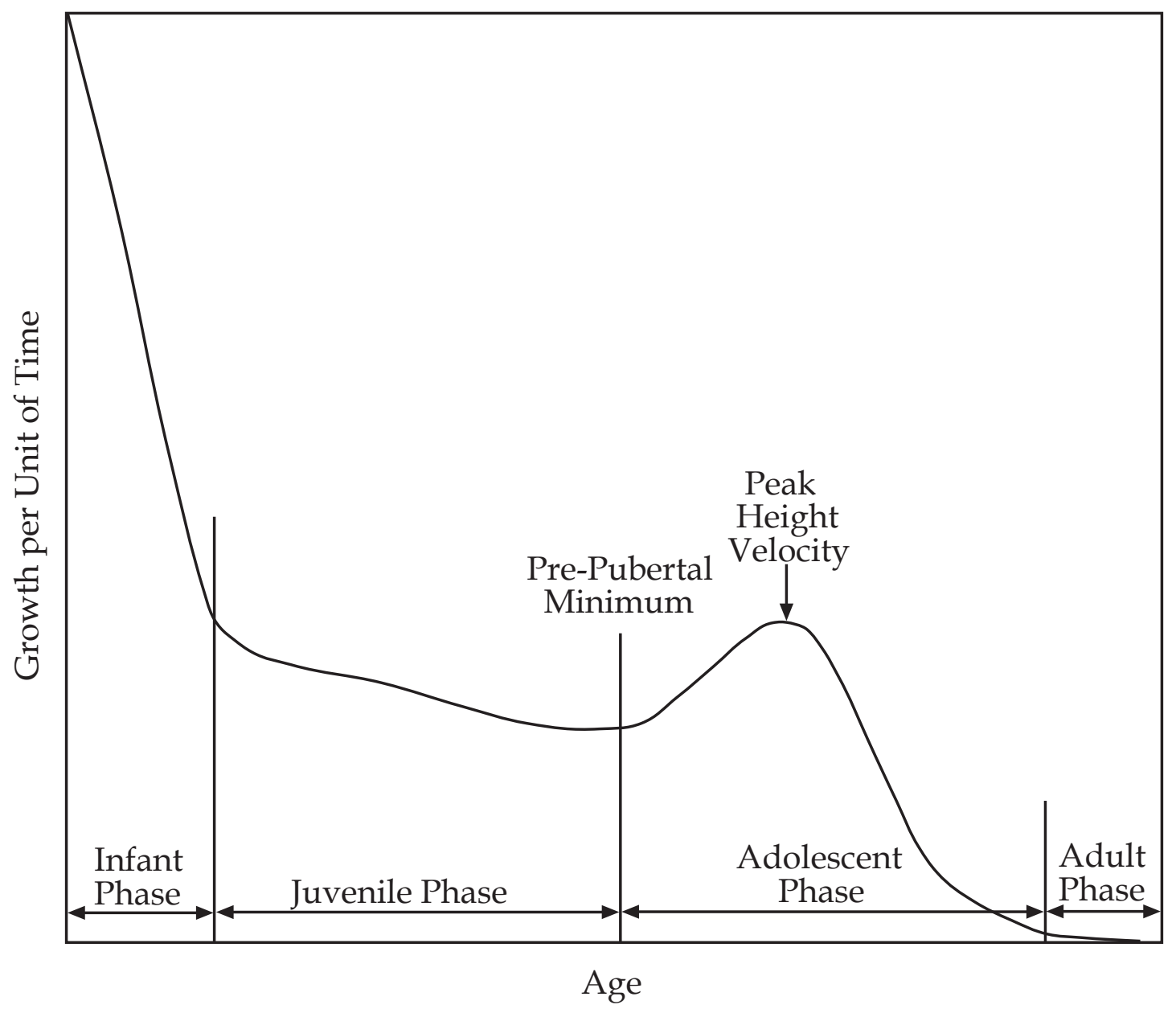

Fig. 1. Human growth velocity chart for somatic tissues partitioned into the four major intervals of postnatal growth.

Source: Tanner JM. Fetus into man. Harvard: Harvard University Press, 1978. 
to heredity, nutrition, morbidity, and socioeconomic status (Björk and Helm 1967; Tanner 1978; Bogin 1988).

\section{Sex Differences in Parapubertal Growth}

An important factor that influences the timing of the adolescent growth spurt is the individual's sex (Tanner 1978; Fishman 1979; van der Linden 1986; Bogin 1988). Beginning with birth, boys are and remain slightly taller and larger than girls until the onset of the girl's growth spurt. The velocity of the parapubertal growth spurt in girls is smaller and occurs an average of 2 years earlier in life than in boys (Tanner 1978; Hägg and Taranger 1980; Taranger and Hägg 1980; Hägg and Taranger 1982; Farkas et al. 1992). Björk and Helm (1967) found that maximum pubertal growth in height occurred in girls at age 12.6 and for boys at age 14.0. This age difference in the onset of the parapubertal growth spurt adds to the sexual diversity in physiological maturity.

Hägg and Taranger (1980) obtained hand-wrist and stature data for 212 Swedish children. These children's data were recorded once a year until the age of 18 years. The onset of the pubertal growth spurt in stature occurred around age 10 for girls and 12 for boys. Peak height velocity and end of the spurt each occurred two years later, ending in girls at about 15 and in boys about 17.

Guo et al. (1992) analyzed human statural growth of 227 subjects with two mathematical models, one that accounts for a mid growth spurt and one that 
does not. Females, age $9.4 \pm 1.0$, reached the pubertal growth spurt 2 years earlier on average than males, age $10.9 \pm 1.3$. Since females reached the onset of their spurt earlier than males, their shorter stature at the onset is not surprising, $133.2 \mathrm{~cm}(\mathrm{sd}=6.9)$ in girls compared to $144.4 \mathrm{~cm}(\mathrm{sd}=8.6)$ in boys. This difference in stature at the onset of the growth spurt is due to the two more years of childhood growth in boys (Tanner 1978; Guo et al. 1992). In addition, males exhibit a greater peak growth velocity, averaging $9.2 \mathrm{~cm} / \mathrm{yr}$, than females, averaging $7.9 \mathrm{~cm} /$ year. So, not only do boys begin the growth spurt later in life but also the maximum adolescent velocity is larger than the maximum in girls (Largo et al. 1978; Guo et al. 1992). This difference in velocity and timing of the adolescent growth spurt are illustrated in Figure 2. At the end of their adolescent growth spurts, boys characteristically are taller and larger than girls.

Largo et al. (1978) found a sex difference of $12.6 \mathrm{~cm}$ in stature in early adulthood. This difference was determined to come from four sources: (1) 1.6 $\mathrm{cm}$ due to increased prepubertal growth in boys, (2) $6.4 \mathrm{~cm}$ due to the delayed growth spurt in boys, (3) $6.0 \mathrm{~cm}$ due to the larger velocity of the boy's growth spurt, and (4) $-1.4 \mathrm{~cm}$ due to more post-spurt growth in girls. This study by Largo and coworkers also found that boys tend to have a smaller percentage of total adult height prepubertally, but both sexes have achieved $91.3 \%$ of their respective adult heights at the peak of the growth spurt (Largo et al. 1978). This is in partial agreement with Guo et al. (1992) who found that both sexes had 


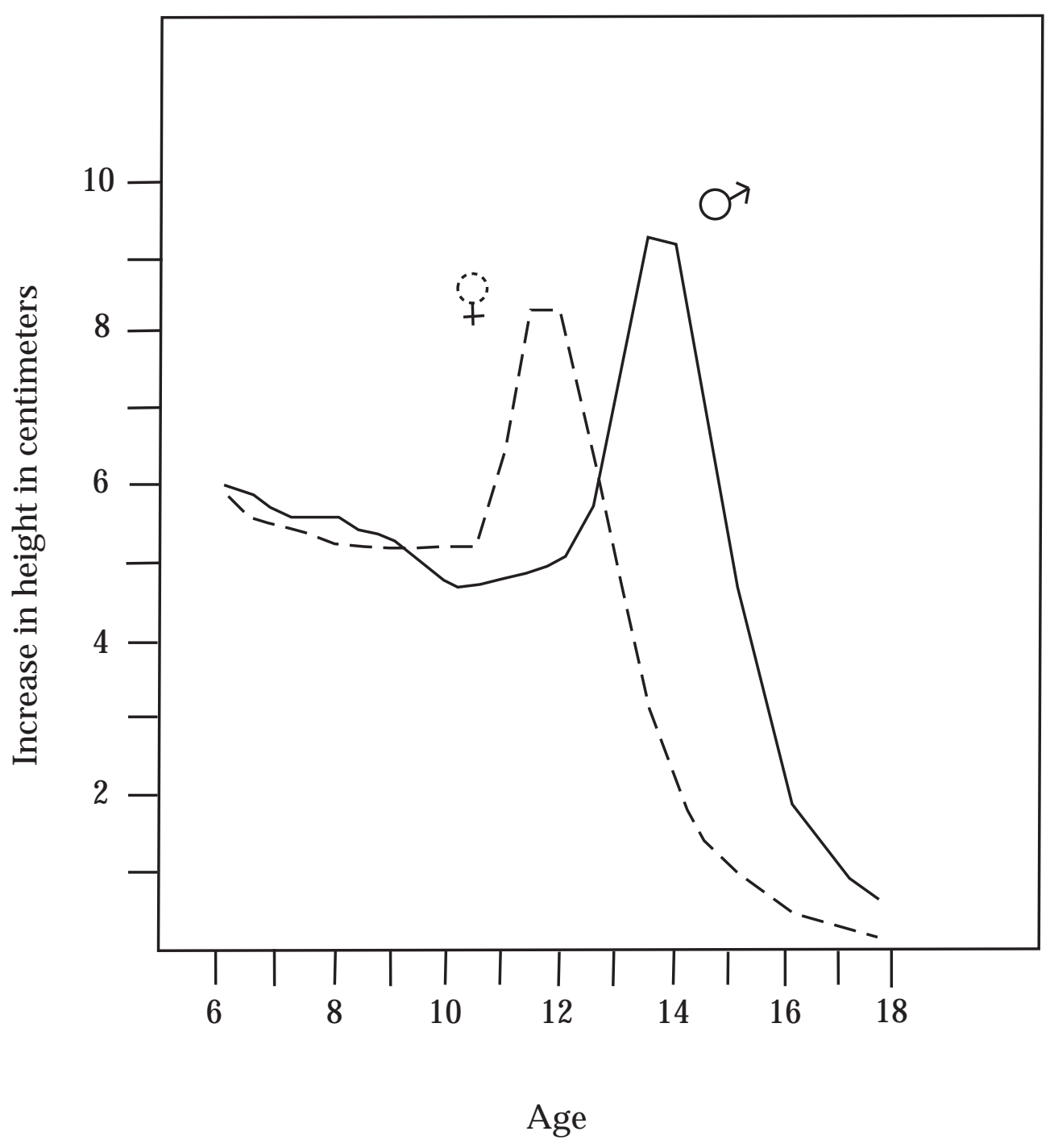

Fig. 2. Height velocity curve for boys and girls.

Source: Tanner JM. Fetus into man. Harvard: Harvard University Press, 1978. 
similar percentages of complete stature at the onset and peak velocity of statural growth. Largo et al. concluded that boys have a more intense growth spurt to account for the same adult height percentage as girls at peak velocity. After the growth spurt, boys and girls have reached $97.5 \%$ and $96.5 \%$ of their adult heights, respectively (Largo et al. 1978). This information allowed Largo to state that boys have less postpubertal growth than girls.

\section{Stature and Facial Dimensions}

In ways analogous to those seen for stature, facial dimensions also grow and undergo proportional changes from the time of birth at least until adulthood. On a gross scale, the calvaria first grows rapidly after birth and then growth progressively declines in velocity. Growth of the face parallels the general growth velocity curve (Tanner 1978; Fishman 1982).

Growth of the face continues once mature stature has been obtained (Bambha 1961). Hunter (1966) conducted a study in which chronological age, skeletal age, and stature were assessed in 25 boys and 34 girls. These data were recorded at six-month intervals over a span of seven years. Skeletal ages were determined using hand-wrist radiographs with the Greulich and Pyle (1959) standards. Cephalometric radiographs were taken every 9 months until the subjects reached a chronological age of 13 years. Hunter measured seven linear dimensions to assess facial growth: (1) Articulare-Gonion, (2) Gonion-Pogonion, 
(3) Articulare-Pogonion, (4) Articulare-A Point, (5) Sella-Nasion, (6) Sella-

Gnathion, and (7) Nasion-Menton. The onset of the pubertal growth spurt occurred an average of 2.4 years earlier in girls, 10.4 years of age, than boys, 12.8 years of age. Hunter found that subjects' maximum increments of facial growth occurred simultaneously with maximum statural velocity in $57 \%$ of the cases, while $14 \%$ occurred before and $29 \%$ after maximum statural velocity. This finding (and others) needs to be evaluated against the examination interval. In this study, 'coincident' means that the maxima occurred within the same ninemonth interval. Maximum velocity for mandibular length occurred most commonly coincident with maximum statural velocity. On the other hand, some males (13/59) exhibited maximum mandibular velocity one year after maximum statural growth. Hunter suggested that facial growth continues in females until late into the second decade of life, ceasing when stature ceases to increase. For males, Hunter found 5 to have continued facial growth beyond the completion of statural growth, 2 ceased facial growth before statural growth completion, and 10 had not completed body height growth in the study.

Singh and Savara (1966) studied 50 American girls of European descent were evaluated using lateral and frontal cephalometric radiographs. Individuals were observed for at least six years, with the starting age between of 10 to 16 years of age. Parameters of interest included maxillary height, maxillary length and maxillary width. They found maxillary height velocity to be the greatest of 
these, with Nasion-Prosthion and Nasion-Anterior Nasal Spine measurements to increase a mean of $1.65 \mathrm{~cm}$ and $1.53 \mathrm{~cm}$ from 3 to 16 years of age, respectively. Maxillary length had a slower rate of growth than width until the age of 7 at which it increases to greater rates than width. Overall from the age 3 to 16, they found maxillary length increased in Anterior Nasal Spine-Pterygomaxillary Fissure by $1.19 \mathrm{~cm}$ while maxillary width increased in the distance between right and left zygomaticomaxillary sutures by $1.54 \mathrm{~cm}$. Singh and Savara also found an adolescent spurt in maxillary growth in girls with the maximum growth increment in each dimension occurring between the ages 10 and 12 years. Singh and Savara (1968) also studied boys $(n=52)$ and found growth patterns similar to girls occurring one to three years later in life than girls. A difference with boys is the larger increases in the dimensions. Nasion-Prosthion and Nasion-Anterior Nasal Spine increased 2.1 and $1.7 \mathrm{~cm}$ from age 3 to 16 while girls only increased 1.6 and $1.5 \mathrm{~cm}$, respectively. The maxillary height and width also illustrated this difference with Anterior Nasal Spine-Pterygomaxillary fissure and right and left zygomaticomaxillary fissure measurements being 1.2 and $1.9 \mathrm{~cm}$, respectively, for boys while girls only increased 1.2 and $1.5 \mathrm{~cm}$, respectively.

Bergersen (1972) assessed serial cephalometric radiographs of 23 American white boys. He evaluated seven cephalometric dimensions in addition to stature: (1) Articulare-Gnathion, (2) Nasion-Menton, (3) Sella-Gnathion, (4) Anterior Nasal Spine-Menton, (5) Sella-Nasion, (6) Sella-Anterior Nasal Spine, 
and (7) Nasion-Anterior Nasal Spine. Hand-wrist bone age was evaluated using the Greulich and Pyle atlas (1959). Bergersen also found the variation in skeletal age of the onset of growth of Articulare-Gnathion, Nasion-Menton, and SellaGnathion to be one-third that of the chronological age. Onset of four of the dimensions (stature, Articulare-Gnathion, Nasion-Menton, and Sella-Gnathion) occurred in a range of 10.7 to 14.9 chronological years of age, yielding a range of 4.2 years. If, instead, bone age is used to calculate onset of the four dimensions, the range was between 11.7 to 13.2 years of age, so the range was 1.5 years. Bergersen, as well as other researchers (Bambha and van Natta 1963; Hunter 1966) found no significant difference between chronological and physiological age when compared to the onset of normal maturing individuals, but found a significant difference in the two when compared to early or late maturers. So, by using chronological age, plus or minus one year of the mean, to estimate the adolescent growth spurt, one would not account for 35\% of the cases in which the individual could be an early or late maturer. This large percentage error is due to the inability of chronological age to predict growth patterns of early or late maturing individuals. Therefore, if skeletal age is employed instead of chronological age, all estimations (including early and late maturers) would fall plus or minus one year of the mean. 
Synchronicity of Statural and Facial Growth Spurts

Bergersen (1972) stated that there is no difference in the onset of the adolescent growth spurt in body height, facial height (Nasion-Menton), or mandibular length (Articulare-Gnathion). Other researchers have also demonstrated peak height velocity and facial growth velocity to occur in harmony (Brown, Barnette and Grave 1971; Grave 1973; Thompson and Popovich 1973; Bishara et al. 1981; Lewis, Roche and Wagner 1985).

Moore, Moyer, and DuBois (1990) assessed the usefulness of hand-wrist radiographs for skeletal maturation to amounts of craniofacial growth assessed from cephalometric radiographs. Cephalometric and hand-wrist radiographs, and stature were recorded annually for 47 girls, in the age range 10 to 15 years; and for 39 boys, in the age range of 11 to 16 years. The craniofacial measurements used were: (1) Sella-Nasion, (2) Gonion-Gnathion, (3) SellaGonion, and (4) Nasion-Menton. They used Tanner Whitehouse (1975) TW2 RUS method to determine skeletal maturity. They found the greatest velocity in stature to occur between 11 and 12 for girls and between 12 and 13 for boys. They found the maximum velocity of Gonion-Gnathion and Nasion-Menton in girls to coincide with the peak velocity in stature. For the remaining craniofacial measurements, they found the maximum velocity to occur after maximum statural velocity. It is interesting to mote that if a smaller interval of time between examinations were used, the results of this study might be more 
significant and show different craniofacial growth and statural velocity relationships.

Other studies have shown that maximum facial velocities occur later in life than maximum statural velocity. Nanda (1955) studied serial cephalometric radiographs of 10 males and 5 females from the Denver Child Growth Study. Data on seven measurements were gathered: (1) Sella-Nasion, (2) NasionGnathion, (3) Nasion-Prosthion, (4) Nasion-Infradentale, (5) Sella-Gonion, (6) Gonion-Gnathion, and (7) Sella-Gnathion. Nanda found 28\% of the 15 cases had coincident stature and craniofacial growth spurts, $57 \%$ had craniofacial growth spurts occurring six months or later in life than the spurt for stature, and 14\% had craniofacial growth occurring earlier than stature. The author did not specify amounts of time when referring to early or late growth spurts, and like the previous study, might have benefited from a reduced time interval between examinations.

\section{Early, Average and Late Maturers}

The tempo at which an individual is maturing can be somewhat different or closely resemble another individual of the same chronological age. For this, average growth percentiles for both sexes have been established so one can compare individuals to the mean and elicit retarded or accelerated growth patterns in a population. 
Burstone (1963) believes assessment of the peak velocity in facial growth by peak velocity in stature is misleading. He attributes the inability of statural peak velocity to be predictive of peak facial velocity to the age range at which statural peak velocity occurs. The average of statural peak velocity for girls is 11.5 years of age, but the range is 9.5 to 14.5 years of age, and likewise for boys but at older chronological ages. The large age range is due to early and late maturers, which hinders chronological age from being used as a predictor of growth. Although the argument seems reliable, one could argue that although the age range is large for statural peak velocity, it varies likewise in facial peak velocity; meaning early and late maturers in stature also mature early and late in facial growth. Nevertheless, Burstone does suggest that assessment from chronological age is the main reason for the inability and not the rate of maturation of the individual

Tofani (1972) found the earlier the growth spurt, the greater its magnitude but less its intensity and vice versa for late growth spurts. This is in agreement with Burstone (1972) where he noted that early maturers tend to have greater rates of adolescent growth than late maturers. Shuttleworth (1937) attributes this difference to the increased amount of growth early maturers need to complete growth as compared to the decreased amount of growth late maturers need to attain $100 \%$ maturity. 
Fishman (1979) assessed whether skeletal or chronological age provided the more accurate estimate of craniofacial growth. Skeletal assessment was made by hand-wrist radiographic evaluation of 60 boys and 68 girls. Standing height was recorded for each subject, with age ranges from 7 to 15 , along with a cephalometric radiograph. Records were taken in six-month intervals for the study. The craniofacial dimensions measured were: (1) Articulare-Gonion, (2) Gonion-Pogonion, (3) Gonion-Gnathion, (4) Articulare-Gnathion, (5) SellaGnathion, (6) Articulare-A Point, and (7) Sella-Point A. He found only a select few individuals exhibited coincident skeletal and chronological ages. For females, he noted skeletally advanced individuals seem to exhibit less growth than their later maturing counterparts. For males, he noted skeletally delayed individuals possess a decrease in growth velocity than those maturing at a normal age. He reiterates the need for skeletal assessment, not chronological, of the individual. If only chronological age is used to determine when to initiate orthodontic treatment, then growth modification with use of headgears and functional appliances, could yield substantially decreased results if the patient is a early or late maturer. Although his results do show some significance of craniofacial measurements between chronological and skeletal age levels, he contends it's the importance is below that of timing of the events. The timing of the growth events is far more important than the actual measurements themselves. 
Hägg and Taranger (1991) studied a sample of 103 Swedish boys and 80 Swedish girls until the age 25 for significant differences in rates of maturity. They categorized each subject by peak height velocity into three groups: (1) early maturers, (2) average maturers, and (3) late maturers. They found girls did not differ significantly in final height, but late maturing boys were $6.5 \mathrm{~cm}$ and 4.2 $\mathrm{cm}$ taller than their early and normal maturing counterparts respectively.

Silveira et al. (1992) compared the amounts of growth observed in early, average, and late maturers during orthodontic treatment at the Orthodontic Department of the Eastman Dental Center. Using the skeletal maturation assessment system devised by Fishman (1982), they determined maturational stages for each of 70 adolescents (Fig. 3). The patients were divided into three groups based on their skeletal maturational indicators (SMI): (1) SMI 8 to 11, (2) SMI 9 to 11, and (3) SMI 10 to 11. Each group was subdivided by chronological age into three more groups of early, average and late maturers. Cephalometric measurements of (1) Sella-Point A, (2) Articulare-Point A, (3) Sella-Gnathion, (4) Articulare-Gnathion, (5) Articulare-Gonion, and (6) Gonion-Pogonion were assessed. They found late maturers to have a larger increase in growth percentage in all six of these dimensions. Although these authors concluded that late maturers experience the greatest difference in growth in the late stages of pubertal growth, their data show that the greatest difference of growth in three of the measurements occurred in group 1 (SMI 8-11), two remained the same 
Ossification

Adductor Sesamoid

1

Width

Proximal Phalanx III

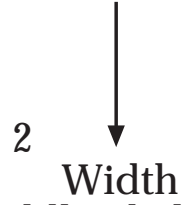

Middle Phalanx III

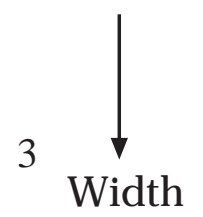

Middle Phalanx V
5

Capping

Distal Phalanx III

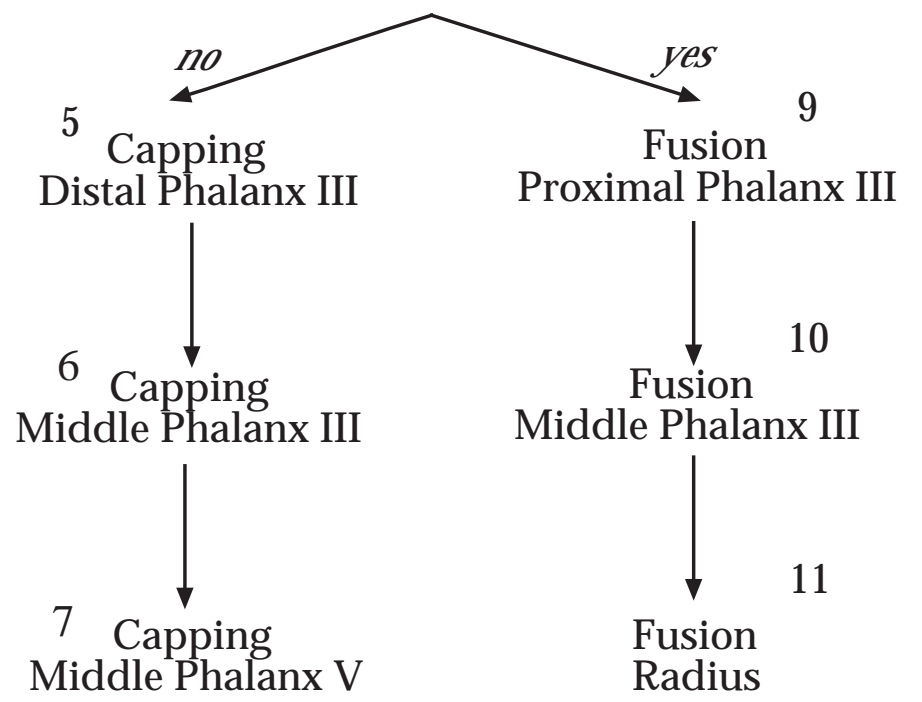

Fusion 8

Distal Phalanx III

Fig. 3. Fishman's 11-grade scheme used to assess skeletal maturity from a hand-wrist radiograph.

Source: Fishman LS. Radiographic evaluation of skeletal maturation. Angle Orthod. 1982;57:178-93. 
across the three groups, and one was larger in group 3 (SMI 10-11). Group 1 shows a Sella-Gnathion growth of $4 \%$ between late and average maturers, while group 3 only shows a $2 \%$ difference.

Contrary to this, Hunter (1966) found no significant difference in the size at the onset, the rate of growth, or the maturity of the face in early, average, and late maturers during pubertal growth, nor any difference in the timing of the facial and statural peak growth velocities.

\section{Craniofacial Growth}

\section{Craniofacial Growth Spurt}

Moore et al. (1990) compared cephalograms and hand-wrist radiographs of 47 girls and 39 boys from the Bolton-Brush studies at Case Western Reserve University. Since "growth usually proceeds in a fairly predictable sequence" and "their timing is quite variable among individual children," the relationship of skeletal maturity and craniofacial maturity was the focus of the study (Moore et al. 1990: 34). The main topic of interest was whether craniofacial growth can be compared to skeletal growth and whether it has any clinical significance. Annual hand-wrist and cephalometric radiographs were used to assess the skeletal and craniofacial growth, respectively. Four linear craniofacial dimensions were used to determine craniofacial growth: (1) Sella-Nasion, (2) Gonion-Gnathion, (3) 
Sella-Gonion, and (4) Nasion-Mention. The results yielded a large distribution of growth patterns and no significant relationship between craniofacial growth spurts and statural height or skeletal maturity. They did, however, find the bone age at age 13 for females to correlate best with the height velocity in the age range of 13 to 14 , and males at a bone age of 16 to correlate best with the height velocity in the age range of 15 to 16 . Their statistical test, analysis of variance (ANOVA), did not show that a growth spurt occurred in any of the facial dimensions, but did identify changes within population velocities for GonionGnathion and Nasion-Menton for both sexes. A Tukey test was then run to identify the time period of the changes and found they occurred over a minimum time span of three years. Upon the conclusion of the study they questioned whether or not a three-year growth acceleration is considered a growth 'spurt' or just an 'acceleration' in growth. Whether a spurt or acceleration, they found no significant clinical predictability between skeletal maturation and craniofacial growth. However, they concluded that although craniofacial growth spurts might occur, the timing of physiological events like "standing height, voice change in boys, menarche in girls, dental development, and skeletal ossification" may be more useful than a craniofacial growth spurt in assessing the development of a child (Moore et al. 1990: 34).

Bishara et al. (1981) compared changes in standing height with those of mandibular growth. The study consisted of 20 boys and 15 girls age, ranging 
from 5 to 17 years of age, from the Facial Growth Study at The University of Iowa. Standing height and cephalometric radiographs were taken biannually between the ages 5 and 12 and then annually until 17 years of age. The linear craniofacial measurements used were Articulare-Pogonion, while the angular measurements of importance used were: Sella-Nasion-Pogonion and SellaNasion-Point B. The statistical test employed in this study was analysis of variance. Statural and craniofacial growth during the study was divided into three time periods: (1) premaximum growth period, (2) maximum growth period, and (3) postmaximum growth period. He found only standing height and Articulare-Pogonion were significantly different for each one of the three time periods, while the angular measurements did not have significant differences between the time periods. Consequently, Bishara concluded that mandibular growth patterns, except for mandibular length (ArticularePogonion), do not follow the growth pattern of stature. Because of this association, Bishara's contention was that mandibular growth spurts do not normally occur and, if in fact there is a spurt, then it is highly variable in its occurrence. One flaw of the study is that the conclusion is based on angular rather than linear measurements. The one linear measurement studied showed a very close correlation with stature, $r=0.83$. Craniofacial growth can be apparent in linear measurements and go virtually undetected in angular measurements due to the essential constancy of the downward-forward growth of the midface. 
For example, Ochoa and Nanda (2004) compared maxillary and mandibular growth in 15 girls and 13 boys. They found no significant change, $0.9^{\circ}$, in SellaNasion-A Point between 6 and 20 years of age. A statistically significant difference was noted in Sella-Nasion-B Point for ages 12 to 14 and 14 to 16, although it was only a $1.2^{\circ}$ and $1.1^{\circ}$ increase for the two time periods respectively. This is comparable to the SNB change of $1.0^{\circ}$ that Bishara et al. (1981) found. While the angular relationships remained virtually constant for Ochoa and Nanda (2004), the linear measurements changed drastically (Articulare-Pogonion). Articulare-Pogonion was found to increase $16.5 \mathrm{~mm}$ from ages 6 to 14, with the peak increase from ages 10 to 12 for females. This illustrates the flaw in Bishara et al. (1981) conclusions because the growth spurt could have occurred and not been detected in angular measurements due to growth patterns.

\section{$\underline{\text { Sex Differences in Facial Growth Spurt }}$}

Fishman (1982) noted that females tend to have a higher growth velocity in the maxilla. His study consisted of cephalometric measurements of 170 females and 164 males followed longitudinally and of 550 females and 550 males assessed cross-sectionally. Fishman scored each individual's degree of maturity using his 11-grade scheme of skeletal maturity indicators (SMI) of the hand (Fig. 3). The amounts of craniofacial growth for (1) Sella-A Point, (2) Articulare-A 
Point, (3) Sella-Gnathion, and (4) Articulare-Gnathion were measured, and Fishman then used a formula to compute the amount of relative growth rate: Relative growth rate $=\left(\mathrm{M}_{1}-\mathrm{M}_{2} / \mathrm{M}_{\text {average }}\right)(100 /$ length of period $) \quad$ [Eq. 1] Fishman then formulated average age standards for the SMIs in both the longitudinal and cross sectional data. He concluded "both sexes completed similar percentages of total growth at comparable SMI's, even though it took place at quite different age periods" (Fishman 1982: 105). Meaning, the amounts of growth were statistically tied to SMI and not chronological age. He also found maximum maxillary and mandibular growth occurred in males, SMI of 7, one SMI later than females, SMI of 6, but chronologically it occurred about 2 years later in life.

\section{Nasomaxillary Complex}

Growth of the maxilla occurs by two complementary processes: (1) sutural growth and (2) appositional bone growth (Enlow and Band 1965; Kurihara et al. 1980). The primary sutures involved in maxillary growth consist of those articulating with the frontal, zygomatic, ethmoid, and palatine bones. Bone growth at the sutures translates into downward-forward movement of the midface. By apposition, the maxillae grow downward by depositing bone in the palatal surface of the maxilla while removing bone on the anterior surface.

Enlow and Bang (1965) found the downward forward growth of the 
nasomaxillary complex to be intricate, with most of the downward forward growth coming from bone deposition on the posterior tuberosity and inferior surfaces of the maxillae. Enlow explained this movement as an expanding V that moved downward and forward as bone deposition occurred along the palatal side of the maxilla. Another substantial contributing factor to the downward forward growth of the nasomaxillary complex is the increase in vertical height from the eruption of permanent teeth (Enlow 1990).

\section{$\underline{\text { Mandible }}$}

The occurrence of a mandibular pubertal growth spurt has been documented. Mitani and Sato (1992) compiled serial cephalometric radiographs, hand wrist radiographs and stature of 33 Japanese girls between 9 and 14 years of age. Mandibular growth, stature, metacarpus and phalanges length, and bone age were assessed annually between the ages of 9 and 14 years. Mitani and Sato reported the maximum growth velocity found in stature, hand bone, cervical vertebrae and hyoid bone to occur around the ages of 9 and 11, but for the mandible it was more variable. For example, the synchrony of maximum growth in length of the bones of the hand and body height was found to occur in $97 \%$ of the subjects, while for the mandible and stature only $72 \%$ were synchronous.

One would expect since the coincidence of the mandible and body height is less than the length of the bones of the hand and stature that the distribution in ages 
to be widely dispersed in terms of maximum growth of the mandible. This was not found as demonstrated by the percentage of girls with the mandible, stature, and hand bone length maximum growth to be $60 \%$ for the age range of 9 to 11 . The hyoid bone and cervical vertebrae were found to be the most variable during this age range with only $54 \%$.

\section{$\underline{\text { Age Assessment }}$}

\section{Chronological Versus Physiological Age}

The common but imprecise way to estimate a child's maturity is to use chronological age. Physiological age is assessed using of maturational indicators (Krogman 1968). In a cross sectional sample of 4,000 subjects, Fishman found "healthy children of any age do not demonstrate any chronologic specificity regarding particular stages of maturation, but identifiable maturational indicators provides a more reliable means of evaluating individualized maturational levels within the very wide chronologic age ranges" (Fishman 1987: 191).

Lewis (1991) used dental and skeletal records of 694 children from an orthodontic practice to compare skeletal and dental ages, to assess if either is coincident with each other and/or chronological age. The sex distribution was 320 boys and 374 girls with a mean age of 10 years. He found dental and skeletal 
ages differed from chronological age by as much as 36 months in normalgrowing children. Fishman (1979) reported that children had skeletal ages that differed from their chronological ages by up to four years. He concluded that the majority of the subjects studied did not show agreement between physiological and chronological ages.

\section{Dental Age Versus Skeletal age}

Liebgott (1978) determined dental and skeletal ages for 32 subjects yearly from age 4 to 18 years and compared these ages to the chronological age of mandibular length (Cd-Gn) peak circumpuberal velocity. Dental ages were determined from a 45-degree cephalometric radiograph using Nolla's 22-method (1952) for assessing dentitions. The skeletal ages were determined using the Tanner Whitehouse (1975) method for evaluation of hand-wrist radiographs. To compare skeletal and dental ages, a matrix of correlation coefficients was made to compare chronological age at maximum mandibular growth, with dental ages and skeletal ages. He found $100 \%$ of the boys reached peak maximum growth spurt within 0.75 years of the skeletal age, while for chronological and dental ages it was within three years. Liebgott concluded that, "dental age is neither a good predictor nor an indicator of the timing of peak circumpuberal growth of the mandible, while skeletal age, on the other hand, shows a very strong relationship to this event" (Liebgott 1978: 226). 
Alternatively, Green (1961) compared chronological, dental, and skeletal ages with weight and height. This study looked at 56 white males from the University of Pittsburgh. Data for each subject consisted of hand-wrist and cephalometric radiographs, height and weight. Hand-wrist radiographs were assessed using the Greulich and Pyle (1959) method while dental age was obtained from the cephalometric radiograph using the Nolla (1952) method. He found that dental age had a stronger correlation with chronological age, 0.6774 , as compared to dental age with weight, height, or skeletal age, where the correlations were in the range of 0.4616 to 0.5630 . He stated that skeletal age had a 'slight' correlation with weight and height, 0.7570 and 0.7859 respectively, but his data reveal a higher correlation than his finding of dental age and chronological age. Regardless, he concluded due to the 'high' correlation of dental and chronological ages, that chronological age is the best predictor of dental maturation.

\section{$\underline{\text { Tooth Formation }}$}

Tooth formation begins with the development of two primary germ layers, ectoderm and mesoderm, and tissue derived from the neural crest (Ten Cate 2003). The ectoderm of the developing odontogenic epithelium provides the origin of enamel and the mesoderm provides the cementum and periodontal tissues. The dentine and pulp are formed from the ectomesenchymal tissue. 
The odontogenic epithelium develops in four different sites in the maxilla and two in the mandible (Ten Cate 2003). The four odontogenic epithelium sites in the maxillae merge to form a continuous dental lamina by the 37th day in utero. The dental lamina is also formed by the fusion of the two sites in the mandibular midline. Later, ectodermal projections from the lamina form ten enamel organs in each arch, one for each deciduous tooth (Ten Cate 2003).

The enamel organ is derived from oral ectoderm. The most superficial layer of the enamel organ forms the outer enamel epithelium. The stellate reticulum lies between the outer and inner enamel epithelium. The inner enamel epithelium resides adjacent to the dental papilla (Ten Cate 2003). The inner enamel epithelium cells first begin to elongate and form ameloblasts. This histodiffereniation interacts with the dental papilla and causes odontoblastic formation from the ectomesenchymal cells of the dental papilla. The odontoblasts then begin dentin formation. After the onset of dentin formation, the ameloblasts formed from the inner enamel epithelium begin enamel formation against the dentin foundation. The outer and inner enamel epithelia are continuous at their proximal ends and form Hertwig's epithelial root sheath. The outer enamel epithelium of the root sheath forms cementum because the absence of a stratum intermedium does not provide the enamel organ with differentiated ameloblasts (Ten Cate 2003). 


\section{$\underline{\text { Tooth Mineralization }}$}

The mineralization of a tooth is a process that begins with initial cusp formation and continues to formation of the root apex. The mineralization of permanent teeth (generally assessed radiographically) has been studied by a number of researchers (see review in Demirijian 1978). One advantage of radiographic assessment of mineralization of teeth is that the information is readily available since panoramic radiographs are part of a routine dental examination.

\section{Tooth Development Variability}

Garn et al. (1958) sampled 255 white children from southwestern Ohio. Each of the mandibular molar and premolar teeth was classified into one of five stages by the degree of mineralization; stages I, II and V being the beginning, progression, and termination of tooth mineralization and stages III and IV being the progression of eruption into occlusion. They excluded data from first molar stage I and stage III, IV, and V of third molars due to the inability of their capture on films. They found that sexual dimorphism was modest, with females being dentally more developed than males by $3 \%$. They also found mineralization and eruption sequences among the teeth were different in $55 \%$ of the children. They concluded from this that stages of mineralization do not accurately predict eruption patterns. Later, Garn et al. (1959) studied the variability of tooth 
formation from the same group of data. They only used three stages of tooth development: (1) beginning calcification, (2) beginning root formation, and (3) apical closure. Garn et al. (1959) found that as individuals aged chronologically, the variability of tooth formation increased, and it was equally variable for each tooth studied. Then they compared the variability of tooth formation to that of other physiological age determinants that had already been studied: (1) eruption of deciduous and permanent teeth, (2) timing of 61 ossification centers, (3) bone age from hand-wrist radiographs, (4) menarche, (5) breast development, (6) pubic hair development, and (7) beginning age of genitalia enlargement. They found that the variability in tooth formation was no more, and sometimes less, than the variability of these other developmental milestones. These findings led them to conclude that tooth development is a useful tool in biological age predictions.

\section{Tooth Classification}

Gleiser and Hunt (1955) assessed the development of the permanent mandibular first molar using series of lateral radiographs of 25 girls and 25 boys. They classified mineralization of the first molar into 15 different stages beginning with the initial presence of a bony crypt to the apical closure of the tooth's roots (Table 1). They formed a classification scheme for teeth by the mesiodistal width of the crown and the length of the root on the tooth. 
Table 1. Definitions of the 15 stages of tooth formation used by Gleiser and Hunt (1955) to grade the mineralization of the mandibular first permanent molar.

\begin{tabular}{|c|c|}
\hline Stage & Definition \\
\hline $\mathrm{I}$ & no calcification: crypt formed but no mineralization yet \\
\hline II & $\begin{array}{l}\text { centers of calcification visible: amelogenesis has begun on the } \\
\text { individual cusp tips }\end{array}$ \\
\hline III & coalescence of centers: centers of calcification are merged \\
\hline IV & cusp outline complete: the coronal outline is mineralized \\
\hline $\mathrm{V}$ & $1 / 2$ crown: amelogenesis is half way to cervical margin \\
\hline VI & $2 / 3$ crown completed \\
\hline VII & $\begin{array}{l}\text { crown completed: morphologically, the crown has mineralized } \\
\text { but root formation has not begun }\end{array}$ \\
\hline VIII & $\begin{array}{l}\text { minimal root formation: there is just a trace of root radiopacity } \\
\text { below the crown outline }\end{array}$ \\
\hline VIII A & cleft minimal: interradicular mineralization is evident \\
\hline VIII B & $\begin{array}{l}\text { cleft rapidly enlarging: significant mineralization evident in the } \\
\text { interradicular area but root not } 1 / 4 \text { formed }\end{array}$ \\
\hline IX & $\begin{array}{l}1 / 4 \text { root: the radiographic morphology of the root is } 1 / 4 \text { of its } \\
\text { projected final size }\end{array}$ \\
\hline$X$ & $1 / 3$ root completed \\
\hline XI & $1 / 2$ root completed \\
\hline XII & $2 / 3$ root completed \\
\hline XIII & $3 / 4$ root completed \\
\hline XIV & $\begin{array}{l}\text { divergent root canal walls: full root length achieved but walls } \\
\text { of root canal have not yet converged terminally }\end{array}$ \\
\hline XV & $\begin{array}{l}\text { convergent root canal walls: walls of root canal converged } \\
\text { terminally and roots appear mature }\end{array}$ \\
\hline
\end{tabular}

Source: Gleiser I, Hunt EE Jr. The permanent mandibular first molar: its calcification, eruption and decay. Am J Phys Anthropol 1955;13:253-83. 
Nolla (1960) classified tooth mineralization into 10 different stages. The study consisted of 25 boys and 25 girls, each having radiographic evaluations once a year from roughly ages 2 to 12 years. The development of the tooth from the radiographic evaluation was compared to a diagram of the 10 stages of mineralization. This classification was novel because if a tooth was between two stages, 0.5 was added to the lower stage to give an intermediate score. If the tooth was minimally advanced past one stage, then 0.2 was added to the stage number. If the tooth was developed slightly less than one stage, then 0.3 was subtracted from the stage. Once the data were gathered, the development of tooth mineralization was plotted against chronological age in months. A line was then drawn between each time interval to give a growth curve for the individual. This growth curve described actual observation points once a year and tabulated values for the time in between the examinations. One assumption made here is that tooth development is a linear process. Lastly, the values at the yearly examinations were averaged to construct a general growth for dental age assessment. This method of dental mineralization assessment, which has not been repeated, is described in Table 2 (Nolla 1960).

Moorrees et al. (1963) conducted a study with 99 children, from the Forsyth Dental Infirmary longitudinal studies of children, for single root (anterior) tooth assessment and 246 older children, from the Fels Research Institute, Ohio, for multirooted tooth assessment. Their aim was to develop 
Table 2. Definitions of the ten stages of tooth formation used by Nolla (1960) to grade the mineralization.

\begin{tabular}{|c|c|}
\hline Stage & Definition \\
\hline 0 & absence of crypt: no sign of tooth development is apparent \\
\hline 1 & $\begin{array}{l}\text { presence of crypt: crypt is formed but no mineralization has } \\
\text { begun }\end{array}$ \\
\hline 2 & initial calcification: amelogenesis has begun on the cusp tips \\
\hline 3 & $\begin{array}{l}\text { one-third of crown completed: amelogenesis is } 1 / 3 \text { the way to } \\
\text { the cervical margin }\end{array}$ \\
\hline 4 & two-thirds of crown completed \\
\hline 5 & $\begin{array}{l}\text { crown almost completed: morphologically, the crown has } \\
\text { mineralized to just short of the cervical margin }\end{array}$ \\
\hline 6 & $\begin{array}{l}\text { crown completed: morphologically, the crown has mineralized } \\
\text { but root formation has not begun }\end{array}$ \\
\hline 7 & $\begin{array}{l}\text { one-third of root completed: the radiographic morphology of } \\
\text { the root is } 1 / 3 \text { of its projected final size }\end{array}$ \\
\hline 8 & two-thirds of root completed \\
\hline 9 & $\begin{array}{l}\text { root almost completed: full root length has been achieved but } \\
\text { apex is still open }\end{array}$ \\
\hline 10 & $\begin{array}{l}\text { root completed: apical end of root completed and apex is } \\
\text { closed }\end{array}$ \\
\hline
\end{tabular}

Source: Nolla CM. The development of the permanent teeth. J Dent Child 1960;27:254-66. 
norms for the formation of permanent teeth. Moorrees et al. (1963) computed cumulative percentage frequencies for each stage of tooth formation for each age that was at or past the corresponding stage. Normal deviates were then found from the percentage frequencies. These normal deviates were then converted into logarithmic conceptional ages. Weighted estimates of the mean attainment age was found with an sd $=0.042 \mathrm{log}$. The percentages outside two standard deviations were discarded and the estimates were averaged to determine the mean attainment age for each developmental stage. These mean ages were then converted from conceptional ages back into chronological ages. They also determined dental development by looking at radiographs and establishing a rating system for tooth development (Fig. 4).

Demirjian, Goldstein and Tanner (1973) used an approach to classify tooth mineralization by maturational changes in tooth development rather than just the enlargement of the tooth. Since final tooth size can vary from individual to individual, this system provides for a method to categorize teeth not on size, but on certain dental maturity stages that are recognizable. This idea is proposed because the length or increase of tooth structure does not indicate an advancement of tooth development into another stage, in part, because of the wide variety of tooth sizes among individuals (and due to radiographic magnification). By evaluating the development of the tooth rather than the size of the tooth, they found 8 tooth mineralization stages useful in describing tooth 


\begin{tabular}{|c|c|c|c|c|c|c|c|c|c|c|c|c|}
\hline \multicolumn{13}{|c|}{ Incisors, Canines, and Premolars } \\
\hline 1 & 2 & 3 & 4 & 5 & 6 & 7 & 8 & 9 & 10 & 11 & 12 & 13 \\
\hline$C_{i}$ & $\mathrm{C}_{\mathrm{CO}}$ & $\mathrm{C}_{\mathrm{oc}}$ & $\mathrm{Cr} \frac{1}{2}$ & $\mathrm{Cr} \frac{3}{4}$ & $\mathrm{Cr}_{\mathrm{C}}$ & $\mathrm{R}_{\mathrm{i}}$ & $\mathrm{R} \frac{1}{4}$ & $\mathrm{R} \frac{1}{2}$ & $\mathrm{R} \frac{3}{4}$ & $\mathrm{R}_{\mathrm{C}}$ & $\mathrm{A} \frac{1}{2}$ & $\mathrm{~A}_{C}$ \\
\hline
\end{tabular}

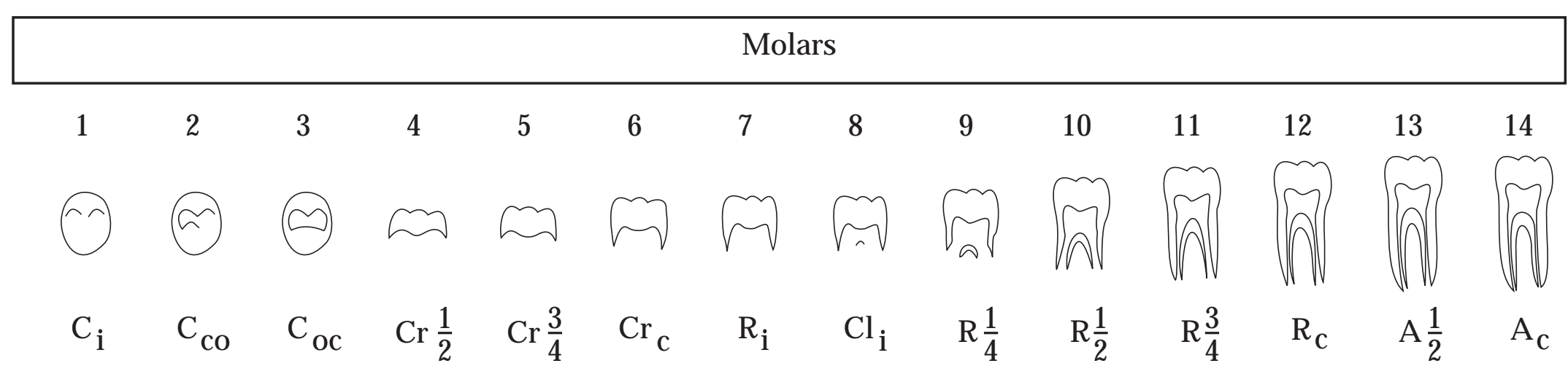

Fig. 4. Schematic drawings of the stages of tooth mineralization used by Moorrees, Fanning and Hunt (1963). There are 13 stages for single-rooted teeth and 14 stages for multi-rooted teeth, the difference being the addition of cleft initiation for the multi-rooted molars.

Source: Moorrees CFA, Fanning EA, Hunt EE Jr. Age variation of formation stages for ten permanent teeth. J Dent Res. 1963;42:1490-1502. 
mineralization. They used panoramic radiographs of 1,446 boys and 1,482 girls from the Ste-Justine Hospital and Growth Center in Montreal, Canada. Using the Tanner, Whitehouse, and Healy (1962) method that had been devised to estimate skeletal maturity, each tooth was assigned a maturity score. The scores of the seven teeth, from the mandibular central incisor to the second molar, evaluated were added together to give an overall dental maturity score. This score total was their maturity score, and by referring to a centile chart a dental age was determined. They found the use of the eight mineralization stages was superior to other classification because it allowed for just enough information for the classifications yet did not confuse the examiner (Fig. 5). Table 3 compares the classification systems that have been devised by various researchers.

\section{Sexual Dimorphism}

As males and females progress through life, they tend to grow in different patterns, rates, and times. These differences in growth among sexes have been termed sexual dimorphism. One reason sexual dimorphism occurs in mineralization of permanent teeth is due to the different tempos of maturation. One example of this is that the completion of mandibular canine roots in females occurs on average 1.5 years earlier than in males (Moorrees et al. 1963). Anderson et al. (1976) found the canine to have the greatest age difference in sexes for stages of mineralization. Anderson et al. stated that, "when sex is 


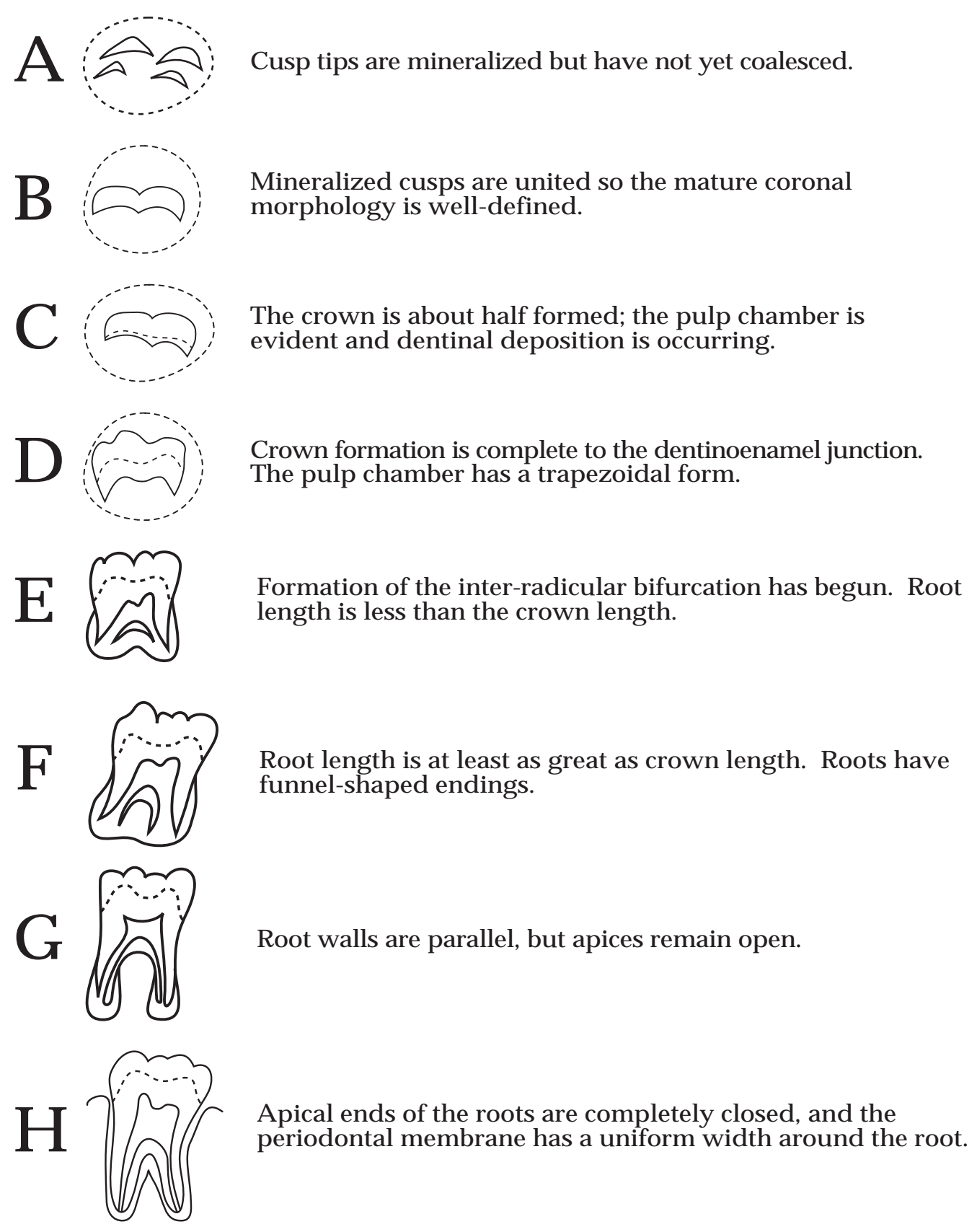

Fig. 5. Schematic drawings along with the textual cues for discriminating between Demirjian's 8 grades of tooth formation.

Source: Demirjian A, Goldstein H, Tanner JM. A new system of dental age assessment. Hum Biol 1973;45:211-27. 
Table 3. Comparative table of mineralization stages used by different authors.

\begin{tabular}{|c|c|c|c|c|c|c|}
\hline & $\begin{array}{c}\text { Gleiser } \\
\text { \& Hunt } \\
(1955)\end{array}$ & $\begin{array}{l}\text { Garn } \\
\text { et al. } \\
(1958) \\
\end{array}$ & $\begin{array}{l}\text { Nolla } \\
(1960)\end{array}$ & $\begin{array}{c}\text { Fanning } \\
\text { (1961) }\end{array}$ & $\begin{array}{c}\text { Moorrees } \\
\text { et al. } \\
(1963)\end{array}$ & $\begin{array}{c}\text { Demirjian } \\
\text { et al. } \\
(1973) \\
\end{array}$ \\
\hline Presence of crypt & I & - & 1 & $\mathrm{O}$ & - & - \\
\hline Cusp formation & II & 1 & 2 & $\mathrm{C}_{1}$ & 1 & $\mathrm{~A}$ \\
\hline Cusp coalescence & III & - & - & $\mathrm{CCO}$ & 2 & - \\
\hline Cusp outline & IV & - & - & COC & 3 & B \\
\hline Crown $1 / 3$ & - & - & 3 & - & - & - \\
\hline Crown $1 / 2$ & V & - & - & $\mathrm{Cr}_{1 / 2}$ & 4 & $\mathrm{C}$ \\
\hline Crown $2 / 3$ & VI & - & 4 & $\mathrm{Cr}_{2 / 3}$ & - & - \\
\hline Crown $3 / 4$ & - & - & 5 & - & 5 & - \\
\hline Crown complete & VII & - & 6 & $\mathrm{Cr}_{\mathrm{C}}$ & 6 & $\mathrm{D}$ \\
\hline Initial root & VIII & 2 & - & $\mathrm{R}_{1}$ & 7 & - \\
\hline Initial cleft & VIII A & - & - & $\mathrm{Cl}_{1}$ & 8 & - \\
\hline Cleft enlarging & VIII B & - & - & Cle & 8 & - \\
\hline Root $1 / 4$ & IX & - & - & $\mathrm{R}_{1 / 4}$ & 9 & E \\
\hline $\operatorname{Root} 1 / 3$ & $x$ & - & 7 & $\mathrm{R}_{1 / 3}$ & - & - \\
\hline Root $1 / 2$ & XI & - & - & $\mathrm{R}_{1 / 2}$ & 10 & - \\
\hline Root $2 / 3$ & XII & - & 8 & $\mathrm{R}_{2 / 3}$ & - & F \\
\hline Root 3/4 & XIII & - & - & $\mathrm{R}_{3 / 4}$ & 11 & - \\
\hline Root complete & XIV & - & 9 & $\mathrm{R}_{\mathrm{C}}$ & 12 & G \\
\hline Apex 1/4 closed & - & - & - & $\mathrm{A}_{1} / 4$ & - & - \\
\hline Apex $1 / 2$ closed & - & - & - & $\mathrm{A}_{1 / 2}$ & 13 & - \\
\hline Apex 3/4 closed & - & - & - & $\mathrm{A} 3 / 4$ & - & - \\
\hline Apex closed & $X V$ & 3 & 10 & $\mathrm{AC}_{\mathrm{C}}$ & 14 & $\mathrm{H}$ \\
\hline
\end{tabular}

Source: Demirjian A. Dentition. In: Falkner F, Tanner JM, editors. Human growth 2. postnatal growth. New York and London: Plenum Press, 1978, p 412-44. 
unknown, the stages of the canines would be the least accurate for age determination because the sex differential in age is greatest for these teeth" (Anderson et al. 1976: 197). Chertow (1980) found significant differences in maturity between the sexes of all teeth except for mandibular canines. Fanning (1961) observed a slight sex difference at the initiation of tooth formation, with an increasing difference as tooth development progressed.

\section{Physiological Age Prediction}

Tooth formation has been studied to determine if it is useful in estimating skeletal maturity, and if so, then is it a useful tool in predicting the adolescent growth spurt. Lewis and Garn (1960) found that apical closure of teeth, when compared to crown and root formation, is the least reliable when estimating skeletal development. Liebgott (1978) supported this finding by suggesting dental age is a poor prognosticator of the adolescent mandibular growth spurt, but added that the poor association between the growth spurt and dental age could be due to developing malocclusions.

Chertkow (1980) compared data of 197 patients from the Orthodontic Department of the School of Dentistry, University of Witwatersrand, South Africa. Panoramic or lateral oblique radiographs of the dentition, along with hand wrist radiographs, were taken to compare the relationship between tooth mineralization and pubertal growth spurt indicators. Chertkow scored maxillary 
and mandibular canines, premolars, and mandibular molars on the left side of the mouth by the system proposed by Demijian, Goldstein and Tanner (Fig. 5) and the hand-wrist radiographs using TW2 method (Tanner et al. 1975). For each tooth he computed the percentage distribution of the calcification stages in each skeletal stage. This allowed him to compare the distribution of tooth calcification across the skeletal stages studied. It had been shown by other researchers (Björk and Helm 1967; Brown, Barrett and Grave 1971; Björk 1972; Chapman 1972) that the appearance of the adductor sesamoid and the ossification of the hook of the hamate are indicators of the pubertal growth spurt. Chertkow (1980) found the mandibular canine possessed the closest association between the mineralization stage $G$, just prior to apical closure, and the skeletal indicators of peak height velocity, thus the mandibular canine could be useful in prediction of the adolescent growth spurt.

Coutinho, Buschang and Miranda (1993) conducted a study consisting of hand-wrist and panoramic radiographs of 200 boys and 215 girls. Their purpose was to determine the relationship between developing mandibular canines and skeletal maturity. Hand-wrist bone age was determined using the Greulich and Pyle method (1959) and dental age was determined using the Demirjian, Goldstein and Tanner (1973) staging system of developing teeth. The appearance of the adductor sesamoid at canine stage $\mathrm{F}$ was only found in 7 of 54 females, while it was found in 96 of 108 females at stage G. With males, the same 
association was found with only 6 of 72 at stage F but 56 of 79 at stage G. They concluded, in agreement with Chertkow (1980), that the timing of the mineralization of the mandibular canine at stage $G$ seems to provide useful information about skeletal development and the estimation of the timing of the peak height velocity.

Krailassiri et al. (2002) studied 361 hand-wrist and panoramic radiographs of Thai individuals to determine if a relationship between tooth calcification stages and skeletal maturity exists. They found mandibular second premolar and canine to be useful markers for the growth spurt in Thai individuals.

\section{Formation and Development of Cervical Vertebrae}

Two of several ways of assessing skeletal maturity are by use of (1) ossification of the adductor sesamoid bone of the hand and (2) morphology of the cervical vertebrae. A common clinical reason for assessing skeletal maturity is to determine whether peak height velocity and peak craniofacial velocity has occurred.

Lamparski (1972) developed a system for skeletal assessment based on morphological changes in the cervical vertebrae. He noted there were progressive morphological changes in the vertebral bodies as one matures, beginning with $\mathrm{C} 2$ and continuing caudally. The skeletal assessment system (Fig. 6) includes six stages using the second (C2) through the sixth (C6) vertebrae: 


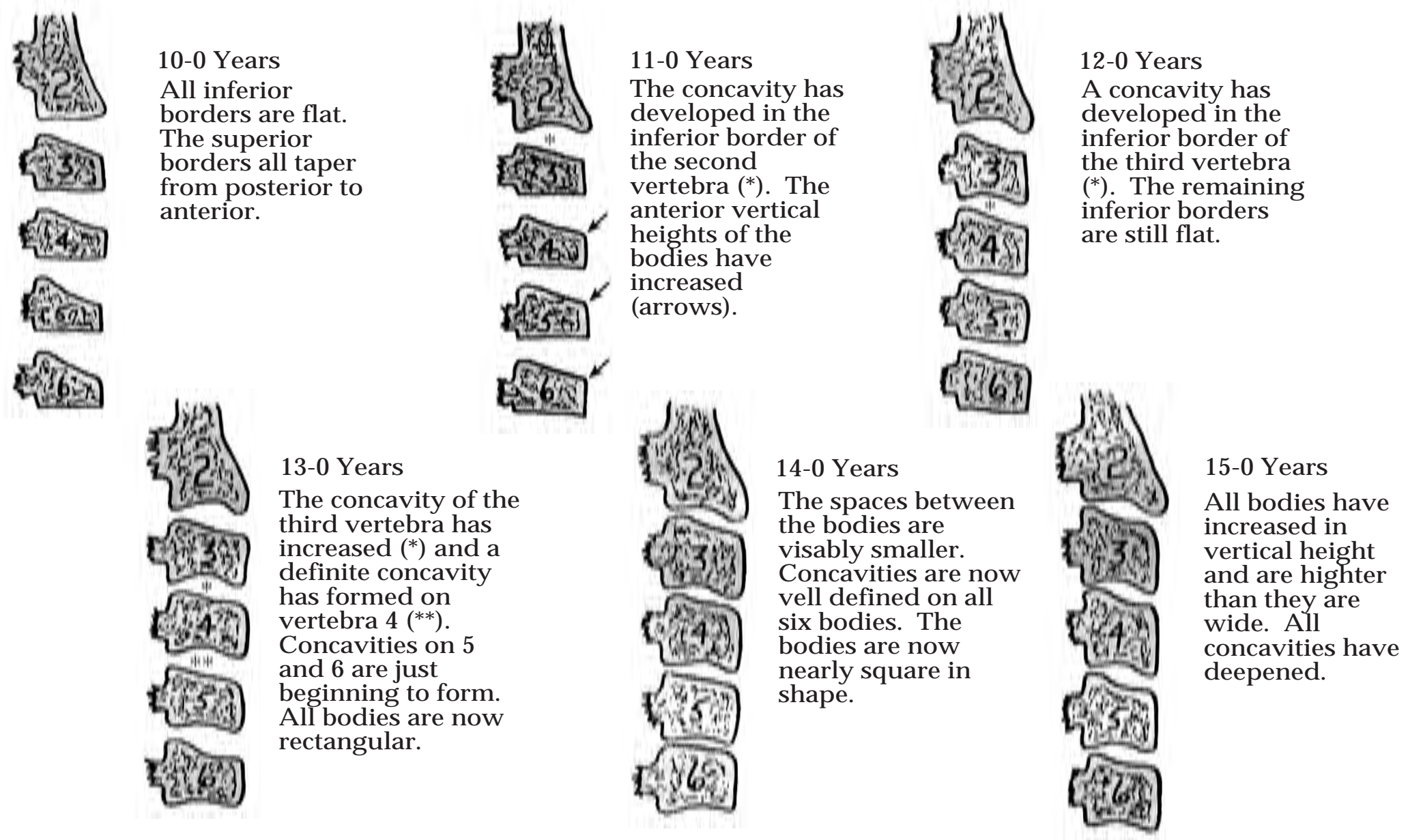

Fig. 6. Sketches of the six morphological grades of the cervical vertebrae.

Source: Lamparski DG. Skeletal age assessment utilizing cervical vertebrae. M.S. thesis, Univeristy of Pittsburgh, 1972. 
Stage 1: All of the bodies are flat and superior borders are tapering from posterior to anterior.

Stage 2: Concavities are present on the inferior border of the $\mathrm{C} 2$. C3 and C4 are still trapezoid in shape, but may possess a rectangular horizontal shape.

Stage 3: C2 and C3 have developed concavities on their inferior borders with C4C6 inferior borders still being flat.

Stage 4: C2, C3, and C4 now all have concavities on their inferior borders of the bodies. Concavities on $\mathrm{C} 5$ and $\mathrm{C} 6$ are beginning to form.

Stage 5: C2, C3, C4, C5 and C6 have concavities on their inferior borders of the bodies and are nearly square in shape.

Stage 6: All bodies are now shaped rectangular in a vertical direction.

Prior to cervical vertebral assessment, skeletal assessment was routinely done by hand-wrist radiograph assessment. Now the development of cervical vertebral assessment, the additional radiograph needed for skeletal maturity assessment, via hand-wrist assessment, can be avoided. This decreased the exposure of radiation to the patient and is more biologically safe for both the patient and the examiner.

O'Reilly and Yanniello (1988) conducted a study to determine the relationship between mandibular growth and morphology of the cervical vertebrae. The study used data of 13 white females compiled by Tofani (1972) from the Bolton Broadbent growth study. Cephalometric radiographs had been 
taken annually between the ages 9 and 15. The three cephalometric dimensions studied were (1) mandibular length (Articulare-Pogonion), (2) corpus length (Gonion-Pogonion), and (3) ramus height (Articulare-Gonion). Using the stages of cervical vertebrae morphology developed by Lamparski (1972), they measured the increase in the craniofacial dimensions. They found significant increases in the following dimensions and stages: (1) mandibular length increased between stages 1, 2, 3, and 4, (2) corpus length increased between stages 1, 2, and 3, and (3) ramus height increased between stages 1 and 2. For all dimensions they found stages 2 and 3 usually occurred in the year prior to the peak velocity, and the peak usually occurred between stages 3 and 4 (Fig. 7).

Hassel and Farman (1995) conducted a study to develop a cervical vertebral maturational index, CVMI, from lateral cephalometric and hand-wrist radiographs of 220 individuals from the Bolton-Brush Growth Center at Case Western Reserve University. They grouped the cervical vertebral morphologic changes of $\mathrm{C} 3$ by their corresponding SMI evaluations. This gave 11 groups of cervical vertebrae. They compared for morphological changes in C3 over the 11 SMIs and found only six recognizable groupings (Fig. 8). They termed the six groupings: (1) initiation- the beginning of the adolescent growth spurt, (2) acceleration- growth acceleration with $65-85 \%$ of growth remaining, (3) transition- continuing toward peak height velocity, (4) deceleration- growth was past peak with $10-25 \%$ of growth remaining, (5) maturation- only $5-10 \%$ of 


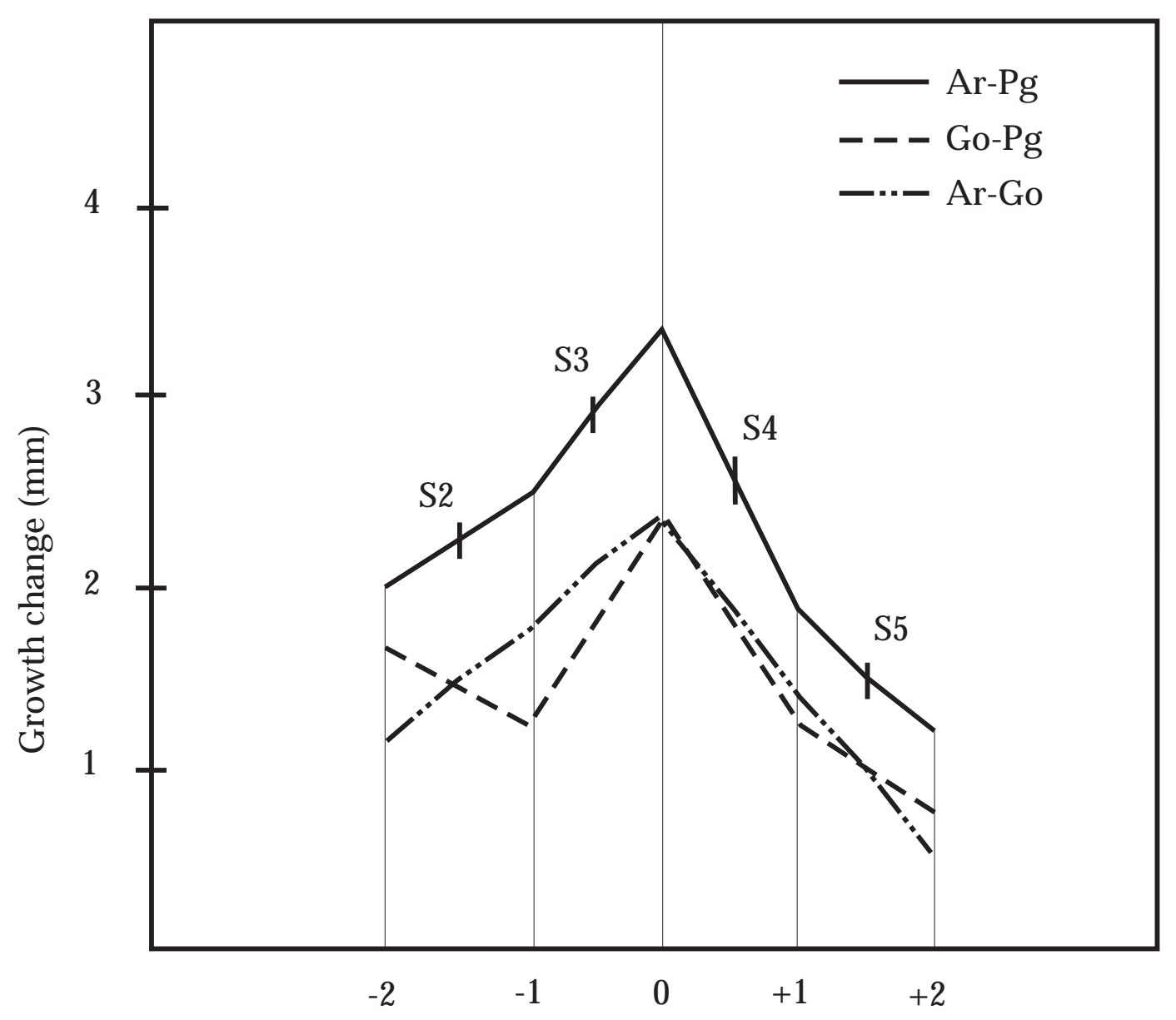

Fig. 7. Mandibular growth in each cervical vertebrae maturational stages.

Source: O'Reilly MT, Yanniello GJ. Mandibular growth changes and maturation of cervical vertebrae-a longitudinal cephalometric study. Angle Orthod. 1988;58:179-84. 
1

Initation

SMI 1-2

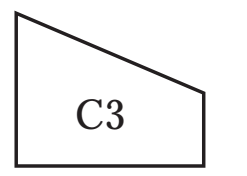

2

Acceleration

SMI 3-4

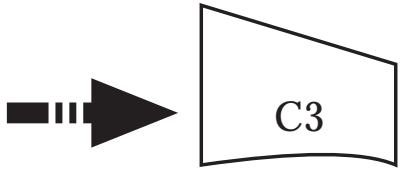

3

Transition

SMI 5-6

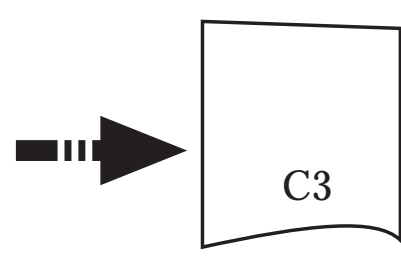

4

Deceleration

SMI 7-8

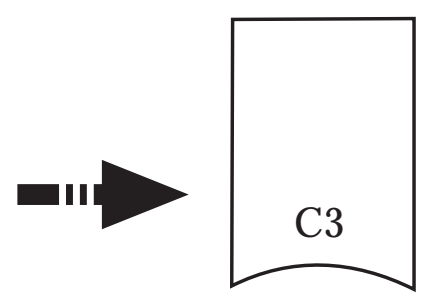

5

Maturation

SMI 9-10

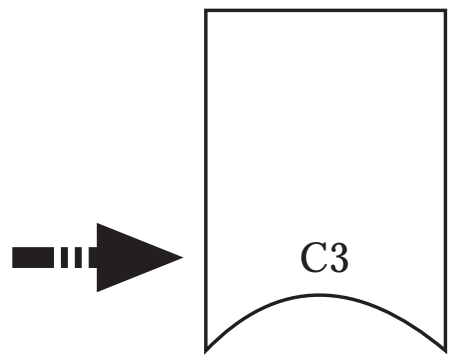

6

Completion

SMI 11

Fig. 8. Six CVMI as described by Hassel and Farman.

Source: Hassel B, Farman AG. Skeletal maturation evaluation using cervical vertebrae. Am J Orthod Dentofacial Orthop. 1995; 107:58-66. 
growth remaining, and (6) completion- virtually no growth was expected to occur. They concluded by confirming what Lamparski (1972) had found and that this method of skeletal assessment could be used to estimate future potential growth in individuals.

Kucukkeles et al. (1999) conducted a study to determine if morphological changes in cervical vertebrae could be used as a skeletal maturity index. They compared hand-wrist and cephalometric radiographs of 180 individuals (99 girls and 81 boys) from the Orthodontic Clinic at Marmara University School of Dentistry. Kucukkeles et al. (1999) assessed skeletal maturity using the Fishman (1982) SMI index for hand-wrist ossification. The third and forth cervical vertebrae were evaluated and assessed on of six CVMI stages determined by Hassel and Farman (1995). The SMI and CVMI groups were then split into 3 growth groups: (1) pre-peak height velocity (SMI 1-4 and CVMI 1-2), (2) peak height velocity (SMI 5-8 and CVMI 3-4), and (3) post-peak height velocity (SMI 911 and CVMI 5-6). They found the reproducibility of SMI was greater than CVMI and a "high level of concordance among observers in determinations related to pre and post-peak stages, whereas the level of concordance in the peak stage was low" (Kucukkeles et al. 1999: 51). They concluded that cervical vertebrae provide a reliable tool for growth stage assessment, giving an added benefit of reducing radiation exposure to the patient. 
Baccetti et al. (2002) compared mandibular length (Cd-Gn) growth and cervical vertebrae maturation. They studied 30 subjects ( 18 boys and 12 girls) from the Michigan elementary and secondary school growth study, each with at least six serial cephalometric radiographs, two during maximum mandibular growth, two before, and two after. The vertebral bodies of C2, C3, and C4 were evaluated for concavities on their inferior borders. They compared the vertebral morphologies of the cervical vertebral bodies for all time points for significant changes using a chi-square test with Yates' correction, and used an analysis of variance to determine if the changes were significant in terms of mandibular growth. They found no significant difference between the first 2 cephalometric radiographs, in terms of cervical vertebral morphology. From this they contented no discrimination between stages 1 and 2 in Lamparski's method can be made, so they combined the first two stages. Using this 'new' method, Baccetti et al. (2002) found that a visible concavity on the lower border of the third vertebra (C3), coded as CVMS II, usually is an indicator for the stage just prior to peak mandibular growth, which would correspond to stage 3 in the Lamparski system.

Another study used two groups of 20 Japanese girls to predict mandibular growth potential using cervical vertebral morphology (Mito et al. 2003). Average chronological age at each cervical vertebral morphological stage had been defined in a previous study by Mito et al. (2002). By using dimensional ratios of 
the vertebral bodies of C3 and C4 (Fig. 9) and chronological age, they determine a linear equation to estimate age. The formula determined to describe cervical vertebral bone age (CVBA) is:

$$
\text { CVBA }=-0.02+6.20\left(\mathrm{AH}_{3} / \mathrm{AP}_{3}\right)+5.90\left(\mathrm{AH}_{4} / \mathrm{AP}_{4}\right)+4.74\left(\mathrm{AH}_{4} / \mathrm{PH}_{4}\right) \quad \text { [Eq. 2] }
$$

Where $\mathrm{AH}$ is the height of the anterior portion of the body, $\mathrm{PH}$ is the height of the posterior portion of the body, and AP is the anteroposterior length of the body. So by using one group to assess the amount of growth occurring over the growth spurt, a formula was derived to predict mandibular growth potential:

$$
\text { Mandibular growth }=-38.68-2.76(\mathrm{CVBA})
$$

where CVBA is defined in Equation 2. This formula was then tested on the second group of 20 girls. The amount of mandibular growth was defined as the distance from Condylion to Gnathion. The mandibular growth potential was calculated three different ways: (1) by using CV, (2) by bone age by TW2 method, and (3) by chronological age. These three estimations were then compared with the actual growth observed. The formula used gave an average difference between the predicted value and the actual amount of mandibular growth to be $1.79 \mathrm{~mm}$. Both average differences were found to be significantly less $(\mathrm{P}<0.001)$ than when chronological age was used in the formula, which gave a mean difference of $3.48 \mathrm{~mm}$. They stipulated the sample only consisted of Class I individuals and that a different formula may be needed for different types of growth patterns. 


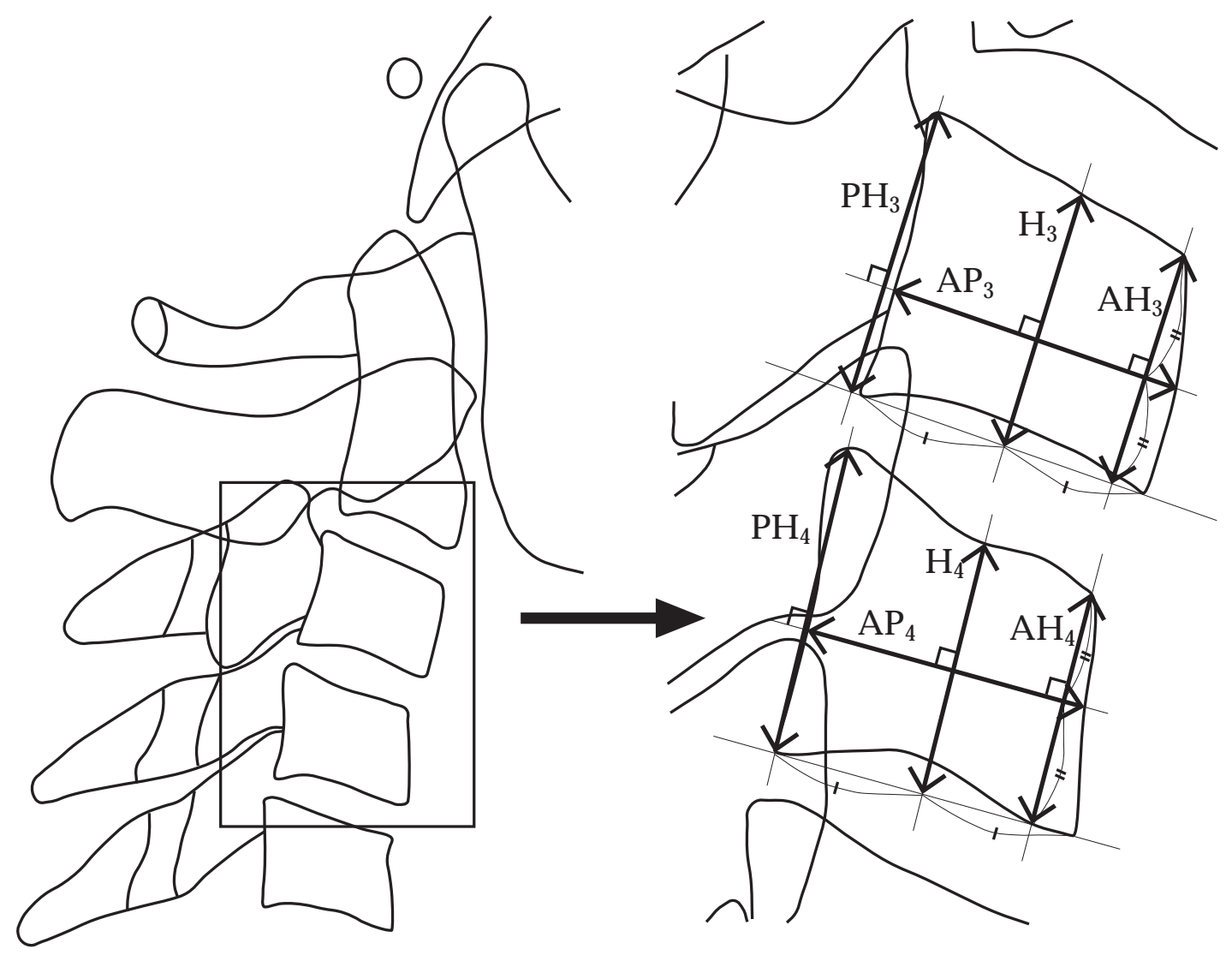

Fig. 9. Diagram of cervical vertebral dimensional measurements used in determining dimensional ratios of the vertebral bodies of $\mathrm{C} 2$ and C3.

Source: Mito T, Sato K, Mitani H. Cervical vertebral bone age in girls. Am J Orthod Dentofacial Orthop. 2002;122:380-5. 
Roman et al. (2002) evaluated hand-wrist skeletal maturity against cervical vertebral development. The study compared hand-wrist and cephalometric radiographs of 958 Spanish children. The authors assessed three parameters of the cervical vertebrae, namely: (1) concavity of the lower border of the body, (2) vertebral body height, and (3) the shape of the vertebral body. These three variables were compared to the maturational stage assessments from the handwrist radiographs to determine if one variable provided a more accurate estimate of skeletal age. The time between cephalometric and hand-wrist radiographs was less than one month intervals. It was found that the concavity of the lower border had the highest correlation with maturational stages determined from the hand-wrist radiographs, with females $r=0.84$ and males $r=0.75$. They concluded by noting Hassel and Farman's classification scheme was more accurate than Lamparski's method, and unlike Lamparski's, could be used for both sexes. Body height seemed to be the least accurate assessment of skeletal age with females $r=0.70$ and males $r=0.60$. They also compared different cervical vertebral classification systems with hand-wrist radiographs. They found the Hassel and Farman (1995) system to have a high correlation with females and males with $r=0.84$ and 0.77 , respectively. Lamparski's system was found to be slightly lower with females $r=0.79$ and males $r=0.69$. 


\section{$\underline{\text { Overview }}$}

Growth during the early teens increases in velocity for a period of time, termed the parapubertal growth spurt. A common measure to determine the parapubertal spurt is stature. Although stature is a global measure of growth and can indicate the parapubertal spurt by its velocity, the parapubertal spurt affects every measure of growth, including growth of the face. One well-known difference in the parapubertal growth spurt is the timing between the sexes. Females tend to experience the spurt earlier than their counterpart males, but it generally is of less intensity.

Chronological age is a common way of estimating when an individual is at or near the adolescent growth spurt. Although chronological age is routinely used, some measure of physiological age is a better predictor of a person's maturational status because it accounts for the developmental status of the individual.

Dental age can be used to estimate the maturity of an individual. Although most tooth developmental stages have shown no significance between tooth development and overall maturity, the apexification of the mandibular canine has shown to be a useful tool in adolescent growth spurt prediction.

The morphology of cervical vertebrae has recently been studied to determine their usefulness and accuracy for describing the maturity of an 
individual. Cervical vertebrae have been shown to be useful in assessing maturity levels and predicting the amounts of craniofacial growth yet to occur. 


\section{CHAPTER III}

\section{MATERIALS AND METHODS}

At face value, one might suppose that a patient's facial growth during treatment could be estimated by his chronological age. Chronological age is known to be a poor predictor, though, because it disregards differences in tempos in growth between sexes and among individuals. The purpose of the present study is to determine if pretreatment biological age, as assessed from cervical vertebral morphology and tooth maturation, has any statistical relationship to the amounts of growth occurring in a patient during the course of orthodontic treatment.

\section{Sample Description}

Subjects in this study were collected from the archived records of patients treated at The Department of Orthodontics, College of Dentistry, The University of Tennessee Health Science Center, Memphis. The criteria for subject selection were (1) Angle's Class II division 1 malocclusion, (2) American white ethnic background, (3) four premolar extraction pattern, and (4) availability of records, which consisted of a pretreatment and posttreatment cephalometric radiographs and a pretreatment panoramic radiograph. The Angle's Class II division 1 
malocclusion classification was assessed from inspection of the pretreatment cephalometric radiograph.

From perusing the orthodontic records, 1250 Class II division 1 records were found. Of these 1,250, 106 records of females and 77 records of males met the inclusion criteria and were used in the present study. The age distribution of the subjects is presented in Table 4. Due to the differences in perception in the need of orthodontic treatment, the greater number of female orthodontic patients is not surprising. A listing of the number of subjects by vertebral maturation stage and, separately, by tooth mineralization stage is provided in Table 5.

\section{Cervical Vertebrae Maturation}

The determination of biological age of the patient was assessed by the sixgrade ordinal scheme developed by Lamparski (1972). The cervical vertebral bodies are scored based on their shape. Figure 6 illustrates the stages of vertebral maturation against which the vertebrae imaged on the pretreatment cephalometric radiograph were scored (Lamparski 1972). The first cervical vertebra is not used in the assessment because it does not possess a body and is very hard to see on a cephalogram. Since children do not routinely have orthodontic records made until the need for orthodontic correction is recognized by the parent, the distribution of subjects over the cervical vertebral maturation stages is not surprising with rather few in stage 1 to evenly distribution 
Table 4. Chronological age distribution of pretreatment orthodontic subjects used in the present study.

\begin{tabular}{llll}
\hline Age Interval & Total & Female & Male \\
\hline Below 10 & 11 & 9 & 2 \\
$10-11$ & 19 & 14 & 5 \\
$11-12$ & 20 & 12 & 8 \\
$12-13$ & 42 & 24 & 18 \\
$13-14$ & 40 & 19 & 21 \\
$14-15$ & 22 & 10 & 12 \\
$15-16$ & 5 & 3 & 2 \\
$16-17$ & 3 & 2 & 1 \\
$17-18$ & 2 & 1 & 1 \\
Over 18 & 12 & 12 & 0 \\
Totals & 176 & 106 & 70 \\
\hline
\end{tabular}


Table 5. Subject distribution among stages of CV2 and mandibular canine

\begin{tabular}{llll}
\hline Stage & Total & Female & Male \\
\hline \multicolumn{4}{c}{ CV2 Maturation } \\
1 & 22 & 12 & 10 \\
2 & 40 & 17 & 13 \\
3 & 29 & 14 & 15 \\
4 & 24 & 14 & 10 \\
5 & 27 & 20 & 7 \\
6 & 32 & 30 & 2 \\
& \multicolumn{4}{c}{} \\
9 & 3 & 2 & 1 \\
10 & 6 & 4 & 2 \\
11 & 24 & 12 & 12 \\
12 & 47 & 19 & 28 \\
13 & 94 & 69 & 25 \\
\hline
\end{tabular}


occurring in stages 3, 4, and 5. For each pretreatment vertebral assessment, the amount of craniofacial growth that occurred during orthodontic treatment was measured.

\section{$\underline{\text { Tooth Mineralization }}$}

The amounts of facial growth also were assessed against the degree of mandibular canine root formation that had occurred. The ordinal scale of tooth mineralization described by Moorrees et al. (1963) for single rooted teeth was used. These stages are illustrated in Figure 4 and radiographic interpretation of the stages is presented in Figure 10. The following is a description of the 13 tooth grades (Moorrees et al. 1963): (1) Ci: Initial cusp formation, (2) Cco: Coalescence of cusps, (3) Coc: Cusp outline complete, (4) $\mathrm{Cr}^{1 / 2}$ : Crown $1 / 2$ complete, (5) $\mathrm{Cr}^{3 / 4}$ : Crown 3/4 complete, (6) Crc: Crown complete, (7) Ri: Initial root formation, (8) $R$ $1 / 4$ : Root length $1 / 4,(9) R \frac{1}{1 / 2}$ : Root length $1 / 2,(10) R 3 / 4$ : Root length $3 / 4,(11) R c$ : Tooth length complete, (12) A 1/2: Apex $1 / 2$ closed, and (13) Ac: Apical closure complete. A relationship between skeletal age and the degree of somatic maturity has been established by a number of researchers (Steel 1965; Tanner 1978). The relationship of dental maturity with the pubertal growth spurt has been demonstrated by relatively fewer researchers (Chertkow 1980). Hopefully, after this study, a clinician can use a routine pretreatment 
Stage 1: Initial cusp formation

Stage 2: Coalescence of cusps
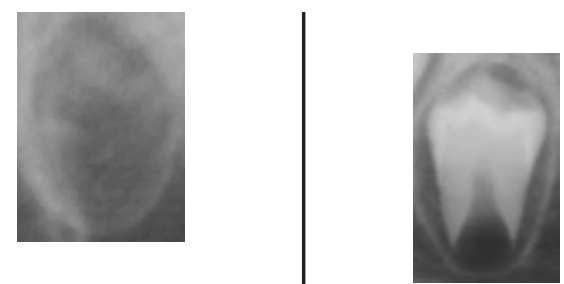

Stage 8: Root length $1 / 4$

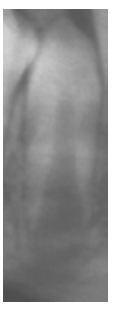

Stage 9: Root length $1 / 2$

Stage 3: Cusp outline complete
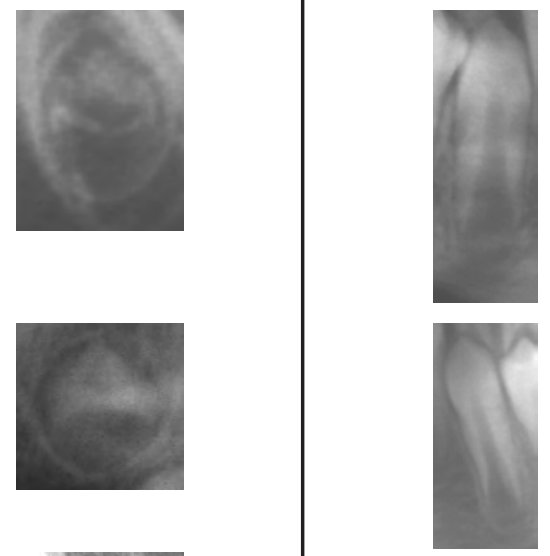

Stage 10: Root length $3 / 4$

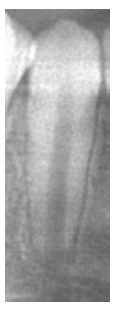

Stage 11: Root Length complete

Stage 5: Crown 3/4 complete
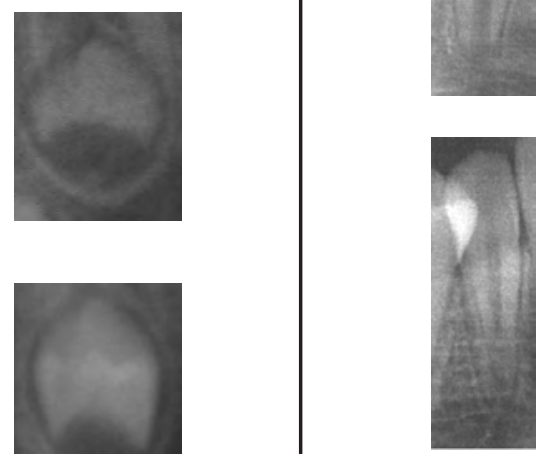

Stage 12: Apex 1/2 closed

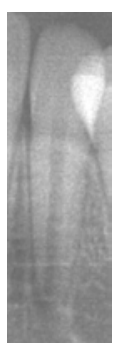

Stage 13: Apical closure complete

Stage 7: Initial root formation

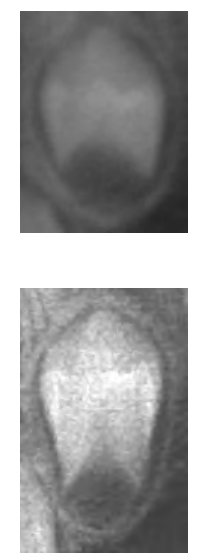

Fig. 10. Radiographic interpretation of Moorrees-Fanning-Hunt ordinal single-rooted tooth grades.

Source: Moorrees CFA, Fanning EA, Hunt EE Jr. Age variation of formation stages for ten permanent teeth. J Dent Res. 1963;42:1490-1502. 
cephalometric or panoramic radiograph to estimate the amount of expected growth during orthodontic treatment.

\section{Facial Bony Growth}

The pretreatment and posttreatment cephalometric radiographs were traced in the traditional fashion using acetate tracing paper and a light box (Athanasiou 1995). Each tracing then was manually loaded in a HewlettPackard $^{\circledR}$ All-in-One 1200 scanner and digitized using the HP ${ }^{\circledR}$ software at 200 dpi. A file for each subject was created in a commercial orthodontic imaging program called Dolphin ${ }^{\circledR}$ Imaging (9.0v build 18). For each subject's file, two timepoints were entered to define the subject's ages when the pretreatment and posttreatment cephalometric radiographs were taken. Both pretreatment and posttreatment scanned tracings were captured in the subject's file. Dolphin ${ }^{\circledR}$ software then was used to identify each relevant landmark on the scanned tracing. Additional hard and soft tissue landmarks were identified to allow for a more recognizable traditional cephalometric tracing. Dolphin ${ }^{\circledR}$ was customized to measure five distances: (1) Sella-Nasion, (2) Sella-A Point, (3) Sella-B Point, (4) Sella-Gnathion, and (5) Sella-Gonion (Fig. 11). The difference in pretreatment and posttreatment measurements corresponds to the anatomical growth occurring in the following structures: 


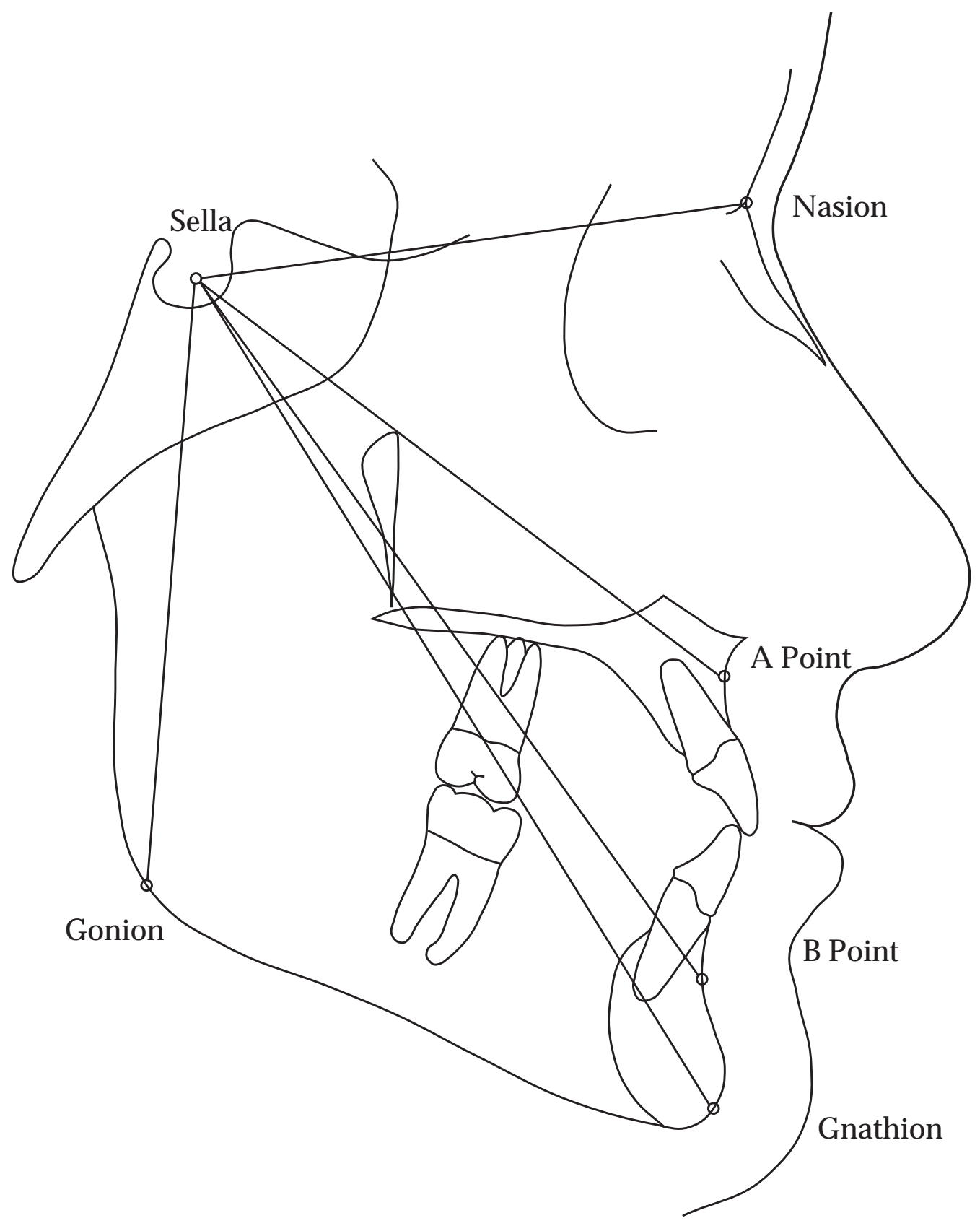

Fig. 11. Five craniofacial measurements used in this study. 
(1) $\Delta \mathrm{Se}-\mathrm{Na}$ is the growth of the anterior cranial base length

(2) $\Delta$ Se-A Point is the growth of the maxilla

(3) $\Delta$ Se-B Point is the growth of the mandible

(4) $\Delta \mathrm{Se}-\mathrm{Gn}$ is a comprehensive measure of facial growth

(5) $\Delta$ Se-Go is the growth of posterior facial height

Both pretreatment and posttreatment measurements were exported out of Dolphin ${ }^{\circledR}$ as a Microsoft ${ }^{\circledR}$ Excel 2000 spreadsheet. These data were collated into a master spreadsheet that combined all patients and their data, including demographic information (patient's sex, birth date, treatment start date, treatment ending date, and length of treatment) and their vertebral and canine developmental stages.

This was a sample of convenience in that cases were collected at random so long as they met the selection criteria. In consequence, the resulting age distribution (at pretreatment) was unimodal, centered on early adolescence when most patients seek treatment (Fig. 12). Because people of virtually any age can be treated orthodontically, the age distribution originally was positively skewed because of a few subjects in the middle age. We truncated the sample at 20 years of age (at pretreatment) to prevent the few older cases from acting as leverage points and having undue influence on the statistical results. The resulting sample ( $\mathrm{n}=183$ subjects) had a mean age of 13.4 years $(\mathrm{sd}=2.56$ years) with a range of 8.3 to 19.9 years. 


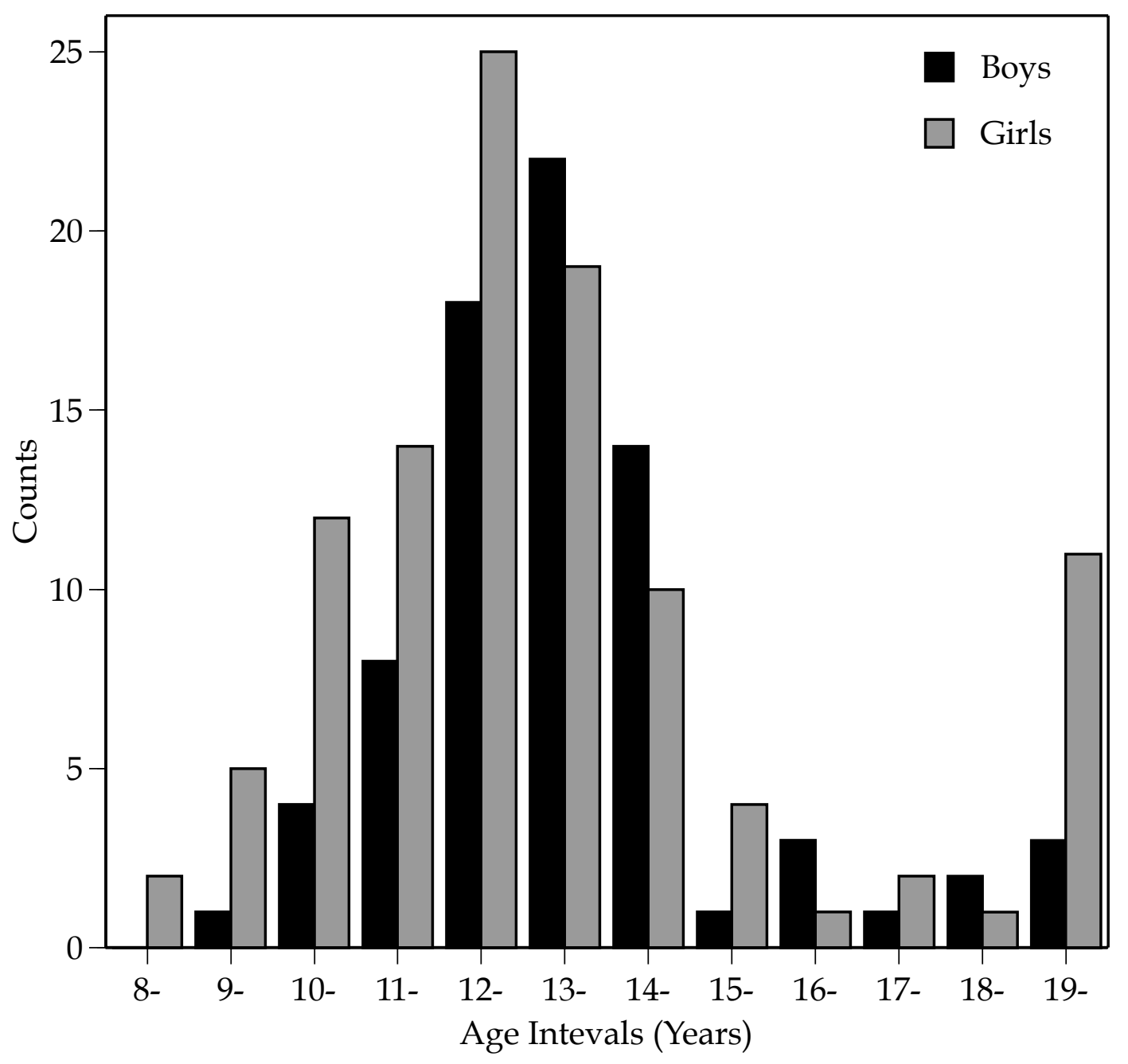

Fig. 12. Age distributions of the total sample $(n=183)$ by sex. 


\section{$\underline{\text { Statistical Analysis }}$}

Descriptive statistics described here all conform to conventional formulations (Sokal and Rohlf 1995), specifically sample size (n), arithmetic mean $(\bar{x})$, standard deviation (sd), and standard error of the mean (sem). The inferential statistics used here rely primarily on factorial analysis of variance (ANOVA); formulations are described in Winer et al. (1971).

The basic analytical question is whether the amount of facial growth differed significantly by maturational grade - where 'grade' is either the ordinal grades of cervical vertebral maturation or those of the mandibular canine. This is tested by using the ordinal grades as "treatments" in the ANOVA model and the amount of facial growth for one of the five dimensions as the dependent variable. During the exploratory phase the ANOVA model was elaborated to include subject's age at the start of treatment, the duration of treatment, subject's sex, along with the various interaction effects among these factors were tested to assess how complex and what sort of model best captured the salient portions of the variation in facial growth.

All of the stages for vertebral maturation assessment were used in the statistical model. For tooth grades, only the last two grades were used in the statistical model. Reasons for this are because only apexification of the mandibular canines has been suggested to occur near adolescent peak height velocity (Chertkow 1980) and this is the only stage useful to the orthodontist. 
Although to be determined, the degree of association of vertebral maturation should be closer than that of tooth mineralization to growth. One would expect a closer association in vertebral maturation due to CV2 grades spanning the whole age range studied, where as only two grades were assessed for tooth mineralization. 


\section{CHAPTER IV}

\section{RESULTS}

\section{Age and Time in Treatment}

The focus of the present study is to see whether information about a patient's biological age is informative as regards the amounts of facial growth occurring during the course of treatment.

Since time in treatment is itself tied to the amount of observed growth, it is of interest whether a patient's chronological age is tied the duration of treatment. Males and females were analyzed separately to avoid well-known differences in their tempos of growth, and the age interval was truncated to between 9 and 17 years at the start of treatment in order to eliminate outliers.

In neither sex was there any suggestion that age in itself predicted the duration of treatment. That is, is the chronological age when treatment started tied to how long it took to treat the case? Linear regression analysis was used to test this, with starting age as the independent variable and duration of treatment as the dependent (outcome) variable. In boys,

$$
\text { Duration }=4.1 \mathrm{yrs}-0.05 \text { (Age at Start) }
$$

With $t=0.89$ and $\mathrm{P}=0.38$ for the regression coefficient. For the girls,

$$
\text { Duration }=4.1 \mathrm{yrs}-0.08 \text { (Age at Start) }
$$


with $t=1.71$ and $P=0.09$ for the regression coefficient. At face, then, the regression coefficients are both negative (so younger children take very slightly longer to treat), but this vague trend accounts for almost none of the variation in treatment time $\left(\mathrm{r}^{2}=1.0 \%\right.$ in boys; $2.7 \%$ in girls $)$.

The age at start of treatment is not, in itself, predictive of how much growth will occur during the course of treatment, but other variables might be. Certainly one would suppose that the duration of treatment would be associated with the amount of growth since there is an intuitive association with how long patients grow and their resultant size increase. Expectation could be confounded, though, since patients of various ages (10 through 17 years of age) are examined together, and the rates of facial growth vary substantially across this age span (e.g., Love et al. 1990).

Sex of the patient is a second potential influence here; it is well documented that boys grow much faster during adolescence than girls (Hellman 1935; Tanner 1978).

Some measure of physiological age ought to be predictive of the amount of growth since patients should be growing faster during their parapubertal spurt than before or after. The maturational status of CV2 is used here. Root development of the mandibular canine also was scored, but this is expected to be less informative than the CV2 status because only two grades were recorded, whereas the CV2 grades span the whole age range studied. 
Exploratory analysis was run incorporating these four potential sources of variation: (1) age at start of treatment, (2) time in treatment, (3) sex of the patient, and (4) biological age as estimated from the six-grade scheme for CV2 developed by Lamparski (1972). First-order interaction terms were included in the models to search for nonadditivity among the factors. All of the raw data for all subjects are shown in the Appendix.

Results (Tables 6-10) are informative in that most of the five models account for about half of the variation in the amount of facial growth. The adjusted model $\mathrm{R}^{2}$ was $38 \%$ for Sella-Nasion growth, $60 \%$ for Sella-Gnathion growth, 46\% for Sella-Gonion growth, 34\% for Sella-A Point growth, and 40\% for Sella-B Point growth.

For the Sella-Nasion model (Table 6), patient's sex is the only significant factor of the four tested. This may be because there is so little growth of the anterior cranial base (Se-Na) during adolescence, and most of what does occur is in the frontal bone (not strictly part of the cranial base) where cortical bone thickness and the frontal sinuses are vacuolized (Enlow and Hunter 1968). The grand mean for change in Sella-Nasion is $2.2 \mathrm{~mm}(\mathrm{sd}=1.92)$.

Change in Sella-Gnathion, one of the largest facial dimensions, exhibited an average change of $7.8 \mathrm{~mm}$ for the whole sample $(\mathrm{sd}=4.89)$. Two of the main effects are significant in this model (Table 7), namely patient's sex and the grade of CV2 maturation. Little consequence is placed on the two marginally- 
Table 6. Results of four-way factorial ANOVA looking at sources of variation for the in-treatment change in Sella-Nasion distance.

\begin{tabular}{lcccc}
\hline \multicolumn{1}{c}{ Source } & df & $\begin{array}{c}\text { Sum of } \\
\text { Squares }\end{array}$ & F Ratio & P Value \\
\hline Start Age & 1 & 3.6687 & 1.33 & 0.2497 \\
Treatment Time & 1 & 10.0622 & 3.66 & 0.0574 \\
Sex & 1 & 54.1658 & 19.70 & $<.0001$ \\
CV2 Grade & 5 & 37.1672 & 13.52 & 0.0003 \\
Start Age-x-Treatment Time & 1 & 7.2618 & 2.64 & 0.1060 \\
Start Age-x-Sex & 1 & 0.4255 & 0.15 & 0.6946 \\
Start Age-x-CV2 Grade & 5 & 0.6860 & 0.25 & 0.6181 \\
Treatment Time-x-Sex & 1 & 17.1348 & 6.23 & 0.0135 \\
Treatment Time-x-CV2 Grade & 5 & 1.8151 & 0.66 & 0.4177 \\
Sex-x-CV2 Grade & 5 & 0.8295 & 0.30 & 0.5836 \\
\hline
\end{tabular}


Table 7. Results of four-way factorial ANOVA looking at sources of variation for the in-treatment change in Sella-Gnathion distance.

\begin{tabular}{lrrrr}
\hline \multicolumn{1}{c}{ Source } & df & $\begin{array}{r}\text { Sum of } \\
\text { Squares }\end{array}$ & F Ratio & P Value \\
\hline Start Age & 1 & 49.5501 & 4.15 & 0.0431 \\
Treatment Time & 1 & 152.7776 & 12.80 & 0.0005 \\
Sex & 1 & 348.2607 & 29.18 & $<.0001$ \\
CV2 Grade & 5 & 511.2104 & 42.83 & $<.0001$ \\
Start Age-x-Treatment Time & 1 & 1.7434 & 0.15 & 0.7028 \\
Start Age-x-Sex & 1 & 27.4717 & 2.30 & 0.1311 \\
Start Age-x-CV2 Grade & 5 & 1.6826 & 0.14 & 0.7078 \\
Treatment Time-x-Sex & 1 & 10.7357 & 0.90 & 0.3443 \\
Treatment Time-x-CV2 Grade & 5 & 10.6884 & 0.90 & 0.3453 \\
Sex-x-CV2 Grade & 5 & 1.0042 & 0.08 & 0.7721 \\
\hline
\end{tabular}


Table 8. Results of four-way factorial ANOVA looking at sources of variation for the in-treatment change in Sella-Gonion distance.

\begin{tabular}{lrrrr}
\hline \multicolumn{1}{c}{ Source } & df & $\begin{array}{r}\text { Sum of } \\
\text { Squares }\end{array}$ & F Ratio & P Value \\
\hline Start Age & 1 & 1.7473 & 0.14 & 0.7096 \\
Treatment Time & 1 & 202.5419 & 16.13 & $<.0001$ \\
Sex & 1 & 244.3748 & 19.47 & $<.0001$ \\
CV2 Grade & 5 & 298.7878 & 23.80 & $<.0001$ \\
Start Age-x-Treatment Time & 1 & 0.1868 & 0.01 & 0.9031 \\
Start Age-x-Sex & 1 & 11.2908 & 0.90 & 0.3443 \\
Start Age-x-CV2 Grade & 5 & 14.9394 & 1.19 & 0.2769 \\
Treatment Time-x-Sex & 1 & 18.2257 & 1.45 & 0.2299 \\
Treatment Time-x-CV2 Grade & 5 & 0.8840 & 0.07 & 0.7911 \\
Sex-x-CV2 Grade & 5 & 0.1220 & 0.01 & 0.9216 \\
\hline
\end{tabular}


Table 9. Results of four-way factorial ANOVA looking at sources of variation for the in-treatment change in Sella-A Point distance.

\begin{tabular}{lcccc}
\hline \multicolumn{1}{c}{ Source } & df & $\begin{array}{c}\text { Sum of } \\
\text { Squares }\end{array}$ & F Ratio & P Value \\
\hline Start Age & 1 & 0.2491 & 0.04 & 0.8427 \\
Treatment Time & 1 & 6.5952 & 1.05 & 0.3079 \\
Sex & 1 & 33.9349 & 5.38 & 0.0215 \\
CV2 Grade & 5 & 88.1189 & 13.98 & 0.0003 \\
Start Age-x-Treatment Time & 1 & 28.1838 & 1.47 & 0.0360 \\
Start Age-x-Sex & 1 & 0.3650 & 0.06 & 0.8101 \\
Start Age-x-CV2 Grade & 5 & 0.3906 & 1.06 & 0.8037 \\
Treatment Time-x-Sex & 1 & 9.2163 & 1.46 & 0.2283 \\
Treatment Time-x-CV2 Grade & 5 & 0.0307 & 0.00 & 0.9444 \\
Sex-x-CV2 Grade & 5 & 2.3919 & 0.38 & 0.5387 \\
\hline
\end{tabular}


Table 10. Results of four-way factorial ANOVA looking at sources of variation for the in-treatment change in Sella-B Point distance.

\begin{tabular}{lcccc}
\hline \multicolumn{1}{c}{ Source } & df & $\begin{array}{c}\text { Sum of } \\
\text { Squares }\end{array}$ & F Ratio & P Value \\
\hline Start Age & 1 & 71.6321 & 7.69 & 0.0062 \\
Treatment Time & 1 & 31.4568 & 3.38 & 0.0678 \\
Sex & 1 & 254.0637 & 27.28 & $<.0001$ \\
CV2 Grade & 5 & 180.1557 & 19.35 & $<.0001$ \\
Start Age-x-Treatment Time & 1 & 6.6511 & 0.71 & 0.3992 \\
Start Age-x-Sex & 1 & 0.0507 & 0.01 & 0.9413 \\
Start Age-x-CV2 Grade & 5 & 20.2347 & 2.17 & 0.1423 \\
Treatment Time-x-Sex & 1 & 22.1011 & 2.37 & 0.1253 \\
Treatment Time-x-CV2 Grade & 5 & 0.0102 & 0.00 & 0.9736 \\
Sex-x-CV2 Grade & 5 & 0.0766 & 0.01 & 0.9278 \\
\hline
\end{tabular}


significant interaction effects in this model $(0.05>\mathrm{P}>0.01)$ because their influence was not replicated in the other analyses and because the effects are only marginally significant even give the large sample size.

Comparable results were obtained from the model for Sella-Gonion growth (Table 8), where patient's sex and CV2 grade are the only statistically significant effects. Overall, the mean change in Sella-Gonion is $6.1 \mathrm{~mm}(\mathrm{sd}=4.08$ $\mathrm{mm})$.

The change in Sella-A Point $(\bar{x}=2.0 \mathrm{~mm}$; sd $=2.37 \mathrm{~mm})$ actually was the smallest of the five distances tested here, being even less than the average increase in the Sella-Nasion distance. For this model (Table 9), the increase in maxillary depth (Se-A Pt) only depended statistically on the morphological grade of CV2.

The later and prolonged growth in the mandible (Se-B Pt) compared to the maxilla is shown by the mean change of $4.2 \mathrm{~mm}$ in this distance for the whole sample $(\mathrm{sd}=3.65 \mathrm{~mm})$, though Sella-B Point is a diagonal rather than horizontal measure of facial growth.

In sum, the purpose in testing these models shown in Tables 6-10 was to determine how complex the analysis of variance design needed to be. We see, for example, that age at start of treatment and the duration of treatment are never significant, so they can safely be eliminated. Likewise, except for tangential cases in the results for Sella-Gnathion (Table 7), none of the first-order interaction 
effects is significant. Consequently, models to be tested using biological age (below) do not need to be encumbered by these several potentially confounding factors.

\section{Chronological Age and Growth}

Review of the Literature provides an overview of the stronger dependency between growth and physiological age compared to chronological age - primarily because physiological age accounts for differences in the tempos of growth among individuals. Still, there should be significant statistical associations between chronological age and growth during adolescence: older, postpubertal subjects should be growing slower than younger subjects.

This expectation was tested using linear regression analysis, regressing the amount of growth on chronological age at the start of orthodontic treatment. Analysis was performed by sex (Table 11 for boys; Table 12 for girls). Preliminary tests showed, in fact, that a quadratic equation fits the data significantly better than a straight line for several of the variables. For consistency, a quadratic equation of the form

$$
\text { Growth }=a+b_{1}(\text { Age })+b_{2}(\text { Age })^{2}
$$

was fit, where Growth is the amount of in-treatment growth and Age is the chronological age at the start of treatment. Of note, all 10 regression coefficients are negative, showing that, indeed, grow rates slow as age during adolescence 
Table 11. Results of regression of facial growth on chronological age at the start of treatment, in males. ${ }^{1}$

\begin{tabular}{|c|c|c|c|c|}
\hline Term & Estimate & Std Error & t Ratio & Prob $>|t|$ \\
\hline \multicolumn{5}{|c|}{ Sella-Nasion } \\
\hline Intercept & 8.036 & 1.600 & 5.02 & $<0.0001$ \\
\hline Age at Start & -0.369 & 0.123 & -3.02 & 0.0035 \\
\hline Age at Start ${ }^{2}$ & 0.012 & 0.031 & 0.38 & 0.7077 \\
\hline \multicolumn{5}{|c|}{ Sella-Gnathion } \\
\hline Intercept & 26.572 & 3.746 & 7.09 & $<0.0001$ \\
\hline Age at Start & -1.196 & 0.287 & -4.16 & $<0.0001$ \\
\hline Age at Start ${ }^{2}$ & -0.048 & 0.072 & 0.67 & 0.5073 \\
\hline \multicolumn{5}{|c|}{ Sella-Gonion } \\
\hline Intercept & 15.341 & 3.718 & 4.13 & $<0.0001$ \\
\hline Age at Start & -0.495 & 0.285 & -1.74 & 0.0861 \\
\hline Age at Start ${ }^{2}$ & -0.115 & 0.071 & -1.62 & 0.1092 \\
\hline \multicolumn{5}{|c|}{ Sella-A Point } \\
\hline Intercept & 7.199 & 2.338 & 3.08 & 0.0029 \\
\hline Age at Start & -0.311 & 0.179 & -1.74 & 0.0863 \\
\hline Age at Start ${ }^{2}$ & 0.032 & 0.045 & -0.70 & 0.4839 \\
\hline \multicolumn{5}{|c|}{ Sella-B Point } \\
\hline Intercept & 17.268 & 2.986 & 5.78 & $<0.0001$ \\
\hline Age at Start & -0.854 & 0.229 & -3.73 & 0.0004 \\
\hline Age at Start ${ }^{2}$ & 0.033 & 0.057 & 0.58 & 0.5662 \\
\hline
\end{tabular}

${ }^{1}$ A quadratic equation was fit to all variables for consistency, but note the difference in significance of the quadratic term for males and females. 
Table 12. Results of regression of facial growth on chronological age at the start of treatment, in females. ${ }^{1}$

\begin{tabular}{|c|c|c|c|c|}
\hline Term & Estimate & Std Error & t Ratio & Prob $>|t|$ \\
\hline \multicolumn{5}{|c|}{ Sella-Nasion } \\
\hline Intercept & 4.731 & 0.918 & 5.16 & $<0.0001$ \\
\hline Age at Start & -0.271 & 0.074 & -3.66 & 0.0004 \\
\hline Age at Start 2 & 0.040 & 0.017 & 2.38 & 0.0190 \\
\hline \multicolumn{5}{|c|}{ Sella-Gnathion } \\
\hline Intercept & 16.778 & 2.073 & 8.09 & $<0.0001$ \\
\hline Age at Start & -0.902 & 0.167 & -5.41 & $<0.0001$ \\
\hline Age at Start 2 & 0.069 & 0.038 & 1.81 & 0.0725 \\
\hline \multicolumn{5}{|c|}{ Sella-Gonion } \\
\hline Intercept & 12.167 & 1.946 & 6.25 & $<0.0001$ \\
\hline Age at Start & -0.635 & 0.156 & -4.06 & $<0.0001$ \\
\hline Age at Start ${ }^{2}$ & 0.044 & 0.036 & 1.23 & 0.2228 \\
\hline \multicolumn{5}{|c|}{ Sella-A Point } \\
\hline Intercept & 6.002 & 1.402 & 4.28 & $<0.0001$ \\
\hline Age at Start & -0.391 & 0.133 & -3.46 & 0.0008 \\
\hline Age at Start ${ }^{2}$ & 0.059 & 0.026 & 2.26 & 0.0259 \\
\hline \multicolumn{5}{|c|}{ Sella-B Point } \\
\hline Intercept & 12.580 & 1.750 & 7.19 & $<0.0001$ \\
\hline Age at Start & -0.810 & 0.141 & -5.76 & $<0.0001$ \\
\hline Age at Start ${ }^{2}$ & 0.076 & 0.033 & 2.31 & 0.0227 \\
\hline
\end{tabular}

${ }^{1}$ A quadratic equation was fit to all variables for consistency, but note the difference in significance of the quadratic term for males and females. 
progresses. On the other hand, while all of the regression coefficients are highly significantly different from zero in girls, 3 of the 5 tests are nonsignificant $(0.10>$ $P>0.05)$ in the sample of boys.

Inspection of the individual tests for males (Table 11) shows that the amount of growth occurring during treatment decreases significantly for SellaNasion $(b=-0.37)$, Sella-Gnathion $(b=-1.20)$, and Sella B Point $(b=-0.85)$.

Similarly, the downward trends for Sella-Gonion $(b=-0.49)$ and Sella-A Point $(b$ $=-0.31)$ are evident but not significant $(0.10>\mathrm{P}>0.05)$. These relationships are graphed in Figures 13 through 17. For these males, none of the quadratic terms was significant, meaning that a straight line fit the data better than a curvilinear one, so the diminution in growth across the 10 to 20 years age span was monotonic and regular.

For females (Table 12), the first-order term of the regression equation was significant for each of the five variables. The regression coefficient was -0.27 for Sella-Nasion, meaning that there was about $0.3 \mathrm{~mm}$ less growth per year as the age at the start of treatment increased (Fig. 18). Predictably (e.g., Enlow 1965), this growth at Nasion is the least of the five facial dimensions examined. Figure 18 also shows the significant curvilinear relationships, where growth diminishes at an increasingly sharper rate, particularly in the 10 to 17 year age range.

A comparable relationship occurred for Sella-Gnathion, with the deceleration down to zero in the older teen age years being suggestive (Fig. 19) 


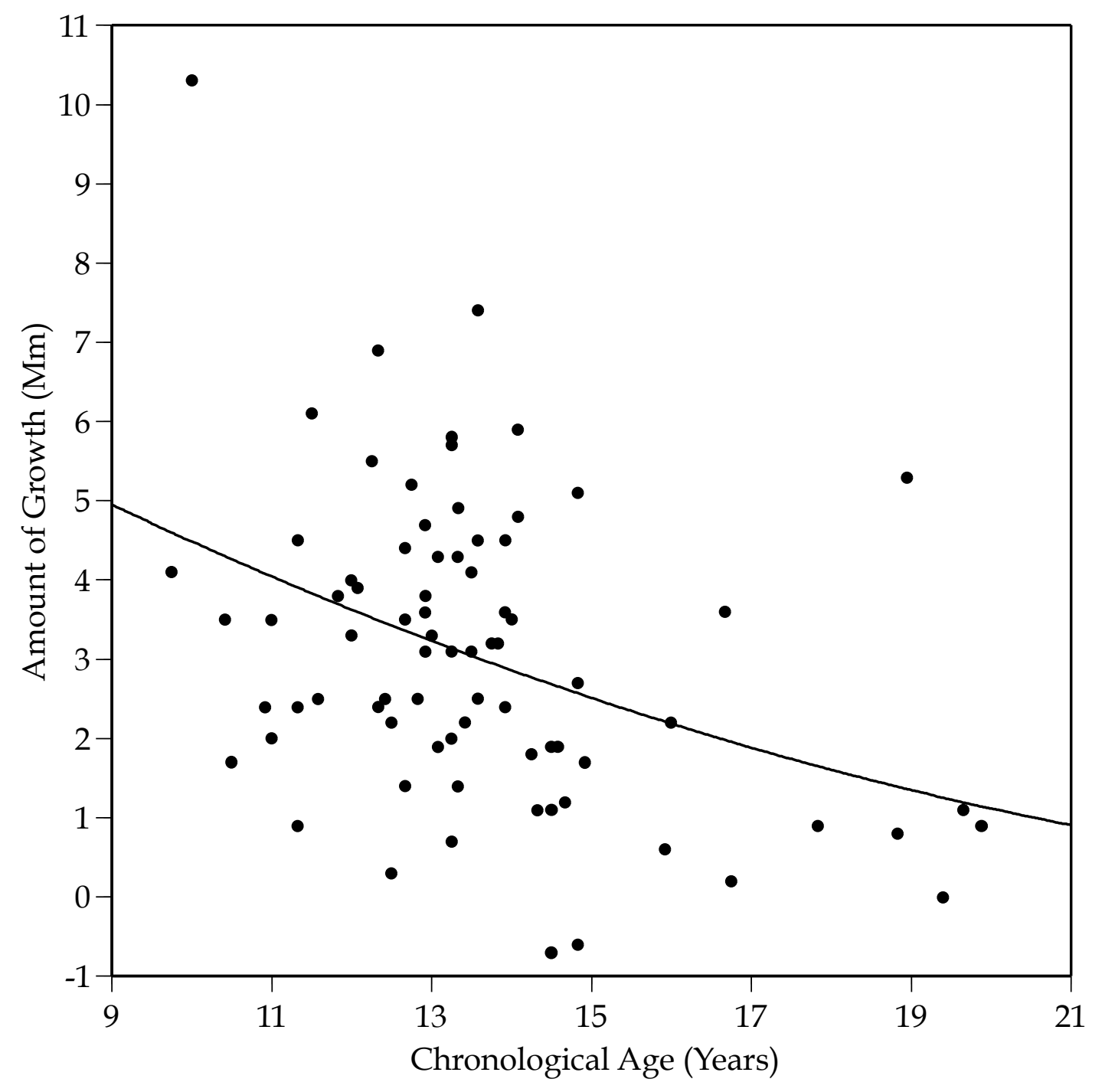

Fig. 13. Plot of amount of growth in Sella-Nasion against chronological age at the start of treatment in males. A quadratic equation is fit to the data. 


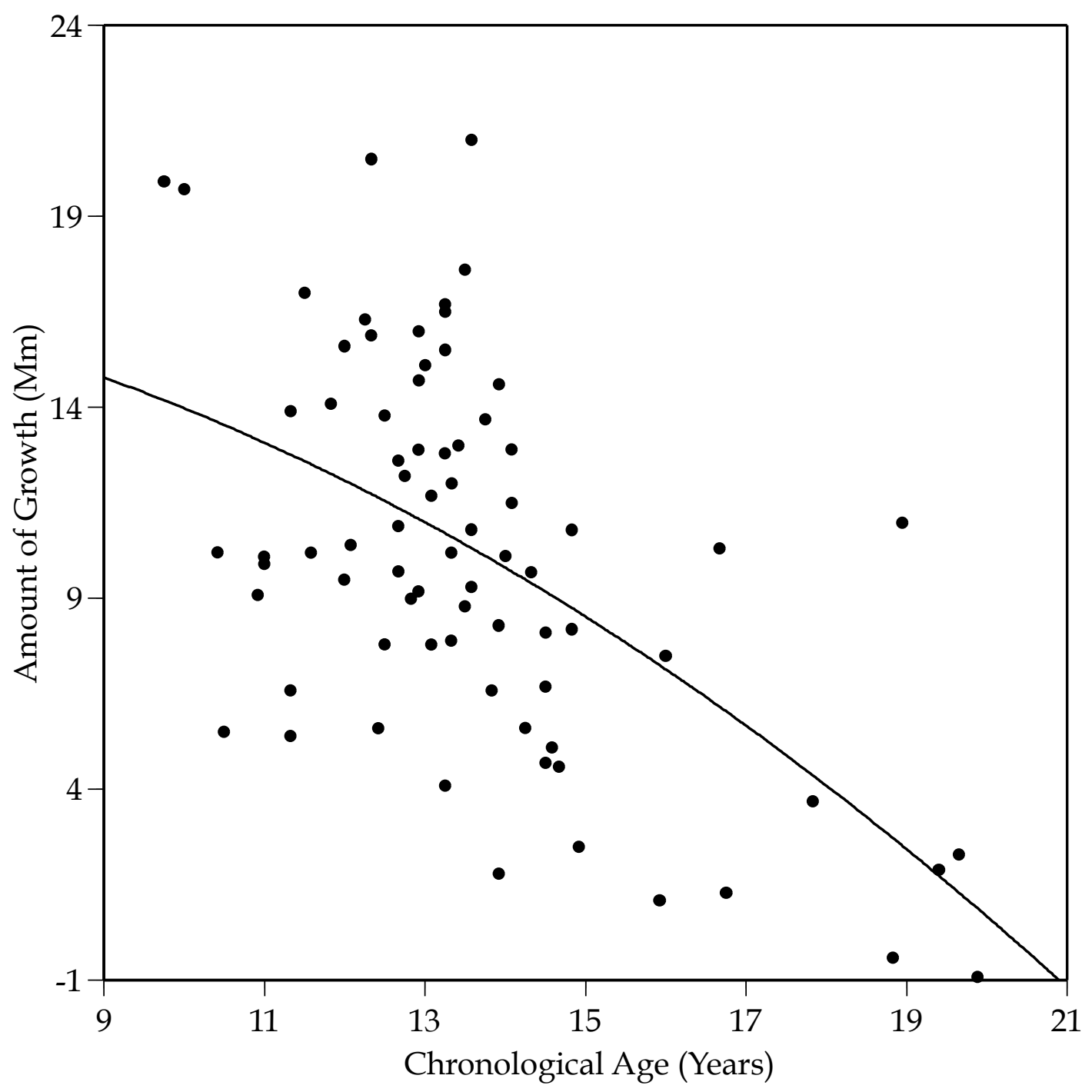

Fig. 14. Plot of amount of growth in Sella-Gnathion against chronological age at the start of treatment in males. A quadratic equation is fit to the data. 


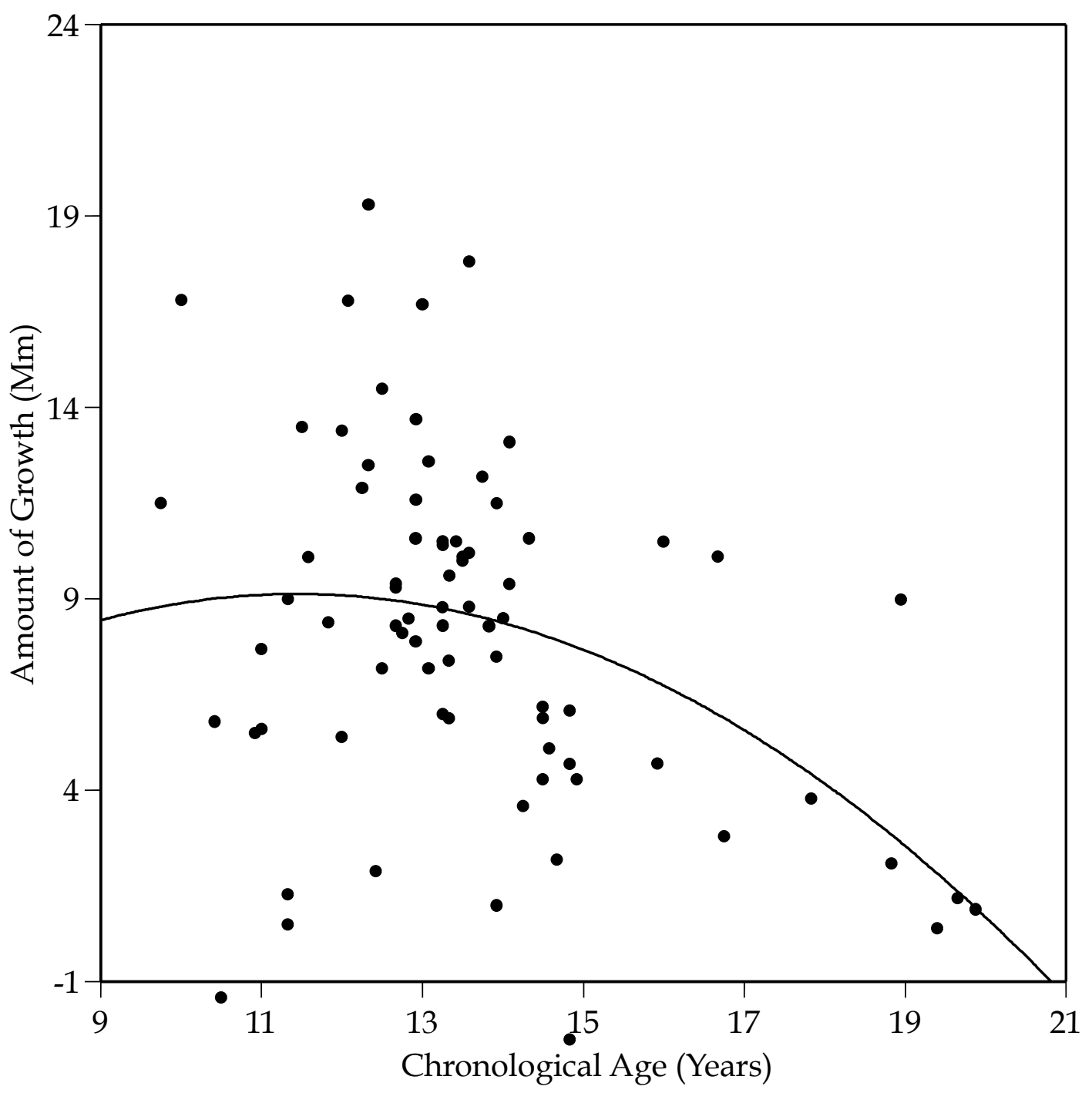

Fig. 15. Plot of amount of growth in Sella-Gonion against chronological age at the start of treatment in males. A quadratic equation is fit to the data. 


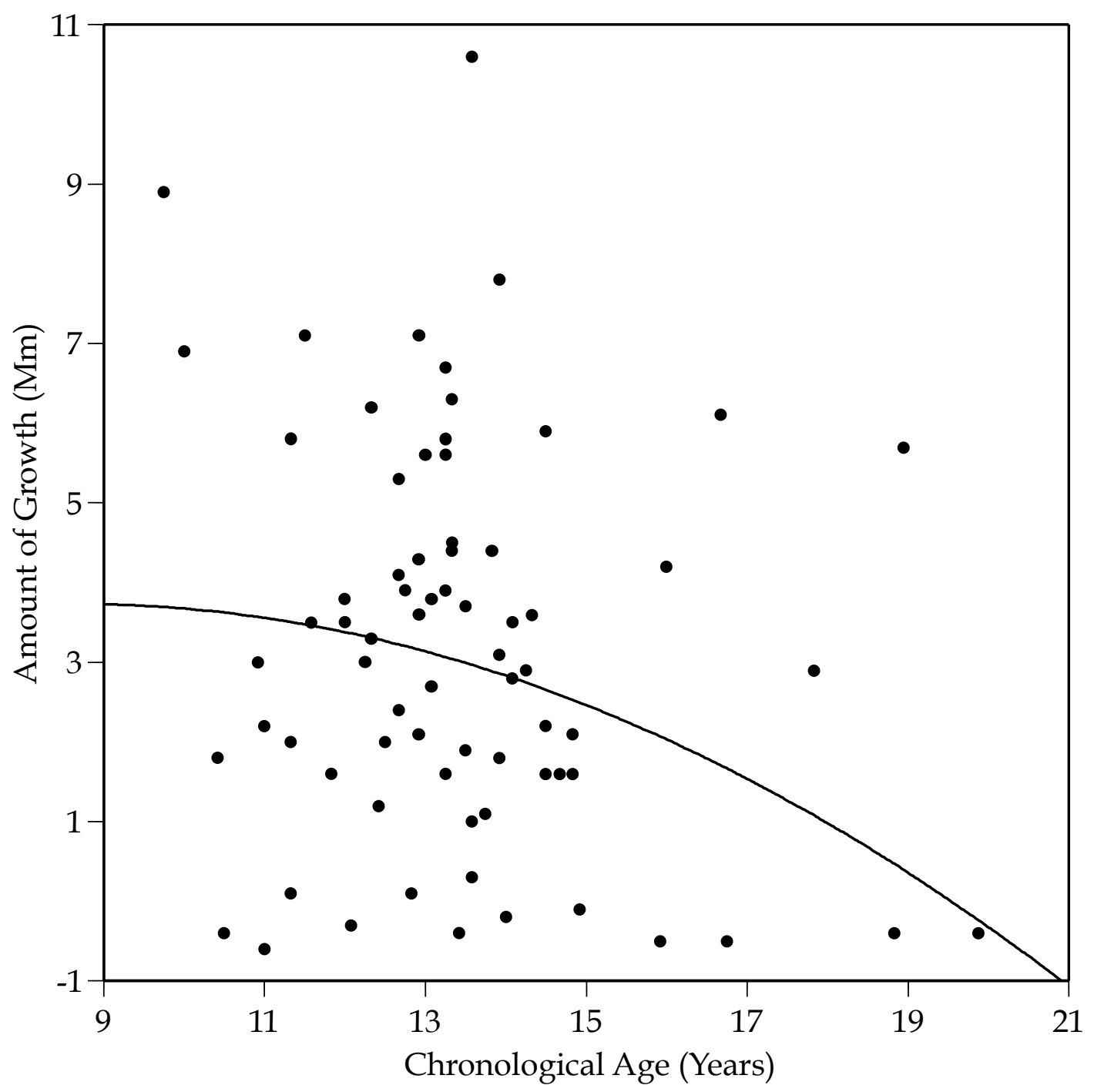

Fig. 16. Plot of amount of growth in Sella-A Point against chronological age at the start of treatment in males. A quadratic equation is fit to the data. 


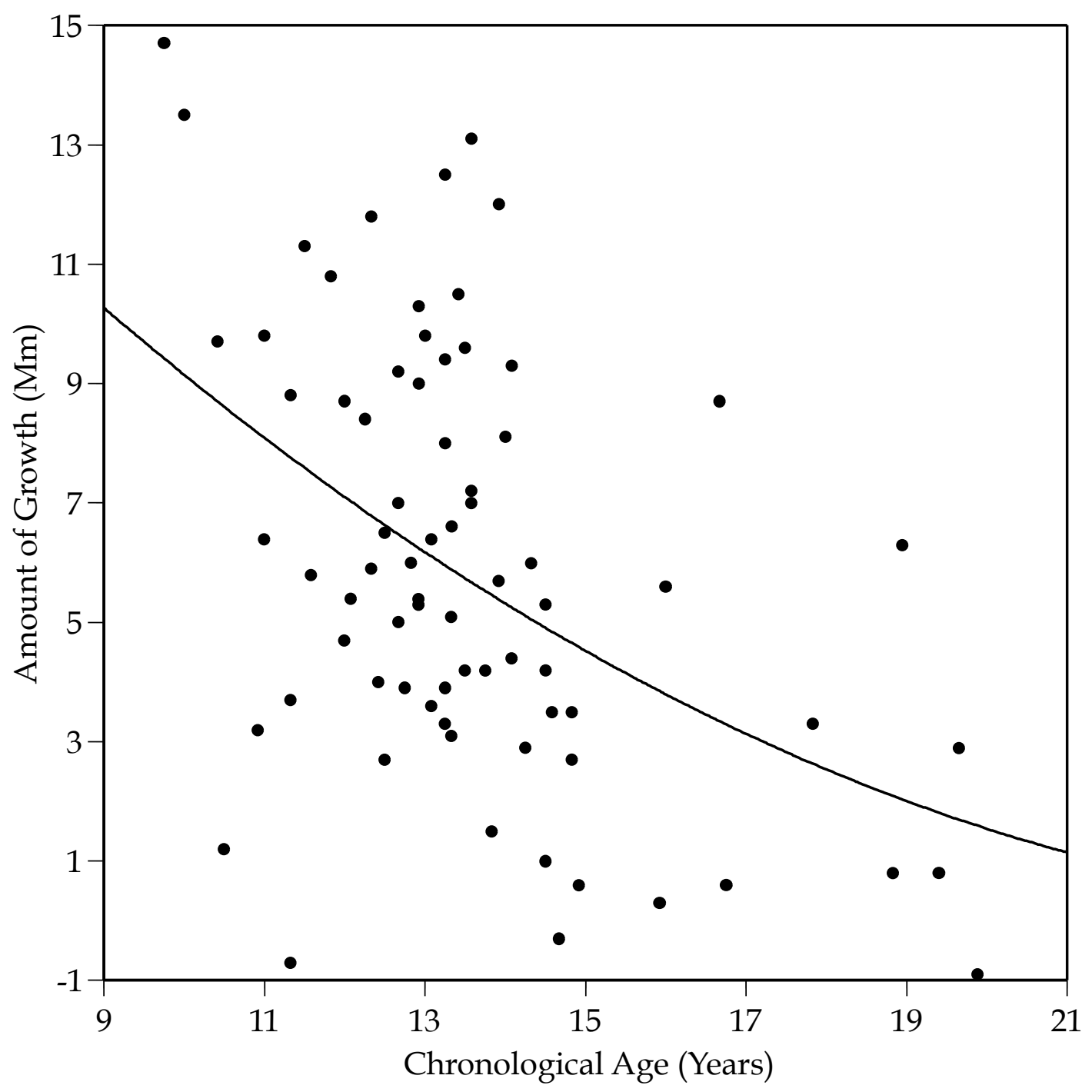

Fig. 17. Plot of amount of growth in Sella-B Point against chronological age at the start of treatment in males. A quadratic equation is fit to the data. 


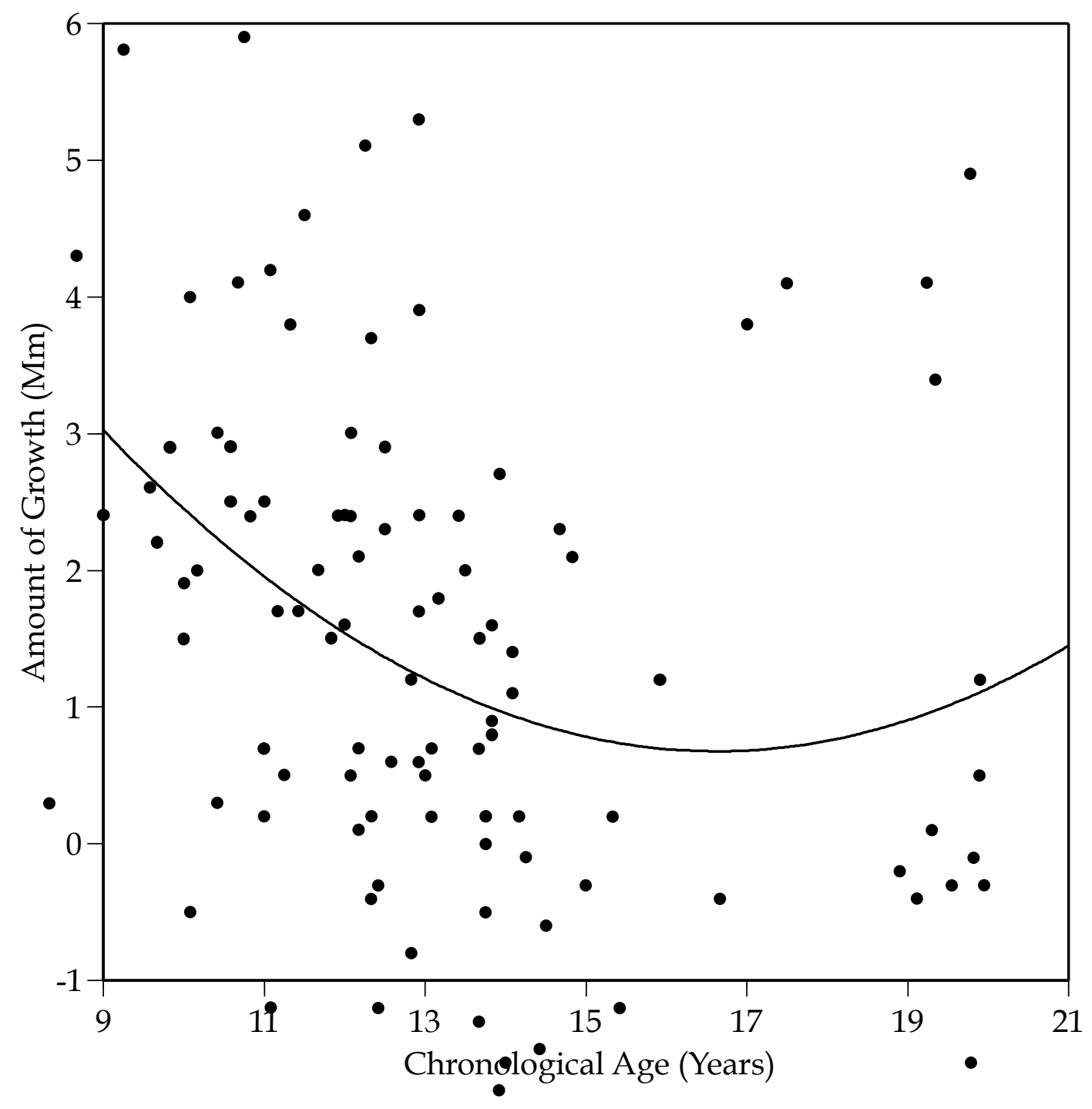

Fig. 18. Plot of amount of growth in Sella-Nasion against chronological age at the start of treatment in females. A quadratic equation is fit to the data. 


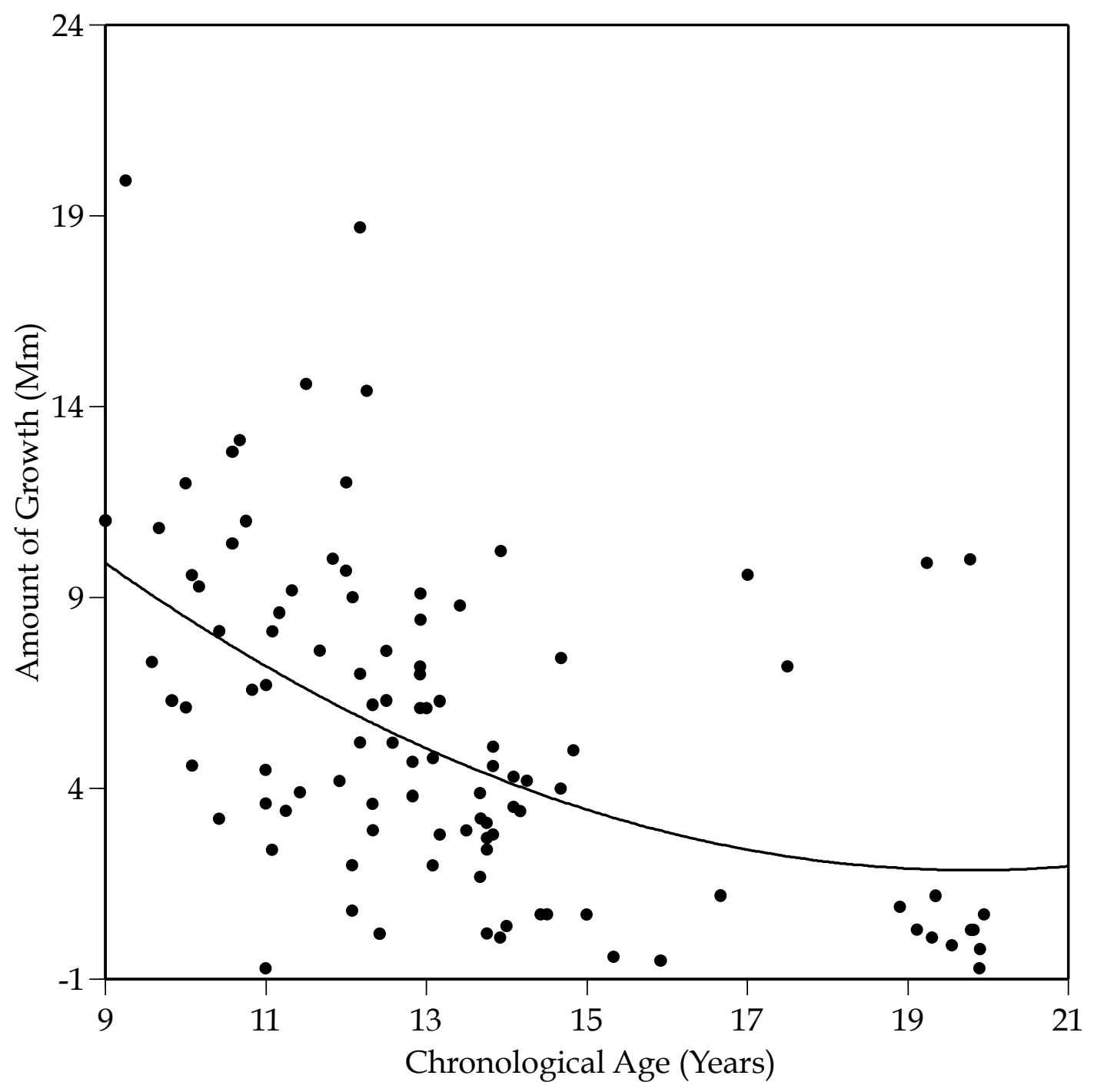

Fig. 19. Plot of amount of growth in Sella-Gnathion against chronological age at the start of treatment in females. A quadratic equation is fit to the data. 
though not explicitly significant $(P=0.07)$. The same can be said of the data for Sella-Gonion (Fig. 20).

Midface growth (Sella-A Point; Fig. 21) exhibits a significant, decelerating curve of the form

$$
\Delta \text { Se-A }=6.00-0.39 \text { Age }+0.06 \text { Age }^{2}
$$

Similarly, the relationship between growth of Sella-B Point and age is significantly curvilinear (Fig. 22).

$$
\Delta \text { Se-B }=12.58-0.81 \text { Age }+0.08 \text { Age }^{2}
$$

Intuitively, then, facial growth is less in females who start orthodontic treatment at older adolescent ages, and the decrease is sharper at the older ages such that it has asymptoted to essentially zero in the late teens. The severity of the declines are not as severe in males across this same age span.

These results do not suggest why the associations are so much weaker for boys than girls. One possibility is that males achieve more of their adult size from the parapubertal growth spurt than females, so positioning of the growth spurt is more critical here for males, and the inability of chronological age to account for inter-individual differences in the tempos of growth explains the failure to find significant associations here (Table 11). If this is indeed the explanation, these results in themselves favor the use of some biological measure of a person's tempo of growth. Additionally, males grow for a longer period of 


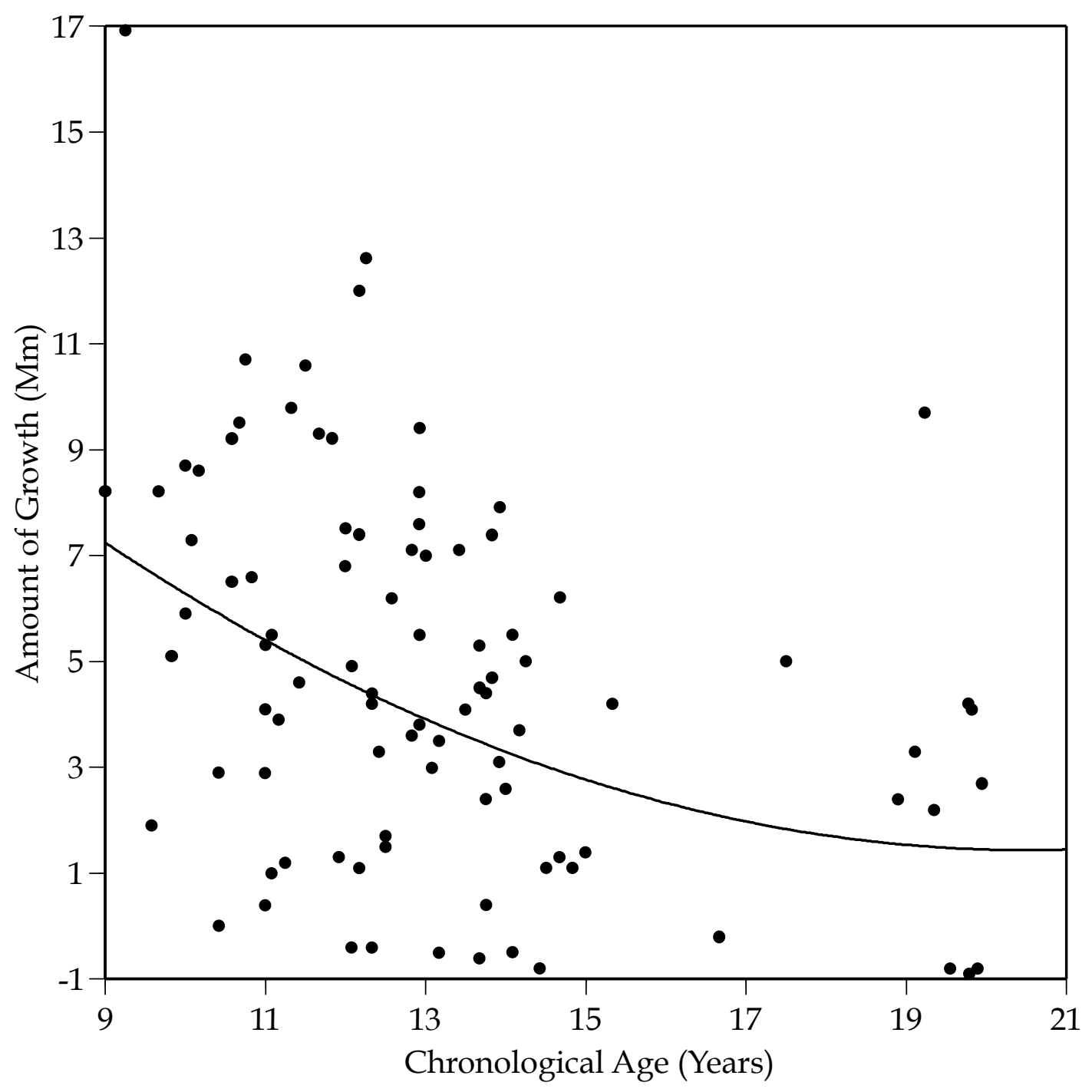

Fig. 20. Plot of amount of growth in Sella-Gonion against chronological age at the start of treatment in females. A quadratic equation is fit to the data. 


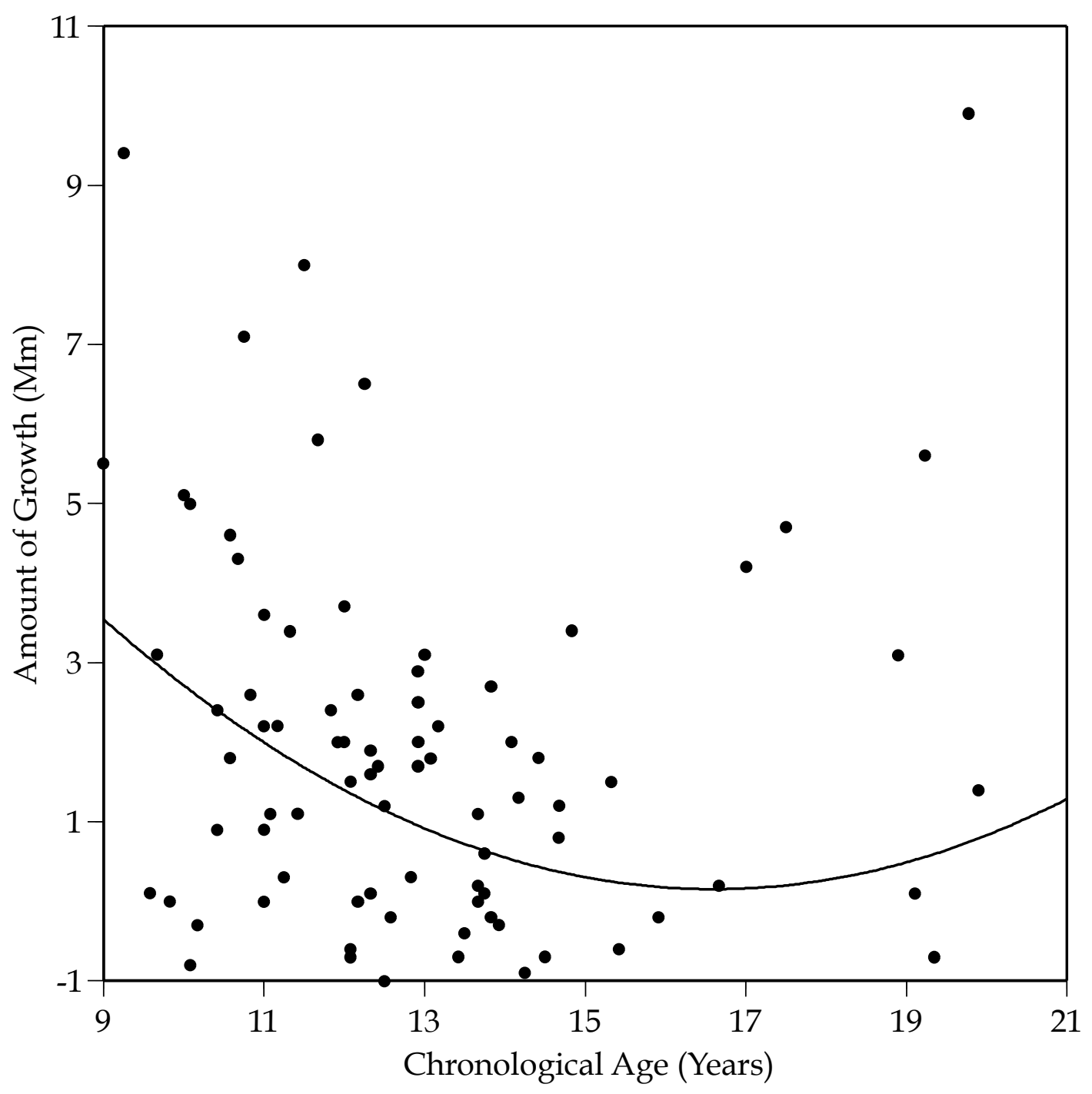

Fig. 21. Plot of amount of growth in Sella-A Point against chronological age at the start of treatment in females. A quadratic equation is fit to the data. 


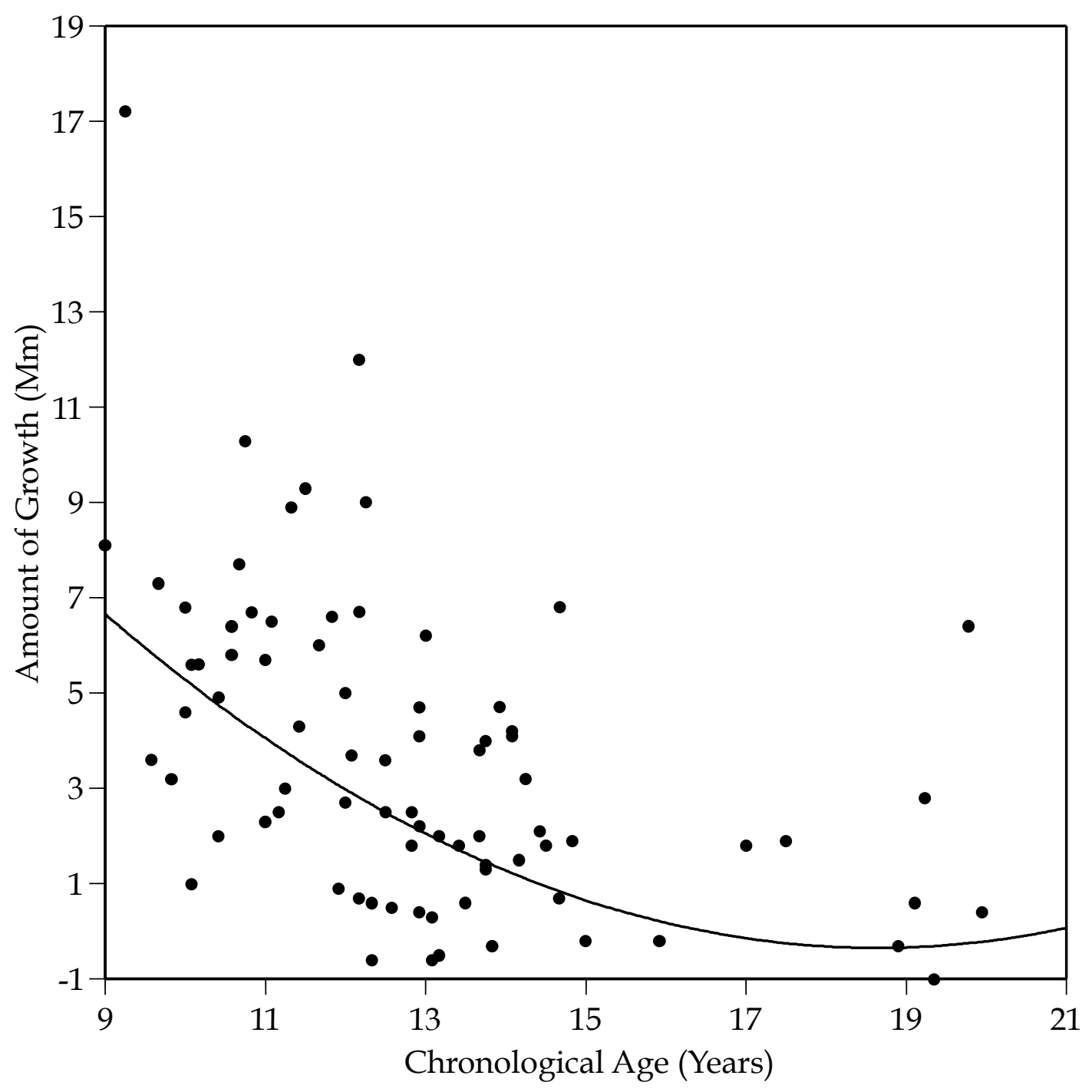

Fig. 22. Plot of amount of growth in Sella-B Point against chronological age at the start of treatment in females. A quadratic equation is fit to the data. 
time than females, so the decrements in later adolescence in girls may not have occurred (or occurred as dramatically) in males.

\section{$\underline{\text { Sex Differences in Growth Rates }}$}

The literature is strongly suggestive that boys grow appreciably faster than girls during adolescence (Tanner 1978; Fishman 1979). This was tested here using analysis of covariance to assess whether there was a sex difference (Table 13). There was, indeed, a highly significant difference - with boys having the higher rate of growth - for each of the five variables. These sex differences also are apparent in the graphs of these data (Figs. 23-27).

\section{Canine Apexification}

Chertkow (1980) suggested that apex closure of the mandibular canine is a maturational event that occurs near adolescent peak height velocity. As such, this marker might prove useful for anticipating the amount of facial skeletal growth during the course of orthodontic treatment.

As noted, we used the Moorrees, Fanning and Hunt (1963) scheme of ordinal grades to score the stages of crown-root formation. The final two stages are labeled grade 12 (root apex half closed) and grade 13 (apex fully closed). The operative question is whether there is significantly more facial growth in patients exhibiting grade 12 at the start of treatment versus those with grade 13. 
Table 13. Results of analysis of covariance testing whether the amount of growth differed between the sexes. ${ }^{1}$

\begin{tabular}{|c|c|c|c|c|c|c|c|c|c|c|c|}
\hline \multicolumn{4}{|c|}{ Start of Treatment } & \multicolumn{4}{|c|}{ Sex } & \multicolumn{4}{|c|}{ Interaction Term } \\
\hline $\mathrm{df}$ & SSQ & F Ratio & P Value & $\mathrm{df}$ & SSQ & F Ratio & P Value & $\mathrm{df}$ & SSQ & F Ratio & P Value \\
\hline 1 & 62.23 & 20.06 & $<0.0001$ & 1 & 129.39 & 40.92 & $<0.0001$ & 1 & 7.92 & 2.55 & 0.1118 \\
\hline 1 & 1007.82 & 62.42 & $<0.0001$ & 1 & 1128.4 & 69.89 & $<0.0001$ & 1 & 87.09 & 5.39 & 0.0213 \\
\hline 1 & 409.15 & 26.95 & $<0.0001$ & 1 & 779.97 & 57.37 & $<0.0001$ & 1 & 16.13 & 1.06 & 0.3040 \\
\hline 1 & 94.44 & 13.56 & 0.0003 & 1 & 117.63 & 16.90 & $<0.0001$ & 1 & 5.85 & 0.84 & 0.3607 \\
\hline 1 & 466.68 & 42.42 & $<0.0001$ & 1 & 571.46 & 51.95 & $<0.0001$ & 1 & 5.84 & 0.53 & 0.4670 \\
\hline
\end{tabular}

'Each row in the table is a separate analysis. The key statistic in these tests is the highly significant test for "Sex", meaning that boys grew at much greater rates than girls. 


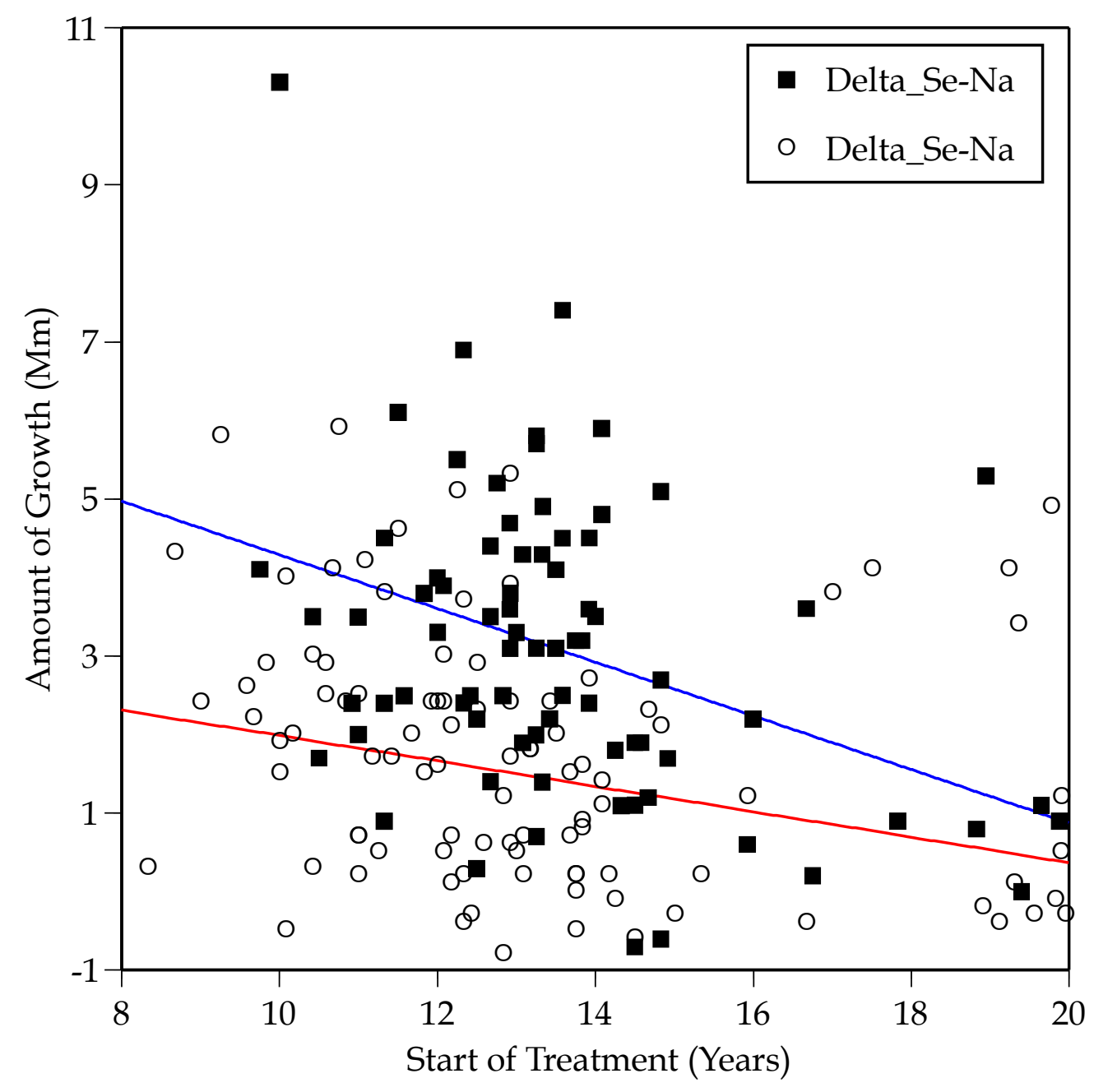

Fig. 23. Plot of age at the start of treatment against the amount of growth during treatment, by sex, for Sella-Nasion. Square symbols denote males; round symbols denote females. Males exhibit more growth during treatment across the age span. 


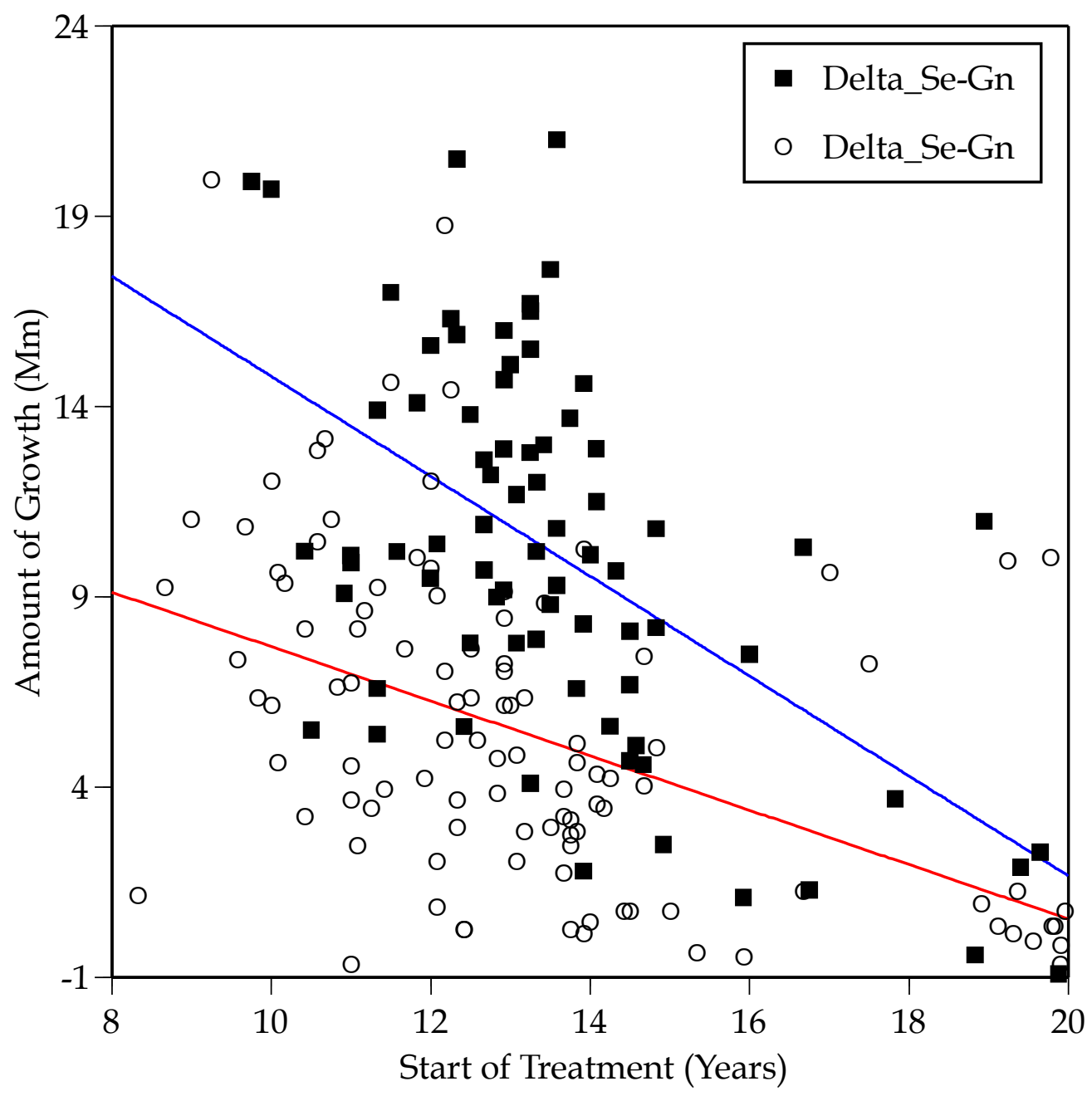

Fig. 24. Plot of age at the start of treatment against the amount of growth during treatment, by sex, for Sella-Gnathion. Square symbols denote males; round symbols denote females. Males exhibit more growth during treatment across the age span. 


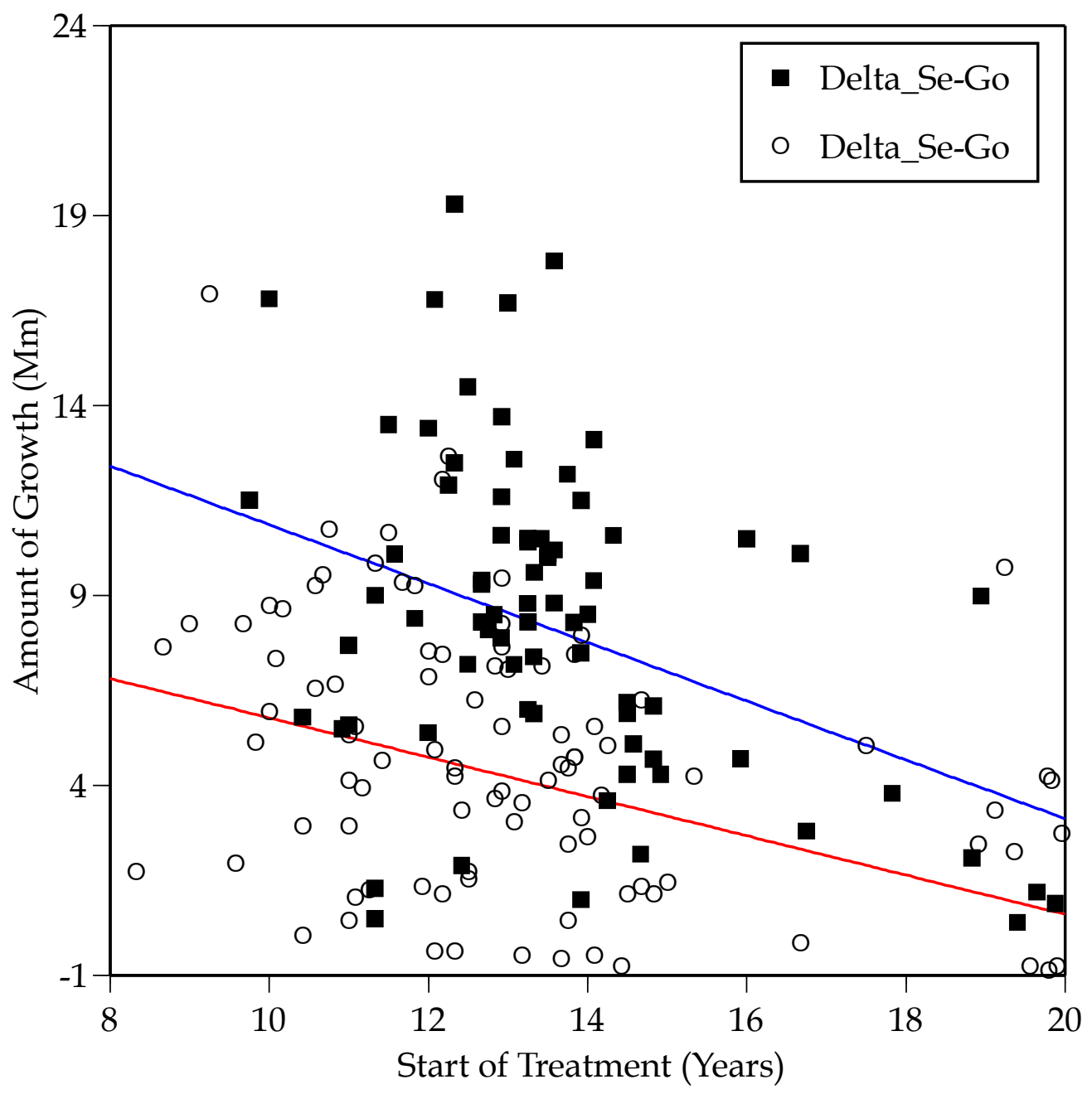

Fig. 25. Plot of age at the start of treatment against the amount of growth during treatment, by sex, for Sella-Gonion. Square symbols denote males; round symbols denote females. Males exhibit more growth during treatment across the age span. 


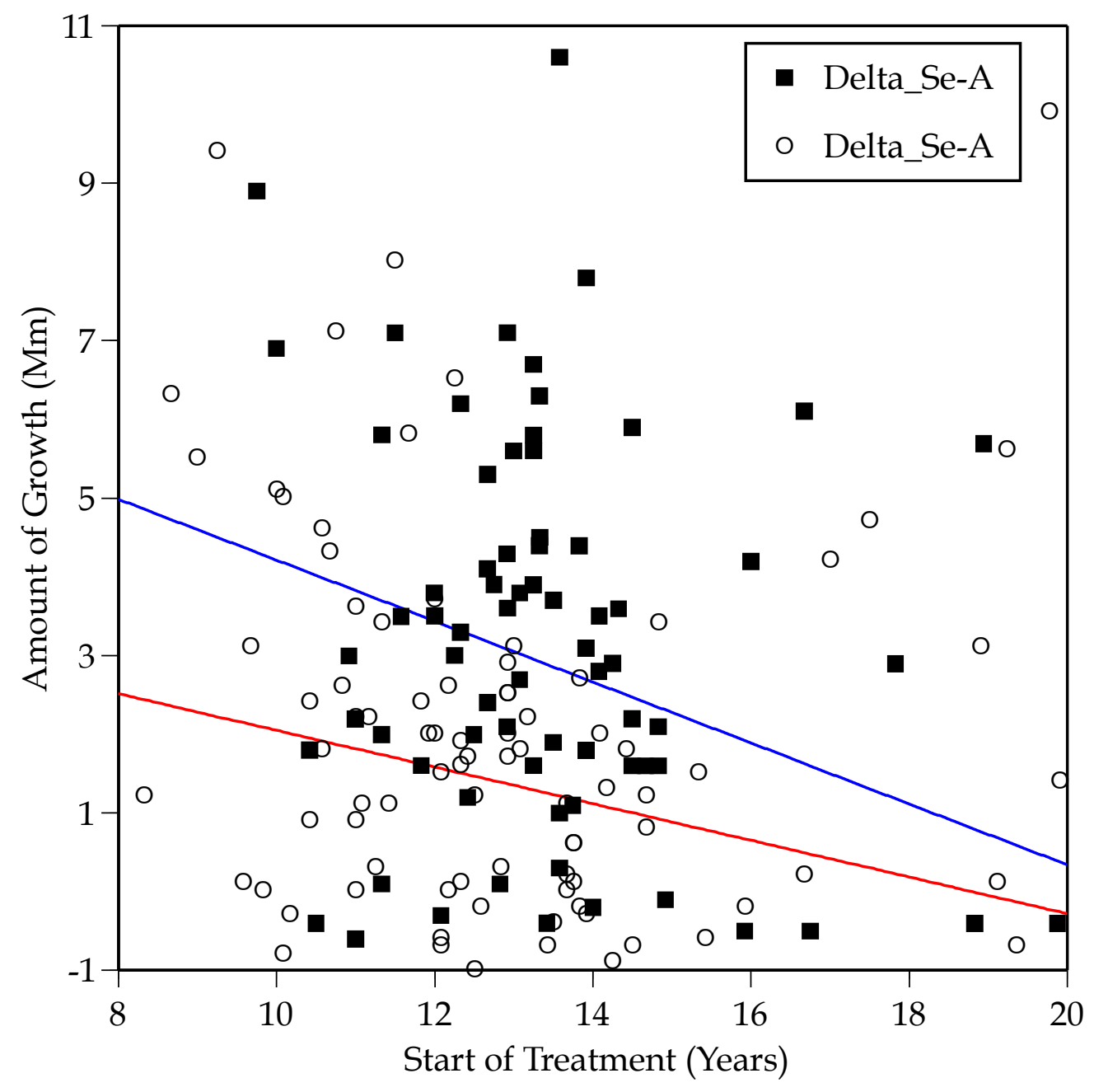

Fig. 26. Plot of age at the start of treatment against the amount of growth during treatment, by sex, for Sella-A Point. Square symbols denote males; round symbols denote females. Males exhibit more growth during treatment across the age span. 


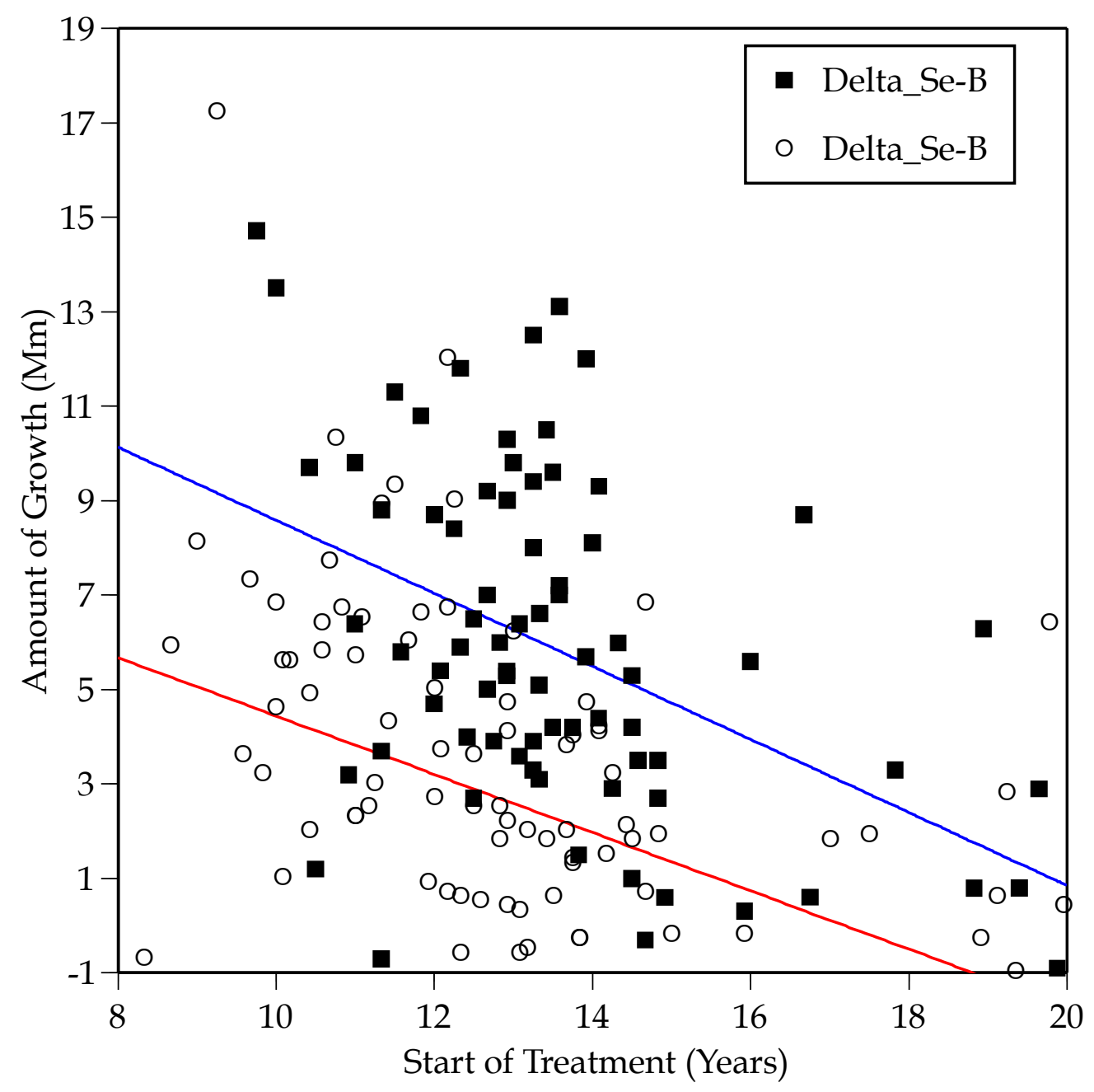

Fig. 27. Plot of age at the start of treatment against the amount of growth during treatment, by sex, for Sella-B Point. Square symbols denote males; round symbols denote females. Males exhibit more growth during treatment across the age span. 
Importantly, the test can be biased either by including young patients who are growing at a fast rate and/or by including older, adult patients who are growing almost not at all.

As an objective test, (1) only cases with grade 12 or 13 were used (arbitrarily, the right canine was used if there was asymmetry) and (2) cases over 17 years of age at the start of treatment were excluded. Necessarily, males and females were examined separately within the ANOVA model because of the greater and prolonged adolescent growth in boys (e.g., Bishara et al. 1994) and earlier tooth formation in girls (e.g., Thompson et al. 1975). The test statistic was a two-way analysis of variance (Winer et al. 1971), with grade and sex as the main effects.

Table 14 lists the descriptive statistics for chronological age at the start of treatment by sex and stage of mandibular canine (LC) formation. It is evident (1) that girls at each stage are younger than the boys and (2) that the mean age at stage 12 is roughly 2 years younger than for stage 13 in both sexes.

Results of ANOVA tests are listed in Table 15, and the corresponding descriptive statistics are in Table 16. The results are variable. On the one hand, it should be noted (A) that none of the interaction effects is significant, indicating that the changes are proportionate between the sexes and (B) that the average amounts of growth were invariably highly significantly larger in boys than girls. This latter feature is anticipated given the well-known fact that parapubertal 
Table 14. Descriptive statistics for chronological age at the start of treatment partitioned by sex and stage of mandibluar canine root formation.

\begin{tabular}{lcc}
\hline \multicolumn{1}{c}{ Statistic } & Males & Females \\
\hline & & \\
Mean & Canine Stage 12 & \\
Std Dev & 12.84 & 11.92 \\
Std Err Mean & 1.06 & 1.31 \\
Upper 95\% Mean & 0.20 & 0.32 \\
Lower 95\% Mean & 13.25 & 12.60 \\
$\mathrm{n}$ & 12.44 & 11.25 \\
& 29 & 17 \\
Mean & & \\
Std Dev & 13.89 & 13.25 \\
Std Err Mean & 1.58 & 1.67 \\
Upper 95\% Mean & 0.31 & 0.22 \\
Lower 95\% Mean & 14.53 & 13.69 \\
$\mathrm{n}$ & 13.25 & 12.80 \\
\hline
\end{tabular}


Table 15. Results of ANOVA tests of whether the amounts of growth differed between mandibular canine grades 12 and 13 assessed at the pretreatment examination.

\begin{tabular}{|c|c|c|c|c|}
\hline Source & $\mathrm{df}$ & Sum of Squares & F Ratio & Prob> F \\
\hline \multicolumn{5}{|c|}{ Change in Sella-Nasion } \\
\hline Canine Grade & 1 & 8.2629 & 2.77 & 0.0985 \\
\hline Sex & 1 & 58.0672 & 19.44 & $<0.0001$ \\
\hline Grade-x-Sex & 1 & 0.0010 & 0.00 & 0.9854 \\
\hline \multicolumn{5}{|c|}{ Change in Sella-Gnathion } \\
\hline Canine Grade & 1 & 289.7557 & 16.65 & $<0.0001$ \\
\hline Sex & 1 & 476.3194 & 27.38 & $<0.0001$ \\
\hline Grade-x-Sex & 1 & 1.0098 & 0.06 & 0.8100 \\
\hline \multicolumn{5}{|c|}{ Change in Sella-Gonion } \\
\hline Canine Grade & 1 & 126.2086 & 7.96 & 0.0055 \\
\hline Sex & 1 & 433.8139 & 27.36 & $<0.0001$ \\
\hline Grade-x-Sex & 1 & 0.0056 & 0.00 & 0.9851 \\
\hline \multicolumn{5}{|c|}{ Change in Sella-A Point } \\
\hline Canine Grade & 1 & 4.1465 & 0.65 & 0.4204 \\
\hline Sex & 1 & 94.8939 & 14.95 & 0.0002 \\
\hline Grade-x-Sex & 1 & 0.0993 & 0.02 & 0.9006 \\
\hline \multicolumn{5}{|c|}{ Change in Sella-B Point } \\
\hline Canine Grade & 1 & 115.1358 & 10.92 & 0.0012 \\
\hline Sex & 1 & 301.4803 & 28.59 & $<0.0001$ \\
\hline Grade-x-Sex & 1 & 6.3381 & 0.60 & 0.4395 \\
\hline
\end{tabular}


Table 16. Descriptive statistics of the amounts of facial growth partitioned by stage of the mandibular canine at the start of treatment and sex.

\begin{tabular}{|c|c|c|c|c|}
\hline Level & $\mathrm{n}$ & Mean & $\mathrm{sd}$ & sem \\
\hline \multicolumn{5}{|c|}{ Change in Sella-Nasion } \\
\hline Grade 12 and Male & 28 & 3.01 & 1.67 & 0.32 \\
\hline Grade 12 and Female & 18 & 1.67 & 1.47 & 0.35 \\
\hline Grade 13 and Male & 30 & 2.48 & 1.84 & 0.34 \\
\hline Grade 13 and Female & 67 & 1.12 & 1.77 & 0.22 \\
\hline \multicolumn{5}{|c|}{ Change in Sella-Gnathion } \\
\hline Grade 12 and Male & 28 & 10.96 & 3.97 & 0.75 \\
\hline Grade 12 and Female & 18 & 6.80 & 4.40 & 1.04 \\
\hline Grade 13 and Male & 29 & 7.59 & 5.43 & 1.01 \\
\hline Grade 13 and Female & 68 & 3.80 & 3.54 & 0.43 \\
\hline \multicolumn{5}{|c|}{ Change in Sella-Gonion } \\
\hline Grade 12 and Male & 28 & 8.66 & 4.52 & 0.86 \\
\hline Grade 12 and Female & 18 & 4.98 & 3.36 & 0.79 \\
\hline Grade 13 and Male & 30 & 6.58 & 4.92 & 0.90 \\
\hline Grade 13 and Female & 67 & 2.87 & 3.39 & 0.41 \\
\hline \multicolumn{5}{|c|}{ Change in Sella-A Point } \\
\hline Grade 12 and Male & 28 & 2.79 & 2.41 & 0.46 \\
\hline Grade 12 and Female & 18 & 0.98 & 1.76 & 0.41 \\
\hline Grade 13 and Male & 30 & 2.35 & 3.10 & 0.57 \\
\hline Grade 13 and Female & 66 & 0.66 & 2.44 & 0.30 \\
\hline \multicolumn{5}{|c|}{ Change in Sella-B Point } \\
\hline Grade 12 and Male & 28 & 6.16 & 3.49 & 0.66 \\
\hline Grade 12 and Female & 18 & 3.69 & 3.29 & 0.78 \\
\hline Grade 13 and Male & 29 & 4.62 & 3.68 & 0.68 \\
\hline Grade 13 and Female & 67 & 1.20 & 2.92 & 0.36 \\
\hline
\end{tabular}


growth is more intense and of longer duration in males (e.g., Forsberg and Odenrick 1979; Behrents 1986; Bishara et al. 1994). Examining the test of whether the amount of growth depended on the stage of LC root formation, the following was seen: Mean growth of Sella-Nasion was slightly less in boys and in girls for stage 13 than at stage 12 (Fig. 28), but the diminution was too small to achieve significance $(P=0.10)$. Just to be clear here, the analysis shows that subjects (of both sexes) with stage 12 did grow more than subjects with the later stage 13, but the difference was not great enough (and Sella-Nasion is not growing much in any event) for the difference to achieve statistical significance. Growth in SellaGnathion, in contrast, exhibited significantly less growth in stage 13 versus stage $12(\mathrm{P}<0.0001)$, which is illustrated in Figure 29. This can be viewed as the most informative of the five variables tested insofar as Sella-Gnathion crosses a large span of the bony face, encompassing both the midface and mandibular complexes. Table 16 shows that there still is appreciable growth in SellaGnathion during stage 13 ( $\sim 7 \mathrm{~mm}$ in boys; $\sim 4 \mathrm{~mm}$ in girls) but much less than during stage 12 ( $\sim 11 \mathrm{~mm}$ in boys; $\sim 7 \mathrm{~mm}$ in girls).

Growth in Sella-Gonion, a paramount measure of posterior face height, was tied significantly to grade of LC $(P=0.039)$, though strength of this association is less than in some other variables. Reduction in the average amounts of Sella-Gonion growth was obvious (Fig. 30) - on the order of 25\% from stage 12 to 13. In other words, the typical patient (boy or girl) exhibiting LC 


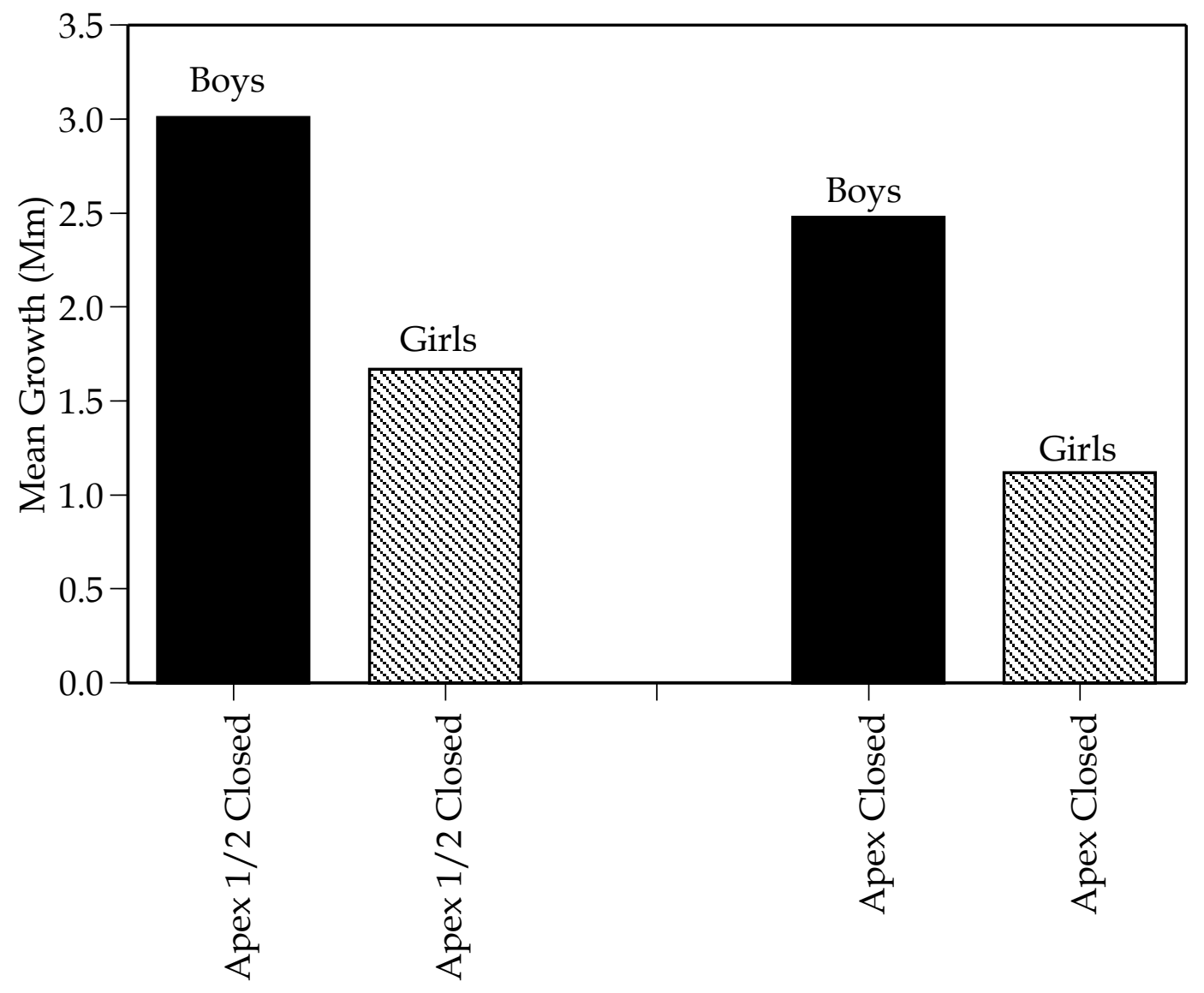

Fig. 28. Mean growth in Sella-Nasion, partitioned by stage of the mandibular canine and sex. 


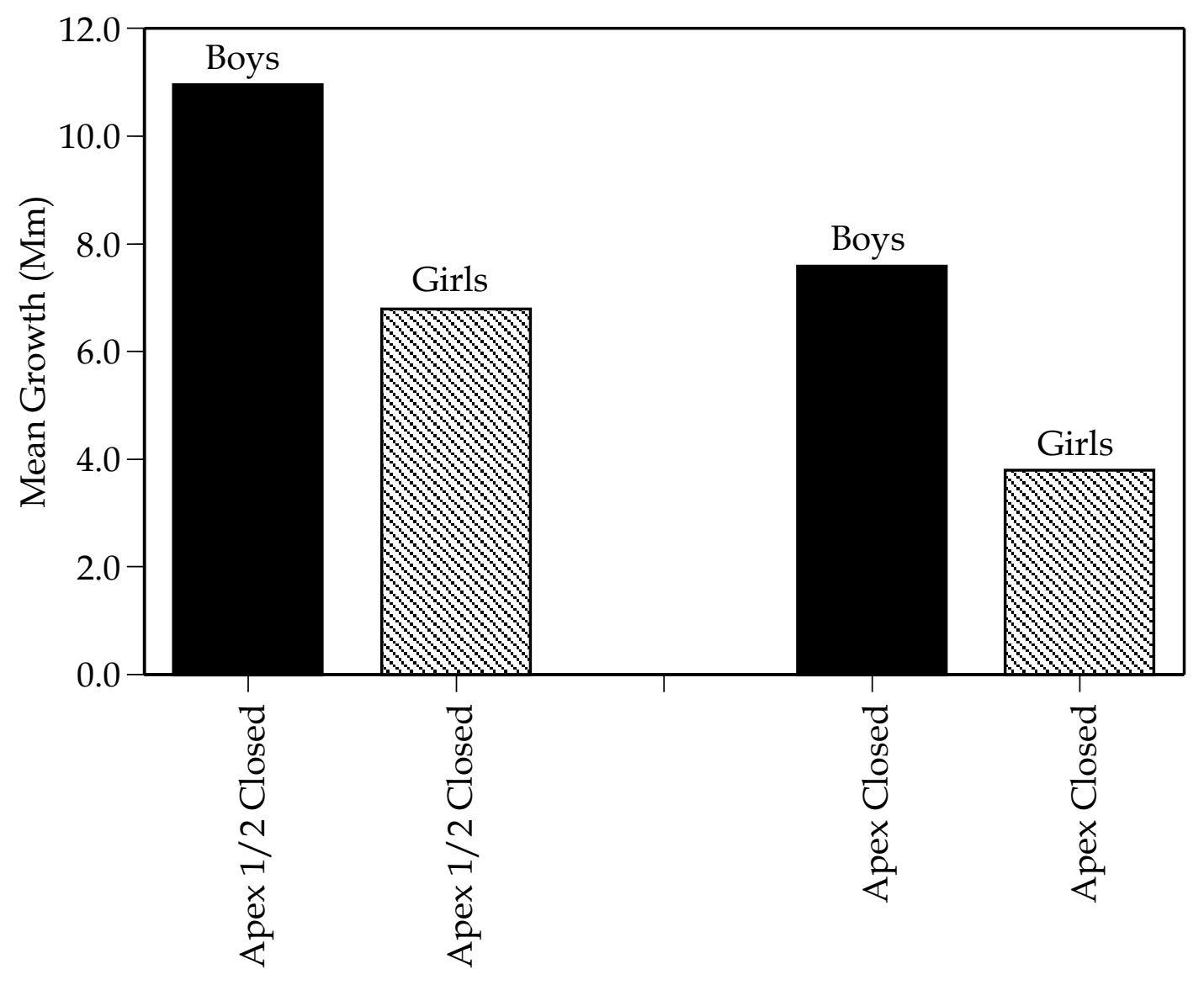

Fig. 29. Mean growth in Sella-Gnathion, partitioned by stage of the mandibular canine and sex. 


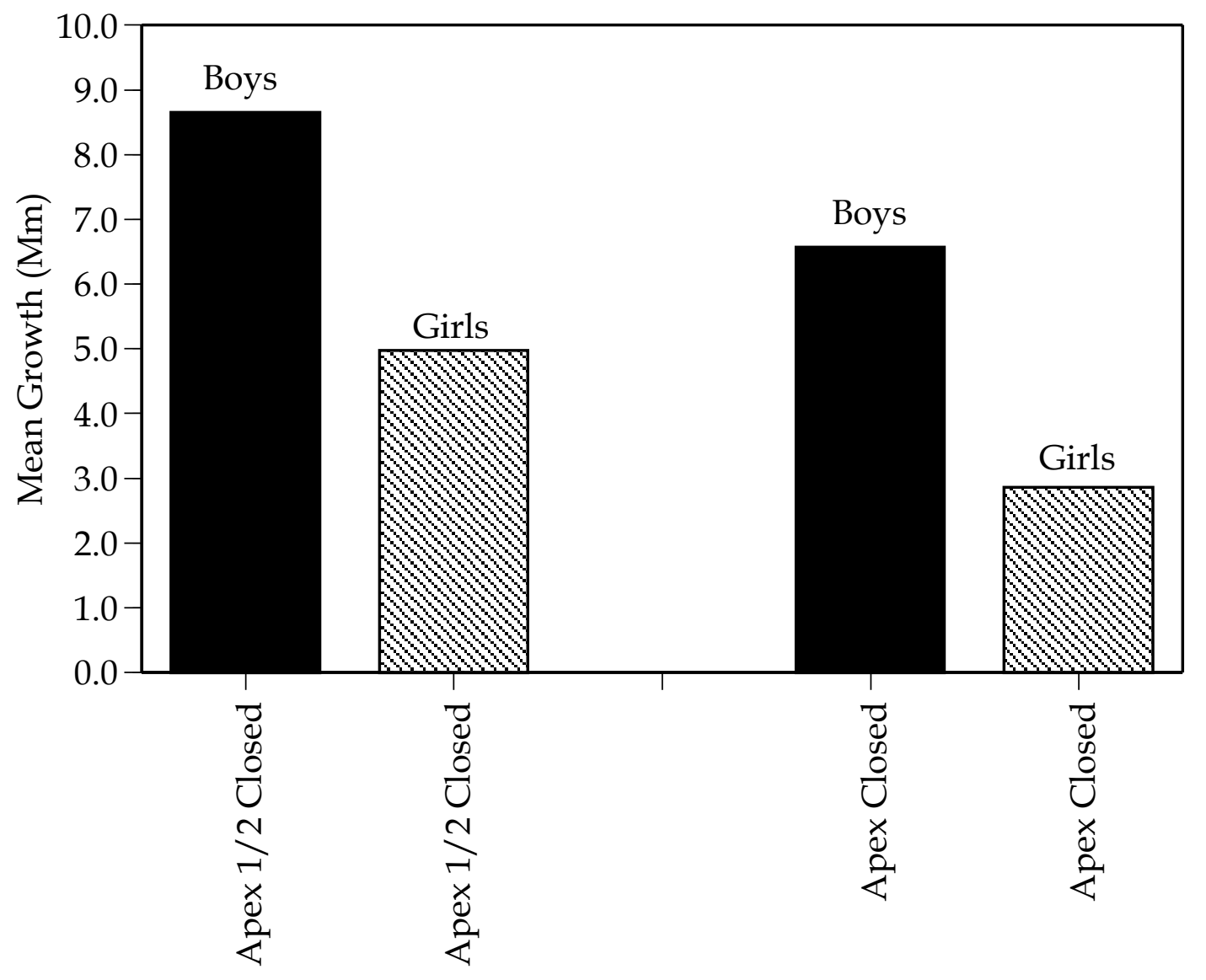

Fig. 30. Mean growth in Sella-Gonion, partitioned by stage of the mandibular canine and sex. 
stage 12 will experience significantly more growth in Sella-Gonion during treatment than the average patient of the same sex with stage 13 at the beginning of treatment.

Mean growth in Sella-A Point was the least of the five variables tested here (Table 16). The trends were in the predicted direction-less growth with stage 13 than with stage $12-$ but the ANOVA results were far from significant ( $P$ $=0.42$ ). With a Class II skeletal relationship, there seldom is the need to achieve substantial maxillary growth (Sella-A Point), but these data suggest that this dimension is indeed fairly quiescent. The average boy with LC stage 12 is 12.8 years old and Sella-A Point will increase $2.8 \mathrm{~mm}$ on the average. In contrast, Sella-B Point will increase $6.2 \mathrm{~mm}$ on the average, which should, of course, improve the parasagittal jaw relationships. Girls in this sample reached LC stage 12 at a mean age of 12.2 years, and Sella-A Point increased just $1.0 \mathrm{~mm}$ on average, which is significantly less than in boys (Fig. 31), and also is less than the average increase in Sella-B Point of $3.7 \mathrm{~mm}$.

Growth in the distance Sella-B Point was the final variable tested, and this measure of mandibular growth exhibited a significant dependency on LC stage of root formation $(P=0.0012)$. Mean growth was $3.7 \mathrm{~mm}$ at stage 12 in females, and this dropped to $1.2 \mathrm{~mm}$ at stage 13. Similarly, growth averaged $6.2 \mathrm{~mm}$ at stage 12 in males, and this dropped to $4.6 \mathrm{~mm}$ at stage 13 (Fig. 32). This lesser decrement in males probably reflects the longer duration of adolescent growth in 


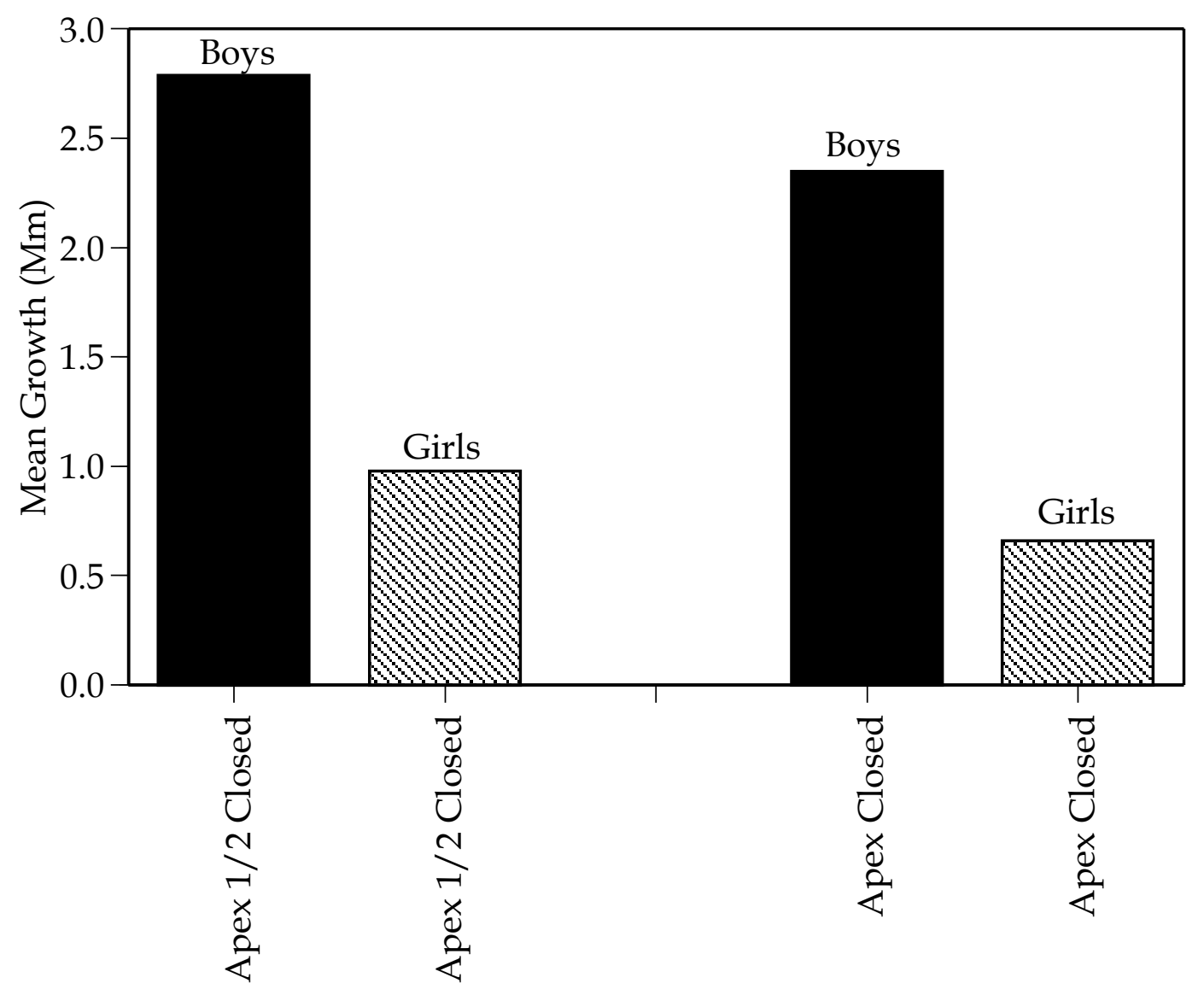

Fig. 31. Mean growth in Sella-A Point, partitioned by stage of the mandibular canine and sex. 


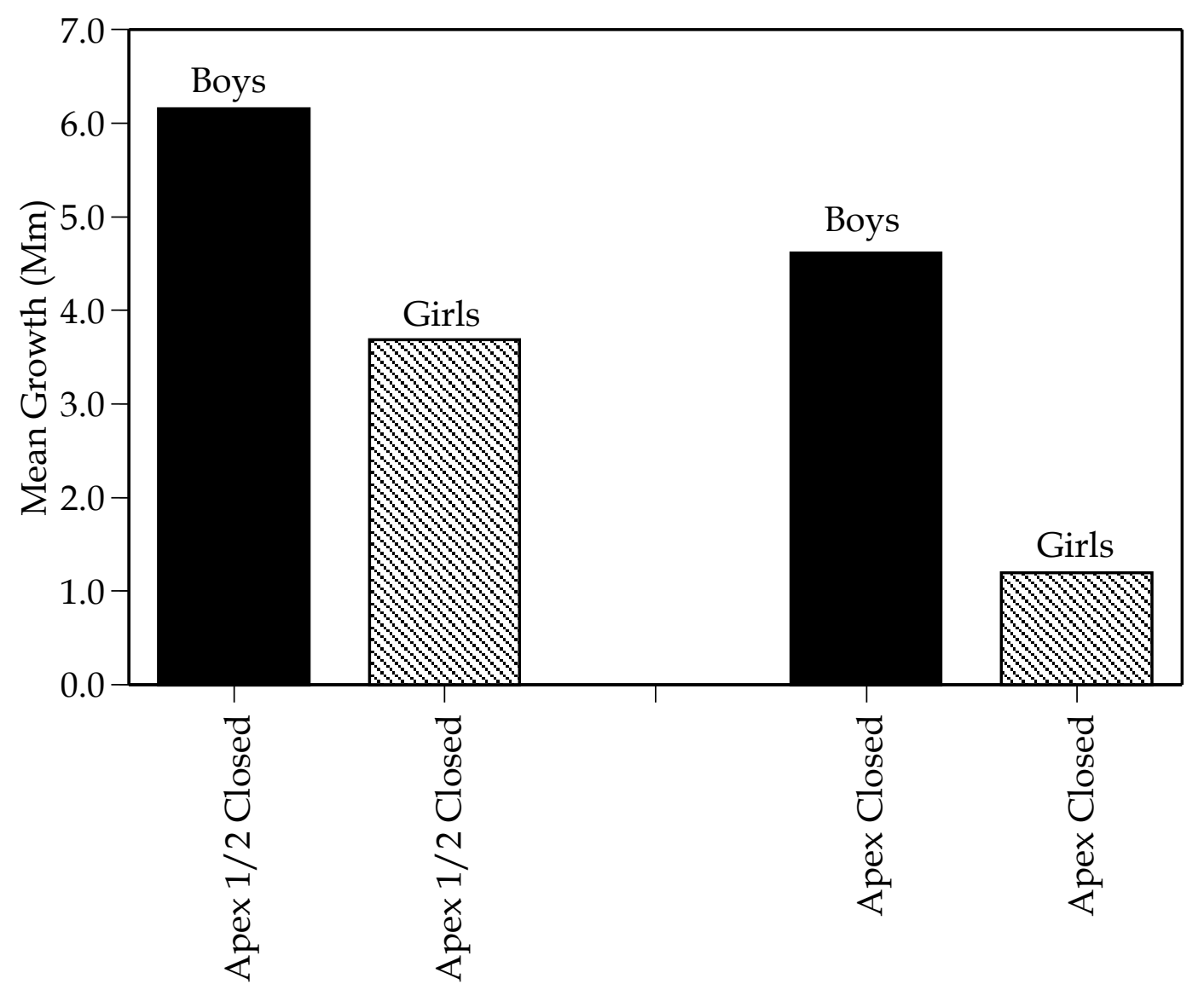

Fig. 32. Mean growth in Sella-B Point, partitioned by stage of the mandibular canine and sex. 
boys than girls. The sex difference $(\mathrm{P}<0.0001)$ also reconfirms the much greater growth and, thus, the greater potential for modification of jaw relationships in boys.

In summary, three of the five variables tested exhibited significant decreases dependent on the stage of LC root development, and on inspection the two variables that did not achieve significance (Se-Na and Se-A) exhibited the least growth of those dimensions tested. Perhaps these comparatively small intreatment changes were the cause of the statistical insignificance since the trends (Table 16) were in the anticipated direction.

\section{$\underline{\text { Second Cervical Vertebra }}$}

Prior studies, notably the work of O'Reilly and Yanniello (1988), have shown that the annual increments of facial growth in untreated subjects differ according to the morphological stage of the cervical vertebrae. In the present study, the question was whether the morphological stage of the vertebra - as a measure of the person's biological age - is robust enough to predict the amounts of facial growth over the course of treatment, not just annually.

The six-stage scheme of Lamparski (1972) was used to score the vertebrae. Three cervical vertebrae (C2, C3, and C4) were scored on each subject from their pretreatment cephalogram. The morphological stages are strongly intercorrelated among the vertebrae, though there is a discernible cranial-to- 
caudal gradient, with the cranial elements tending to achieve each stage at an earlier chronological age. In this data set, nonparametric correlations (Spearman's rho) between the morphological stages of C2, C3, and C4 all were highly significant $(\mathrm{P}<0.0001)$. Correlation between $\mathrm{C} 2$ and $\mathrm{C} 3$ was $0.976(\mathrm{n}=$ 160 pairs), and between $\mathrm{C} 3$ and $\mathrm{C} 4$ the correlation was $0.982(\mathrm{n}=156$ pairs). There is, then, considerable redundancy of information among the series of vertebrae. Because of the strong intercorrelations, attention was focused here on $\mathrm{C} 2$ as the maturity indicator.

Patients starting treatment after 17 years of age were excluded here, and the chronological ages per $\mathrm{C} 2$ stage are listed in Table 17. Inspection of the means shows that, predictably (e.g., Greulich and Pyle 1959; Tanner 1962), females achieve each CV2 stage well ahead of the slower maturing males (see Fig. 33). Sex differences are on the order of 1 year. There also is a clear-cut age progression across the stages, though some sample sizes for males are critically small.

Table 18 lists results of the five two-way ANOVA tests of whether the stage of CV2 development is predictive of the amount of facial growth over the course of treatment. Of note, none of the stage-by-sex interaction effects is significant, so the amounts of growth are proportional in the two sexes across the CV2 stages. Also, "Sex" has a highly significant effect in each ANOVA model because boys are growing more (faster) throughout adolescence. The critical 
Table 17. Descriptive statistics for age at the start of treatment partitioned by sex and CV2 stage of development.

\begin{tabular}{|c|c|c|}
\hline Level & Males & Females \\
\hline \multicolumn{3}{|c|}{ CV2 Stage 1} \\
\hline Mean & 12.46 & 10.58 \\
\hline SD & 1.33 & 1.11 \\
\hline SEM & 0.40 & 0.32 \\
\hline $\mathrm{n}$ & 11 & 12 \\
\hline \multicolumn{3}{|c|}{ CV2 Stage 2} \\
\hline Mean & 12.80 & 11.62 \\
\hline SD & 1.74 & 1.24 \\
\hline SEM & 0.35 & 0.31 \\
\hline $\mathrm{n}$ & 25 & 16 \\
\hline \multicolumn{3}{|c|}{ CV2 Stage 3} \\
\hline Mean & 13.19 & 12.05 \\
\hline SD & 0.94 & 0.91 \\
\hline SEM & 0.24 & 0.24 \\
\hline $\mathrm{n}$ & 15 & 14 \\
\hline \multicolumn{3}{|c|}{ CV2 Stage 4} \\
\hline Mean & 14.32 & 12.32 \\
\hline SD & 0.86 & 1.55 \\
\hline SEM & 0.27 & 0.41 \\
\hline $\mathrm{n}$ & 10 & 14 \\
\hline \multicolumn{3}{|c|}{ CV2 Stage 5} \\
\hline Mean & 15.37 & 13.32 \\
\hline SD & 2.57 & 1.42 \\
\hline SEM & 0.97 & 0.32 \\
\hline $\mathrm{n}$ & 7 & 20 \\
\hline \multicolumn{3}{|c|}{ CV2 Stage 6} \\
\hline Mean & 17.08 & 16.23 \\
\hline SD & 2.49 & 3.24 \\
\hline SEM & 0.83 & 0.59 \\
\hline $\mathrm{n}$ & 9 & 30 \\
\hline
\end{tabular}




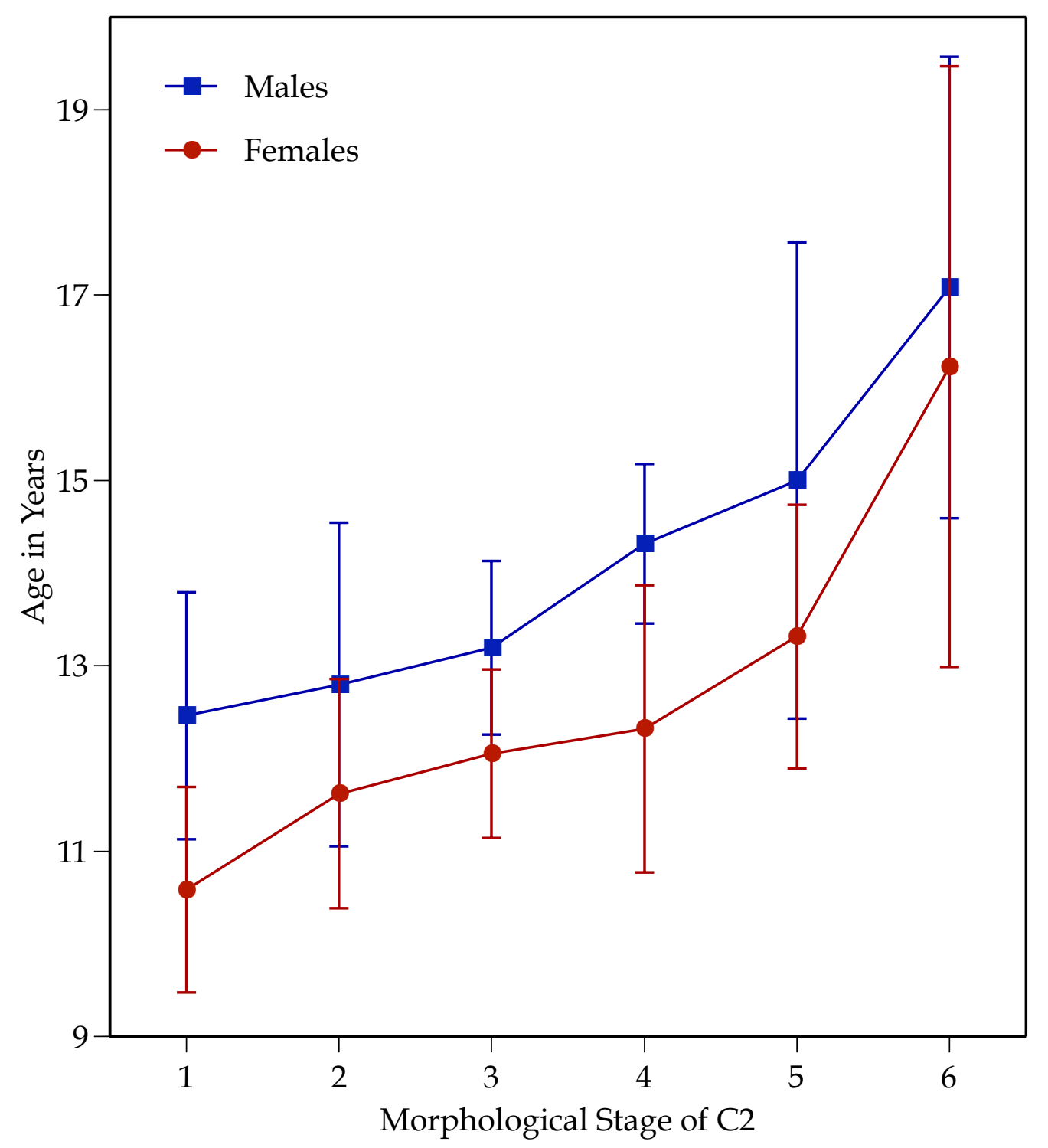

Fig. 33. Mean ages at each morphological stage of cervical vertebra 2. Error bars are standard deviations. 
Table 18. Results of two-way ANOVA tests of whether the amounts of growth differed by CV2 stage of development.

\begin{tabular}{|c|c|c|c|c|}
\hline Source & $\mathrm{df}$ & Sum of Squares & F Ratio & Prob $>F$ \\
\hline \multicolumn{5}{|c|}{ Change in Sella-Nasion } \\
\hline CV2 Morphology & 1 & 89.86 & 31.46 & $<0.0001$ \\
\hline Subject's Sex & 1 & 54.66 & 19.13 & $<0.0001$ \\
\hline CV2-x-Sex & 1 & 5.37 & 1.88 & 0.1721 \\
\hline \multicolumn{5}{|c|}{ Change in Sella-Gnathion } \\
\hline CV2 Morphology & 1 & 1420.65 & 103.01 & $<0.0001$ \\
\hline Subject's Sex & 1 & 363.85 & 26.38 & $<0.0001$ \\
\hline CV2-x-Sex & 1 & 35.27 & 2.56 & 0.1116 \\
\hline \multicolumn{5}{|c|}{ Change in Sella-Gonion } \\
\hline CV2 Morphology & 1 & 607.99 & 45.42 & $<0.0001$ \\
\hline Subject's Sex & 1 & 353.10 & 26.38 & $<0.0001$ \\
\hline CV2-x-Sex & 1 & 6.86 & 0.51 & 0.4751 \\
\hline \multicolumn{5}{|c|}{ Change in Sella-A Point } \\
\hline CV2 Morphology & 1 & 153.95 & 23.98 & $<0.0001$ \\
\hline Subject's Sex & 1 & 39.02 & 6.08 & 0.0147 \\
\hline CV2-x-Sex & 1 & 9.35 & 1.46 & 0.2291 \\
\hline \multicolumn{5}{|c|}{ Change in Sella-B Point } \\
\hline CV2 Morphology & 1 & 661.61 & 67.91 & $<0.0001$ \\
\hline Subject's Sex & 1 & 213.45 & 21.91 & $<0.0001$ \\
\hline CV2-x-Sex & 1 & 0.56 & 0.06 & 0.8103 \\
\hline
\end{tabular}


aspect of these tests is, of course, the highly significant dependence found between CV2 stage and the amount of facial growth experienced during treatment. Table 19 lists the descriptive statistics for the amounts of growth observed in each of the facial dimensions partitioned by the six CV stages. The average amounts of change (growth) that occurred over the course of treatment are listed here. Notice that while the overall sample size $(n=183$ people $)$ is reasonable, the individual cell sizes after partitioning the sample by sex and CV grade can be small, especially for older adolescent males who are sparse in any orthodontic practice. Small sample sizes increase the opportunity for sampling fluctuations, which accounts for the unevenness of the averages across some of the data.

Interpreting the five ANOVA tests in Table 18 becomes repetitive because the same pattern occurs for each of the five dimensions tested, though, of course, the absolute amounts vary considerably among the facial structures. It is helpful to review the graphs based on these data (Figs. 34-38), where the average amounts of growth observed during treatment are plotted against the CV2 morphological stage at the start of treatment.

Sella-Nasion distance (Fig. 34) is lengthening at nearly $4 \mathrm{~mm} /$ treatment in boys at the early CV stages, but this slows to less than $1 \mathrm{~mm} /$ treatment in the older adolescents. (Recall that the sample was truncated at 20 years of age; if older adults had been included, the mean could be even closer to zero.) 
Table 19. Descriptive statistics for dimensions of facial growth, by sex and stage of cervical vertebral morphology.

\begin{tabular}{|c|c|c|c|c|c|c|c|c|c|c|c|c|}
\hline \multirow[b]{2}{*}{$\underline{\text { Statistic }}$} & \multicolumn{2}{|c|}{ Stage 1} & \multicolumn{2}{|c|}{ Stage 2} & \multicolumn{2}{|c|}{ Stage 3} & \multicolumn{2}{|c|}{ Stage 4} & \multicolumn{2}{|c|}{ Stage 5} & \multicolumn{2}{|c|}{ Stage 6} \\
\hline & M & $\mathrm{F}$ & M & $\mathrm{F}$ & M & $\mathrm{F}$ & M & $\mathrm{F}$ & M & $\mathrm{F}$ & $\mathrm{M}$ & $\mathrm{F}$ \\
\hline \multicolumn{13}{|c|}{ Sella-Nasion } \\
\hline Mean & 3.81 & 2.33 & 3.67 & 2.49 & 3.70 & 1.76 & 2.49 & 0.84 & 1.91 & 1.52 & 0.96 & 0.66 \\
\hline SD & 1.45 & 1.57 & 1.89 & 1.93 & 2.19 & 1.56 & 1.18 & 1.46 & 1.47 & 1.44 & 1.22 & 1.85 \\
\hline $\mathrm{n}$ & 11 & 12 & 25 & 16 & 15 & 14 & 10 & 14 & 7 & 19 & 9 & 29 \\
\hline \multicolumn{13}{|c|}{ Sella-Gnathion } \\
\hline Mean & 13.37 & 8.88 & 11.57 & 8.89 & 12.77 & 7.38 & 7.81 & 4.59 & 5.59 & 4.41 & 2.91 & 1.99 \\
\hline SD & 3.80 & 2.67 & 4.36 & 4.98 & 3.91 & 3.57 & 3.10 & 3.37 & 2.43 & 2.87 & 3.56 & 3.25 \\
\hline $\mathrm{n}$ & 11 & 12 & 25 & 16 & 15 & 14 & 10 & 14 & 7 & 20 & 8 & 29 \\
\hline \multicolumn{13}{|c|}{ Sella-Gonion } \\
\hline Mean & 9.29 & 5.59 & 9.52 & 7.45 & 10.02 & 5.39 & 7.69 & 3.18 & 4.33 & 4.22 & 2.81 & 1.21 \\
\hline SD & 2.59 & 2.89 & 4.85 & 3.95 & 3.72 & 3.77 & 3.11 & 3.44 & 3.66 & 3.22 & 3.65 & 2.80 \\
\hline $\mathrm{n}$ & 11 & 12 & 25 & 16 & 15 & 14 & 10 & 14 & 7 & 20 & 9 & 28 \\
\hline \multicolumn{13}{|c|}{ Sella-A Point } \\
\hline Mean & 4.05 & 2.38 & 3.22 & 2.01 & 4.53 & 2.80 & 1.66 & 0.95 & 1.11 & 0.77 & 0.03 & 0.21 \\
\hline SD & 2.40 & 2.82 & 2.46 & 3.25 & 2.32 & 1.73 & 2.03 & 1.27 & 2.19 & 2.10 & 2.84 & 3.09 \\
\hline $\mathrm{n}$ & 11 & 12 & 25 & 16 & 15 & 14 & 10 & 13 & 7 & 19 & 9 & 29 \\
\hline \multicolumn{13}{|c|}{ Sella-B Point } \\
\hline Mean & 7.93 & 5.08 & 6.95 & 5.84 & 6.55 & 2.81 & 4.49 & 2.72 & 2.33 & 1.77 & 2.76 & 0.11 \\
\hline SD & 3.01 & 1.70 & 3.77 & 4.36 & 3.53 & 3.93 & 3.14 & 2.50 & 1.33 & 2.77 & 3.14 & 2.40 \\
\hline $\mathrm{n}$ & 11 & 12 & 25 & 16 & 15 & 14 & 10 & 14 & 7 & 20 & 8 & 28 \\
\hline
\end{tabular}

${ }^{1}$ Abbreviations for sex are males (M) and females (F). 


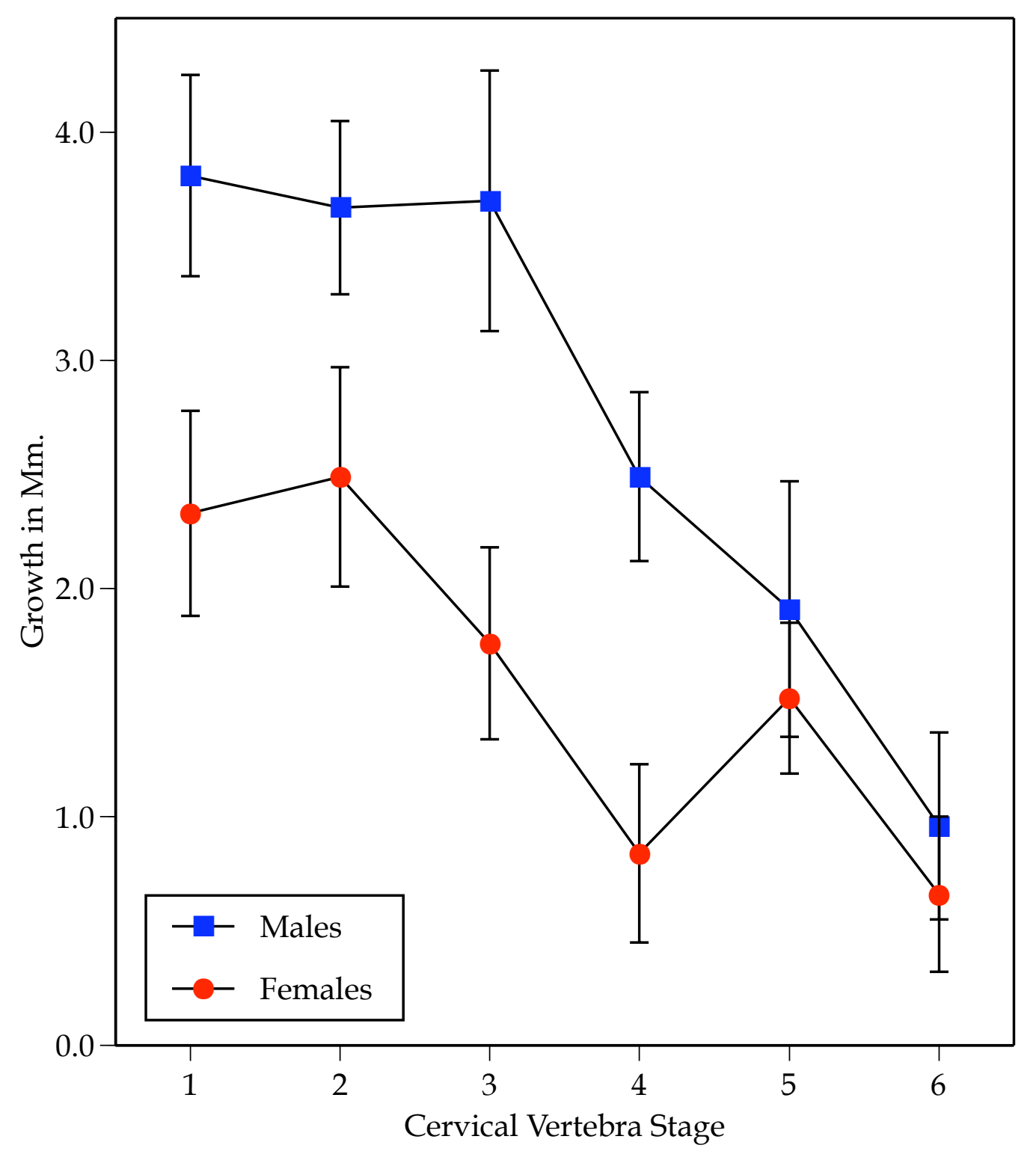

Fig. 34. Plot of mean amounts of growth in Sella-Nasion achieved during treatment, based on the subject's sex and cervical vertebral morphology. Error bars are the SEM of the means. 


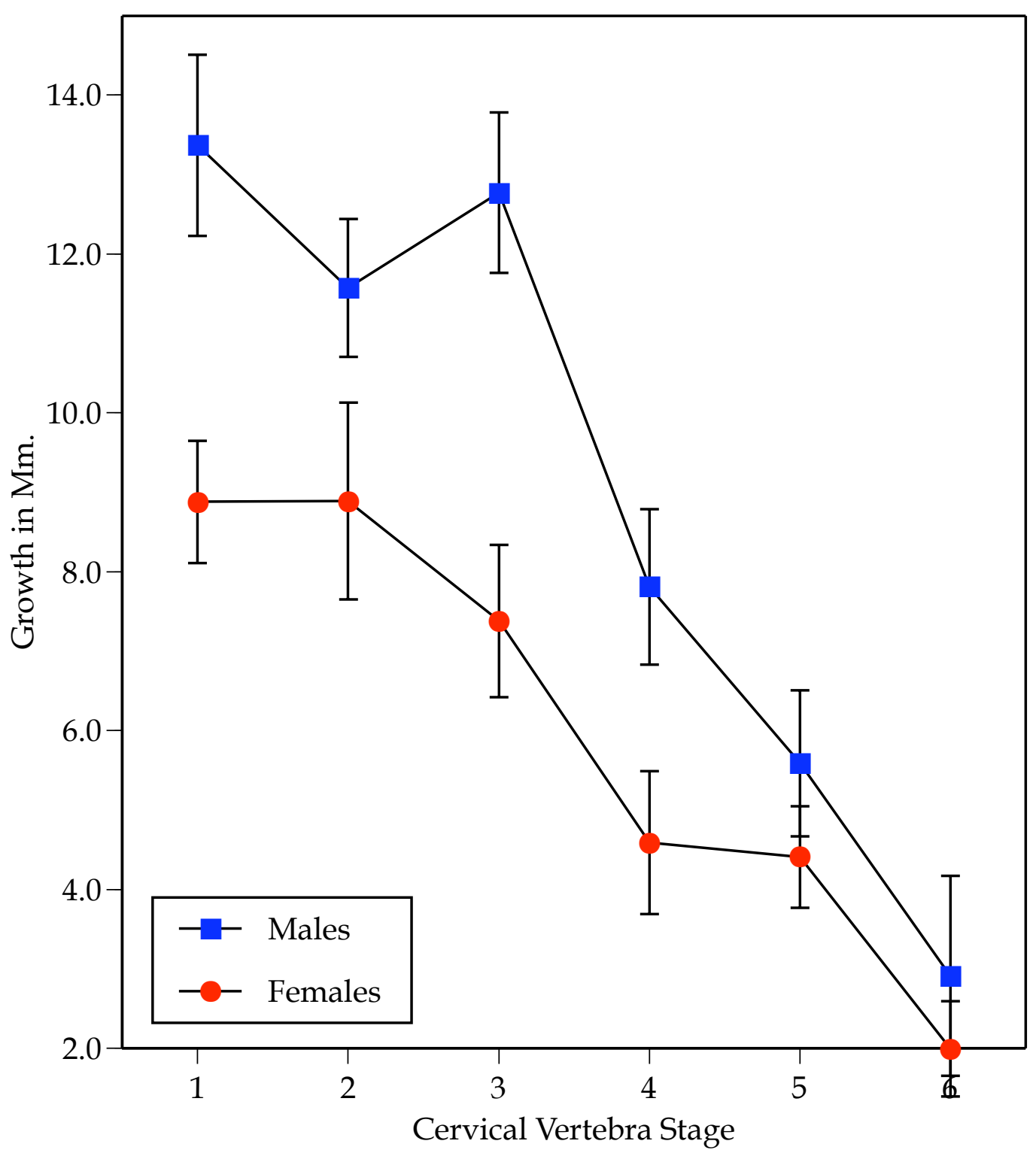

Fig. 35. Plot of mean amounts of growth in Sella-Gnathion achieved during treatment, based on the subject's sex and cervical vertebral morphology. Error bars are the SEM of the means. 


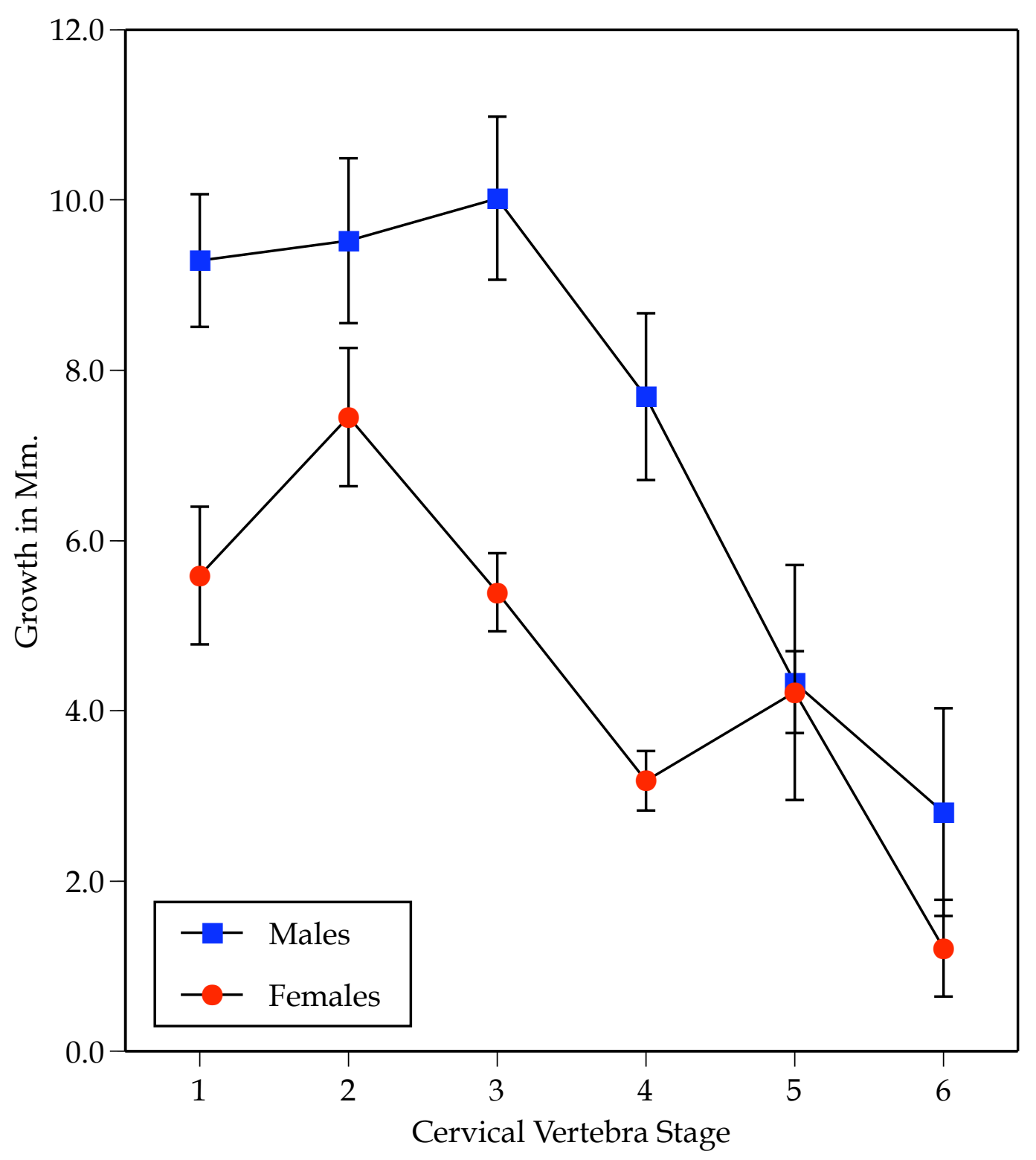

Fig. 36. Plot of mean amounts of growth in Sella-Gonion achieved during treatment, based on the subject's sex and cervical vertebral morphology. Error bars are the SEM of the means. 


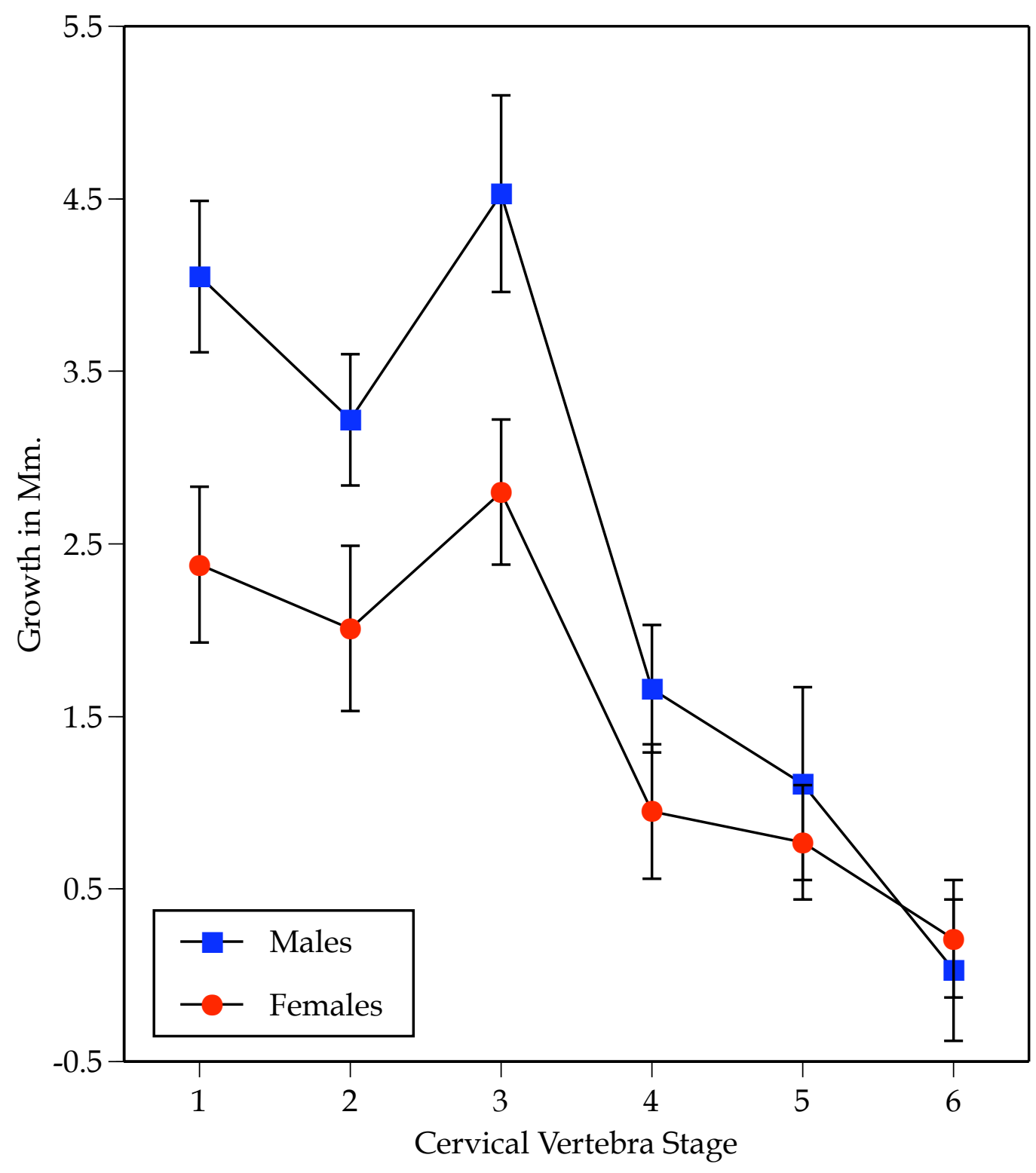

Fig. 37. Plot of mean amounts of growth in Sella-A Point achieved during treatment, based on the subject's sex and cervical vertebral morphology. Error bars are the SEM of the means. 


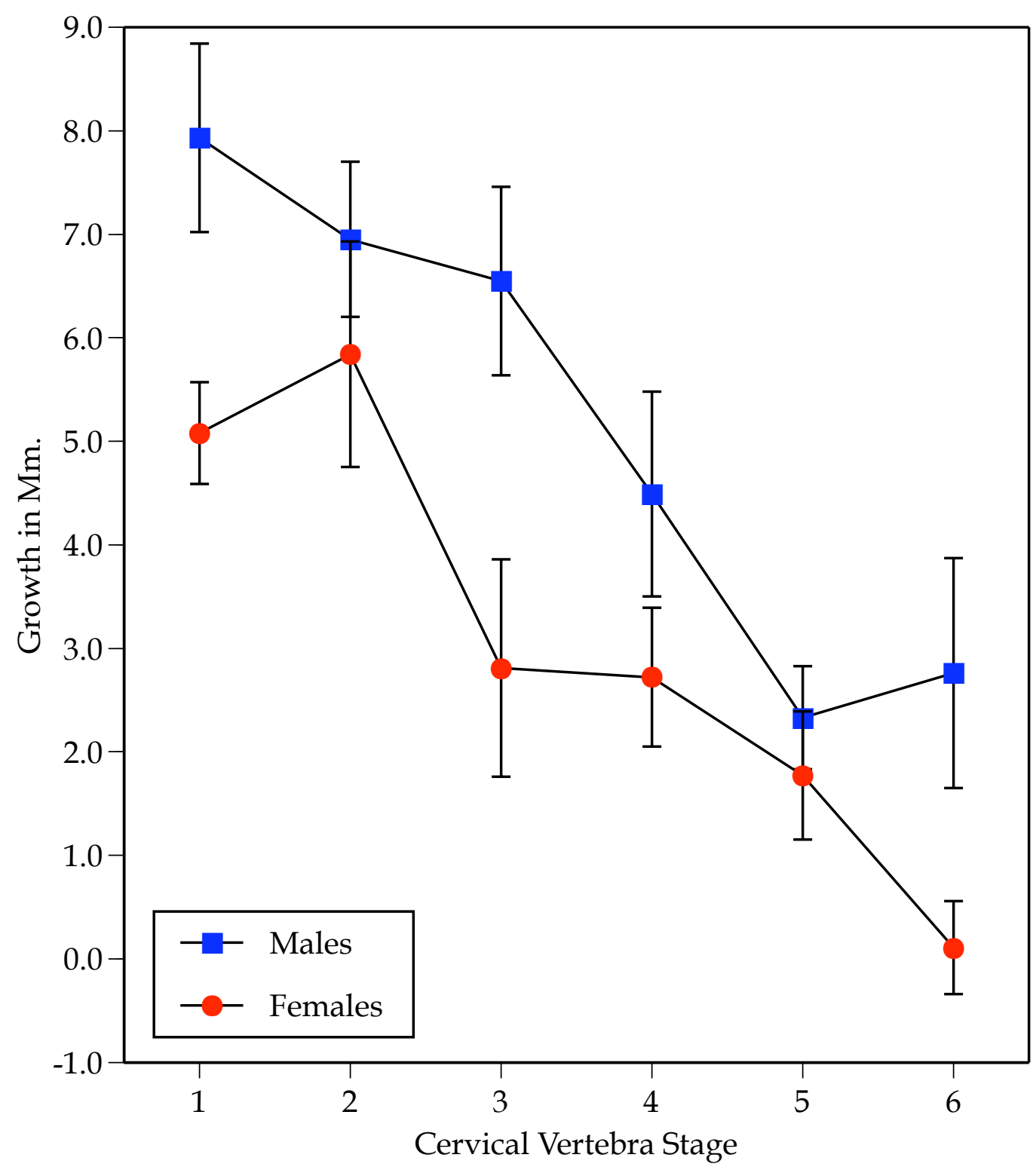

Fig. 38. Plot of mean amounts of growth in Sella-B Point achieved during treatment, based on the subject's sex and cervical vertebral morphology. Error bars are the SEM of the means. 
Sella-Nasion increases in girls at roughly half the rate seen in boys. Maximum growth averaged barely $2.5 \mathrm{~mm} /$ treatment in late childhood. At the terminal stage, Sella-Nasion growth $(\bar{x}=0.1 \mathrm{~mm})$ is barely discernible over the course of treatment.

Sella-Gnathion - the most encompassing dimension assess here-was growing at 12-13 mm during treatment in boys at the early CV stages, and 8-9 $\mathrm{mm}$ in girls. These rates dropped quite noticeably across the CV stages, such that growth was just 2 to $3 \mathrm{~mm}$ for those starting treatment with CV2 stage 6 (Fig. 35).

One of the obvious changes in facial proportions from childhood to adolescence is the disproportionate increase in the vertical dimension (e.g., Enlow 1990), and this evident in the substantive growth rates in Sella-Gonion (Fig. 36). The increase during treatment still is evident in boys at stage $6(\bar{x}=2.8$ $\mathrm{mm}$ / treatment), probably because of bony apposition at the gonial process in response to growth of the pterygomasseterric sling, which does not increase nearly as prominently in girls.

Midface depth (Se-A Pt) grows modestly at all CV stages, and shows comparable declines in rates across the maturity stages (Fig. 37). By stage 6, mean change during treatment is miniscule, averaging $0.03 \mathrm{~mm}$ in boys and 0.21 $\mathrm{mm}$ in girls. 
Sella-B Point increased appreciably more than the midface at all CV stages (Fig. 38). Maximum growth occurs during stages 1 and 2 in this sample, averaging 7 to $8 \mathrm{~mm}$ during treatment in boys and 5 to $6 \mathrm{~mm}$ in girls. This rate drops effectively to zero at stage 6 in girls (Table 19), but remains on the order of $2 \mathrm{~mm}$ in boys, which reflects the higher and longer rate of growth in males versus females (Tanner 1978; Guo et al. 1992).

In sum, there are substantial statistical differences among the rates of growth partitioned by CV stage (Table 18), and these are large enough in terms of millimetric changes to be important clinically as well (Table 19). There are three points to emphasize in closing this section. One, the ordinal CV grades (e.g., Figs. 34-38) are not equidistant as suggested by the graphs. These divisions are based on morphological criteria. The average time between grades 2 and 3 is, for example, shorter than between grades 5 and 6 . Also, while we have emphasized the point before, the changes (millimetric changes, as in Table 19) are measured over the course of treatment; they are not annualized rates. This is both more feasible (data can be gathered retrospectively) and more practical clinically in that the changes are tied to the actual treatment of Class II children who warranted comprehensive treatment.

Probably the key point shown in Figures 34-38 is that maximum growth rates occur at stages 1-3, then drop appreciably across stages 4 through 6 . These graphs plot the mean change, with the SEM (standard error of the mean) as the 
vertical error bars. These SEM serve as a visual guide of where the true mean would be if this study were repeated many times (and 95\% confidence limits would be even broader). As a simple practical gauge, if the means and error bars overlap (as they do, for example, for stages 1 and 2 in Fig. 34), then the two rates at statistically the same. What we see, of course, is that the rates of facial growth for stages 1 and 2 (and sometimes stage 3) are the highest. It is, then, during stages 1 and 2 that parasagittal jaw relationships are most modifiable by constraining growth of one jaw and/or promoting that of the other. When growth rates slow, notably at stage 5 and 6 , there is by definition, little growth that can be manipulated to improve jaw relationships. 


\section{CHAPTER V}

\section{DISCUSSION}

One of the first steps in orthodontic treatment is determining the best, or most appropriate treatment plan for the individual being treated. The orthodontist determines the most appropriate treatment plan from analyzing the diagnostic records taken on the patient. Although many factors are utilized in determining a treatment plan, the maturity of the patient is one factor that rarely is 'modifiable' for the orthodontist.

Normally, orthodontic treatment is primarily dictated by when the parent decides to bring their child in for treatment and not when its the most physiological advantageous for treatment. The orthodontist, then, can assess the maturity of the patient and adjust the treatment plan to accommodate the best outcome for the patient for the specific maturity level. Not only does the treatment plan account for dental malocclusions that must be resolved, but also any anticipated skeletal growth that will occur during treatment to help correct any skeletal disharmonies.

At first glance, it is obvious that a child has a greater growth potential than an adult. This is the reason treatment plans for adults differ from children - meaning, an orthodontist does not expect any growth from an adult, 
while some varying degree of growth is expected from a child. So the next logical question is how does an orthodontist determine whether an adolescent patient is going to grow?

Most orthodontists determine growth potential of patients by their chronological age $(\mathrm{CA})$ - older patients will grow less than younger patients. Although grossly true, it does not take into account the most important person in treatment, the patient currently being treated. Although CA is used to estimate growth potential, or the growth spurt, CA has not been shown to be tied well with a person's tempo of growth. Chronological age also does not assess the individual's maturation and thus, CA has a wide variation in growth potential. Unlike CA, physiological age does address the maturation of the individualmeaning, less variability in growth potential exists when physiological age is used instead of chronological age.

There are a number of markers for physiological assessment of an individual. Some maturational indicators include (1) voice change in boys, (2) menarche and breast development in girls, and (3) pubic hair development (Marshall and Tanner 1969, 1970). Although an orthodontist can use this information, it is usually not available for physiological assessment.

Traditionally orthodontists have used the cumbersome hand-wrist atlas by Greulich and Pyle (1959) for skeletal age assessment. Tanner et al. (1975) revised the hand-wrist method to make it more useful and accurate. Fishman 
(1982) devised the eleven-grade hand-wrist Skeletal Maturation Index (SMI) for easier skeletal assessment as opposed to the cumbersome atlas approach. Recently, the evaluation of cervical vertebrae (CV) have come en vogue for skeletal assessment. CV have been shown by a number of researchers (e.g., Lamparski 1972; Hassel and Farman 1995; Kucukkeles et al. 1999; Chang et al. 2001; Grave and Townsend 2003) to be just as reliable as hand-wrist evaluations for skeletal assessment and growth spurt prediction. The use of $\mathrm{CV}$ gives two advantages over the use of the hand-wrist method for skeletal assessment. First, the additional radiograph needed for hand-wrist assessment is avoided since the $\mathrm{CV}$ are readily visible on the diagnostic cephalometric radiograph needed for orthodontic treatment planning. Secondly, an increased potential for accuracy when assessing skeletal maturity, when related to the face, is due to the close proximity CV has to the face, as opposed to the assessment of a distal appendage in hand-wrist evaluations.

Another tool of estimating the growth velocity in an individual is by tooth mineralization assessment. Although most teeth have shown no association with the growth spurt, the mineralization and apexification of the mandibular canine has shown a close association with the initiation of the growth spurt (Chertkow 1980). This means of assessment has been shown to be not as reliable as traditional skeletal age assessment tools, but is still more accurate than chronological age alone. 
The pretreatment cervical vertebrae and tooth stages were used in this study to provide information about the predictability of craniofacial growth. The key issue is whether growth during treatment is statistically tied to the pretreatment stage of cervical vertebrae or tooth mineralization. If so, then it is useful to the orthodontist to have information on the growth potential of the individual being treated. Although other studies have demonstrated amounts of growth from pretreatment cervical vertebral and tooth stages until completion of growth, this provides little use to the orthodontist. This study provides information from cervical vertebral and tooth stages about the amounts of growth anticipated during the course of treatment and not until complete maturity.

Usual treatment of Class II division 1 cases requires the extraction of premolars for overjet and molar corrections. Although this usually corrects the dental malocclusion, skeletal corrections are not necessarily corrected. Skeletal correction requires growth and/or surgery to correct skeletal relationships. We selected Class II division 1 cases with four premolar extraction without surgical correction for this study. The study consisted of 183 American whites, 106 girls and 77 boys. Although the number of males is somewhat smaller in some stages, this ratio of males to females is far better than the ratio of 2:1 reported by Keim $e t$ al. (2002). 


\section{$\underline{\text { Sexual Dimorphism }}$}

It has been well-documented that sex differences in timing, duration, and magnitude of the adolescent growth spurt exists. It has been found by multiple studies (e.g., Björk and Helm 1967; Tanner 1978; Hägg and Taranger 1980; Taranger and Hägg 1992; Farkas et al. 1992) that females, although smaller in velocity, begin the growth spurt an average of 2 years earlier than boys. Although our data shows females mature before males at all CV stages (Table 17), we noted only a one-year difference in some of the CV stages. Of the stages around the growth spurt, the CV stages 4,5 , and 6 , females reached these stages about 2 chronological years before males (Table 17). The clear cut sex differences in age of CV stage attainment is shown in Figure 33.

One interesting point is whether the amounts of growth at CV stages are significant for that stage. Table 18 presents data from the five two-way ANOVA test that show significance between the CV2 stages and the amounts of growth occurring during the course of orthodontic treatment $(\mathrm{P}<0.0001)$. From Table 18 , sex is also highly significant, which represents boys accelerated growth velocity through the spurt as compared to girls growth velocity.

Mandibular canine (LC) mineralization and apexification showed similar results as the CV2 stages. Table 14 shows females reached stages 12 and 13 before males and the age range between the two stages is roughly 2 years. For each LC stage and craniofacial dimension, the amount of growth is greater in 
stage 12 than 13 and in boys than girls (Figs. 28-32). Although the significance between LC stages and the amounts of growth over the course of orthodontic treatment is not significant for each variable, it is significant for three of them. Of the two variables that no significances were found, Sella- Nasion and Sella-A Point, smaller amounts of growth were occurring over treatment as compared to the other three variable (Table 16). The reduced changes taking place during treatment is the cause of the insignificance since their growth was in the anticipated direction.

\section{Chronological Age versus Physiological Age}

Physiological age has been shown to be a better assessment for maturity and growth spurt prediction in an individual than chronological age (e.g., Green 1961; Fishman 1979; Fishman 1982). Our study shows CV stages to be a more accurate assessment of the amounts of growth in all dimensions occurring over orthodontic treatment than chronological age (Table 6-10). The most logical reason for this result is because chronological age does not account for the tempo of growth in individuals, thus a wide variability exist with chronological age. When physiological age, here CV stages are used, a more narrow variability of growth occurs at each stage, thus a more individualized assessment is interpreted for the patient. 
Dental assessment has been demonstrated in the literature to be a more accurate assessment of maturity than chronological age alone (Lewis 1991). The dental assessment in our study was to determine if the amounts of growth occurring during treatment are statistically tied to the apexification of the lower canine (LC). We found that LC stage assessment for apexification (stages 12 and 13) was a more accurate method of estimating the amounts of growth occurring over the course of treatment than chronological age.

One problem with LC stage assessment is the dichotomous system. Since only stages 12 and 13 can be used for practical application for growth spurt estimation, the patient either has reached stage 13 or they have not reached itmeaning, there is not a gradient scale as in the CV2 system. So, if an individual that presents for treatment has not developed to stage 12 , then the practitioner only knows the patient will grow more than someone at stage 12 , but cannot estimate the amount of growth because of the dichotomous system. As in the CV2 staging system, it is more discriminatory in its grades, therefore a more accurate estimation can be assessed when using the CV2 system than the LC stage system.

\section{Class II Correction}

The heart of Class II correction is the ability to correct the Class II molar, canine, and skeletal relationships. Although most Class II molar and canine 
relationships can be corrected, some Class II skeletal relationships cannot be corrected due to the reduced growth potential of the patient. When a patient present to the orthodontist for treatment, the growth potential of the patient is of the utmost importance due to the ability of the orthodontist to modify growth to correct skeletal relationships. It has been shown that CV2 is much more accurate for growth assessment during orthodontic treatment than chronological age. For Class II correction, two options are available for an orthodontist: (1) impede maxillary growth forward and (2) encourage mandibular growth forward. If we exam the overall difference in growth between Sella-A Point and Sella-B Point, it is significant for the stages. If a Class II female presents for treatment with a CV2 stage of 5 , then the overall difference of growth is $1.00 \mathrm{~mm}, 0.77 \mathrm{~mm}$ growth of Sella-A Point and $1.77 \mathrm{~mm}$ growth of Sella-B Point (Table 19). If growth of the maxilla is completely restricted with a headgear (which is not probable), then only a maximum of $1.77 \mathrm{~mm}$ compensation of B Point can be gained on A Point. Now, if that same patient presents for orthodontic treatment at an earlier CV2 stage, say stage 2 , then more growth is available for modification. At stage 2, Sella-A Point growth mean is $2.01 \mathrm{~mm}$ while Sella-B Point growth mean is 5.84 $\mathrm{mm}$. Now if growth of the maxilla is restricted in this patient, a total of $5.84 \mathrm{~mm}$ of growth will be gained to help correct the Class II skeletal relationship. This amount of growth is very significant for Class II correction and will help benefit the patient more immensely than the smaller amount of $1.77 \mathrm{~mm}$ in the same 
patient at stage 5. The same relationship exists for males, except males are growing more and faster than females - more growth is available for Class II correction in boys than girls. Not only is there more growth in boys than girls, but boys tend to grow longer, so more growth exists in later stages of CV2 than females. Although more growth occurs for boys in later CV2 stages, proportionally the same amount of growth is occurring at each stage for both sexes.

In sum, more growth is occurring at earlier CV2 stages than at later CV2 stages. This difference is significant between the amounts of growth and the CV2 stages themselves. So, for Class II correction, more growth is available for modification in earlier CV2 stages than at later CV2 stages. Although this seems intuitive, it has been shown this is not necessarily true for chronological ages. Chronological age was not found to be significant for the amounts of growth occurring during treatment-estimates based off of chronological age will not be accurate and will lead to misdiagnosis and incorrect treatment of orthodontic Class II division 1 cases. Diagnosis and treatment based off of CV2 stage estimates will be more accurate than chronological age and give the orthodontist the ability to estimate the growth potential of the specific individual being treated. 


\section{CHAPTER VI}

\section{SUMMARY AND CONCLUSIONS}

When choosing a treatment plan, the orthodontist recognizes differences in each patient that presents for treatment, whether it be dental or skeletal differences. Each treatment plan is specific for that individual patient, and it takes into account the amount of anticipated growth that will occur during treatment. In the case of Class II division 1 corrections, the more growth a patient exhibits during treatment, the more favorable the outcome is for the patient because of the compensatory growth of the mandible that helps correct the Class II skeletal discrepancy.

The purpose of the present study was to determine if the amounts of craniofacial growth observed during treatment are statistically tied to the pretreatment stage of the cervical vertebrae $(\mathrm{CV})$ and/or root mineralization of the mandibular canine (LC). The study was confined to Class II division 1 patients and the pretreatment $\mathrm{CV}$ and $\mathrm{LC}$ stages were assessed and the amount of growth over treatment was measured from cephalometric radiographs. The major findings of this study are summarized here:

- The amounts of facial skeletal growth during treatment differed significantly among the CV2 stages, confirming that assessing this measure of the 
patient's maturational stature is predictive of the parasagittal jaw correction that can be attained.

- The amounts of growth occurring seen during CV2 stages 1, 2, and 3 are significantly greater than stages 4,5 , and 6 -meaning the earlier treatment is initiated, the faster and the greater growth modification can be.

- Root completion (apical closure) of the mandibular canine (LC) was confirmed in this study to be predictive of the amount of in-treatment facial growth. Greater amounts (and rates) of growth occurred prior to apical closure than after LC. Apical closure occurs near the peak of the parapubertal growth spurt.

- The use of CV2 and LC stages were found to more accurately predict the amounts of facial growth occurring during treatment than relying on the patient's chronological age.

In sum, the present study shows that CV2 stages evaluated at the start of treatment are a useful tool in estimating the amounts of growth that will occur over the course of orthodontic treatment. Not only are CV2 and LC staging systems useful for growth estimation, they were found to be more accurate than chronological age alone. 


\section{LIST OF REFERENCES}




\section{LIST OF REFERENCES}

Anderson DL, Thompson GW, Popovich F. Age of attainment of mineralization stages of the permanent dentition. J Forensic Sci. 1976;21:191-200.

Athanasiou AE. Orthodontic cephalometry. Baltimore: Mosby-Wolfe, 1995.

Baccetti T, Franchi L, McNamara JA Jr. An improved version of the cervical vertebral maturation (CVM) method for the assessment of mandibular growth. Angle Orthod. 2002;72:316-23.

Bambha JK. Longitudinal cephalometric roentgenographis study of face and cranium in relation to body height. J Am Dent Assoc. 1961;63:776-99.

Bambha JK, van Natta MA. Longitudinal study of facial growth in relation to skeletal maturation during adolescence. Am J Orthod. 1963;39:481-93.

Behrents RG. Atlas of growth in the aging craniofacial skeleton. Monograph 18, Craniofacial Growth Series. Ann Arbor: Center for Human Growth and Development, University of Michigan, 1986.

Bergersen EO. The male adolescent growth spurt: its prediction and relation to skeletal maturation. Angle Orthod. 1972;42:319-38.

Bishara SE, Jamison JE, Peterson LC, DeKock WH. Longitudinal changes in standing height and mandibular parameters between the ages of 8 and 17 years. Am J Orthod. 1981;80:115-35. 
Bishara SE, Treder JE, Jakobsen JR. Facial and dental changes in adulthood. Am J Orthod Dentofacial Orthop. 1994;106:175-86.

Björk A. Timing of interceptive orthodontic measures based on stages of maturation. Trans Eur Orthod Soc. 1972;61:61-74.

Björk A, Helm S. Prediction of the age of maximum puberal growth in body height. Angle Orthod. 1967;37:134-42.

Bogin B. Patterns of human growth. Cambridge: Cambridge University Press, 1988.

Brown T, Barrett MJ, Grave KC. Facial growth and skeletal maturation at adolescence. Tandlaegebladet. 1971;75:1211-22.

Burstone CJ. Process of maturation and growth prediction. Am J Orthod. $1963 ; 49: 907-20$.

Chang HP, Liao CH, Yang YH, Chang HF, Chen KC. Correlation of cervical vertebra maturation with hand-wrist maturation in children. Kaohsiung J Med Sci. 2001;17:29-35.

Chapman S.M. Ossification of the adductor sesamoid and the adolescent growth spurt. Angle Orthod. 1972;42:236-44.

Chertkow S. Tooth mineralizationas an indicator of the pubertal growth spurt. Am J Orthod. 1980;77:79-91. 
Coutinho S, Buschang PH, Miranda F. Relationships between mandibular canine calcification stages and skeletal maturity. Am J Orthod Dentofacial Orthop. 1993;104:262-8.

Demirijian A, Goldstein H. New system for dental maturity based on seven and four teeth. Ann Hum Biol. 1976;3:411-21.

Demirijian A. Dental development: index of physiologic maturation. Med Hyg. 1978;36:3154-9.

Demirjian A, Goldstein H, Tanner JM. A new system of dental age assessment. Hum Biol. 1973;45:211-27.

Enlow DH, Bang S. Growth and remodeling of the human maxilla. Am J Orthod. 1965;51:446-63.

Enlow DH, Hunter WS. The growth of the face in relation to the cranial base. Transactions of the European Orthodontic Society. 1968;44:321-35.

Enlow DH. Facial growth, 3rd ed. Philidelphia: WB Saunders Company, 1990. Fanning EA. A longitudinal study of tooth formation and root resorption. N Z Dent J. 1961;57:202-16

Farkas LG, Posnick JC, Hreczko TM. Growth patterns of the face: a morphometric study. Cleft Pal Cranio J. 1992;29:308-14.

Fishman, LS. Chronological versus skeletal age, an evaluation of craniofacial growth. Angle Orthod. 1979;49:181-9. 
Fishman LS. Radiographic evaluation of skeletal maturation. Angle Orthod. $1982 ; 52: 88-112$.

Fishman LS. Maturational patterns and prediction during adolescence. Angle Orthod. 1987;57:178-93.

Forsberg CM, Odenrick L. Changes in the relationship between the lips and the aesthetic line from eight years of age to adulthood. Eur J Orthod. 1979;1:265-70.

Garn SM, Lewis AB, Koski K and Poacheck DL. The sex difference in tooth calcification. J Dent Res. 1958;37:561-6.

Garn SM, Lewis AB, Polacheck DL. Variability of tooth formation. J Dent Res. 1959;38:135-48.

Gleiser I and Hunt EE Jr. The permanent mandibular first molar: its calcification, eruption and decay. Am J Phys Anthropol. 1955;13:253-83.

Grave KC. Timing of facial growth: a study of relations with stature and ossification in the hand around puberty. Aust Orthod J. 1973:3;117-22.

Grave KC, Brown T. Skeletal ossification and the adolescent growth spurt. Am J Orthod. 1976;69:611-9.

Grave K, Townsend G. Cervical vertebral maturation as a predictor of the adolescent growth spurt. Aust Orthod J. 2003;19:25-32.

Green LJ. The interrelationships among height, weight and chronological, dental and skeletal ages. Angle Orthod. 1961;31:189-93. 
Greulich WW, Pyle SI. Radiographic atlas of skeletal development of hand and wrist, 2nd. Stanford: Stanford University Press, 1959.

Guo S, Siervogel R, Roche A, Chumlea C. Mathematical modeling of human growth: a comparative study. Am J Hum Biol. 1992;4:93-104.

Haavikko K. Tooth formation age estimated on a few selected teeth: a simple method for clinical use. Proc Finn Dent Soc. 1974;70:15-9.

Hägg U, Taranger J. Skeletal stages of the hand and wrist as indicators of the pubertal growth spurt. Acta Odontol Scand. 1980;38:187-200.

Hägg U, Taranger J. Maturation indicators and pubertal growth spurt. Am J Orthod. 1982;82:299-309.

Hägg U, Taranger J. Height and height velocity in early, average, and late maturers followed to the age of 25: a prospective longitudinal study of Swedish urban children from birth to adulthood. Ann Hum Biol. 1991;18:545-7.

Harris EF. Effects of patient age and sex on treatment: correction of Class II malocclusion with Begg technique. Angle Orthod. 2001;71:433-41.

Hassel B, Farman AG. Skeletal maturation evaluation using cervical vertebrae. Am J Orthod Dentofacial Orthop. 1995;107:58-66.

Hellman M. The face in its developmental career. Dental Cosmos. 1935; 77:68599, 777-87. 
Hunter CJ. The correlation of facial growth with body height and skeletal maturation at adolescence. Angle Orthod. 1966;36:44-54.

Keim RG, Gottlieb EL, Nelson AH, Vogels DS. 2002 JCO study of orthodontic diagnosis and treatment procedures. Part 1. Results and trends. J Clin Orthod. 2002;36:553-68.

Krailassiri S, Anuwongnukroh N, Dechkunadorn S. Relationships between dental calcification stages and skeletal maturity indicators in Thai individuals. Angle Orthod. 2002;72:155-66.

Krogman WM. Maturity as a biological concept. Ohio Dent J. 1968;42:116-20.

Kucukkeles N, Acar A, Biren S, Arun T. Comparisons between cervical vertebrae and hand-wrist maturation for the assessment of skeletal maturity. J Clin Pediatr Dent. 1999;24:47-52.

Kurihara S, Enlow DH, Rangel RD. Remodeling reversals in anterior parts of the human mandible and maxilla. Angle Orthod. 1980:50;98-106.

Lamparski DG. Skeletal age assessment utilizing cervical vertebrae. M.S. thesis, University of Pittsburgh, 1972.

Largo RH, Gasser TH, Prader A, Stuetzle W, Huber PJ. Analysis of the adolescent growth spurt using smoothing spline function. Ann Hum Biol. $1978 ; 5: 412-434$.

Lewis AB, Garn SM. The relationship between tooth formation and other maturation factors. Angle Orthod. 1960;30:70-7. 
Lewis AB, Roche AF, Wagner B. Pubertal spurts in cranial base and mandible. Comparisions within individuals. Angle Orthod. 1985;55:17-30.

Lewis AB. Comparisons between dental and skeletal ages. Angle Orthod. 1991;61:87-92.

Liebgott B. Dental age: its relation to skeletal age and the time of peak circumpuberal growth in length of the mandible. Dent J. 1978;44:223-7.

Love RJ, Murray JM, Mamandras AH. Facial growth in males 16 to 20 years of age. Am J Orthod Dentofac Orthop. 1990;97:200-6.

Marshall WA, Tanner JM. Variations in the pattern of pubertal changes in girls. Arch Dis Child. 1969; 44:291-303.

Marshall WA, Tanner JM. Variations in the pattern of pubertal changes in boys. Arch Dis Child. 1970;45:13-23.

McKinney JR, Harris EF. Influence of patient age and sex on orthodontic treatment: evaluations of Begg lightwire, standard edgewise, and straightwire techniques. Am J Orthod Dentofacial Orthop. 2001;120:53041.

Mitani H, Sato K. Comparison of mandibular growth with other variables during puberty. Angle Orthod. 1992;62:217-222.

Mito T, Sato K, Mitani H. Cervical vertebral bone age in girls. Am J Orthod Dentofacial Orthop. 2002;122:380-5. 
Mito T, Sato K, Mitani H. Predicting mandibular growth potential with cervical vertebral bone age. Am J Orthod Dentofacial Orthop. 2003;124:173-7.

Moore RN, Moyer BA, DuBois LM. Skeletal maturation and craniofacial growth. Am J Orthod Dentofacial Orthop. 1990;98:33-40.

Moorrees CFA, Fanning EA, Hunt EE Jr. Age variation of formation stages for ten permanent teeth. J Dent Res. 1963;42:1490-1502.

Nanda RS. The rates of growth of several facial components measured from serial cephalometric roentgenograms. Am J Orthod. 1955;41:658-73.

Nolla CM. The development of the permanent teeth. M.S. Thesis, University of Michigan, 1952.

Nolla CM. The development of the permanent teeth. J Dent Child. 1960;27:25466.

Ochoa BK, Nanda RS. Comparison of maxillary and mandibular growth. Am J Orthod Dentofacial Orthop. 2004;125:148-59.

O'Reilly MT, Yanniello GJ. Mandibular growth changes and maturation of cervical vertebrae - a longitudinal cephalometric study. Angle Orthod. 1988;58:179-84.

Pancherz H, Hägg U. Dentofacial orthopedics in relation to somatic maturation. An analysis of 70 consecutive cases treated with the Herbst appliance. Am J Orthod. 1985;88:273-87. 
Roman SP, Palma JC, Oteo MD, Nevado E. Skeletal maturation determined by cervical vertebrae development. Eur J Orthod. 2002;24:303-11.

Shuttleworth FK. Sexual maturation and the physical growth of girls age 6 to 19 . Society for research in child development: 1937.

Silveria AM, Fishman LS, Subtelny JD, Kassebaum DK. Facial growth during adolescence in early, average and later maturers. Angle Orthod. 1992;62:185-9.

Singh IJ, Savara BS. Norms of size and annuals increments of seven anatomical measures of maxillae in girls from three to sixteen years of age. Angle Orthod. 1966;36:312-24.

Singh IJ, Savara BS. Norms of size and annuals increments of seven anatomical measures of maxillae in boys from sixteen to twenty years of age. Angle Orthod. 1968;38:104-20.

Smith DW. Growth and its disorders: basics and standards, approach and classifications, growth deficiency disorders, growth excess disorders, obesity. Philadelphia: WB Saunders, 1977.

Sokal RR, Rohlf FJ. Biometry: the principles and practice of statistics in biological research, 3rd ed. New York: WH Freeman and Co, 1995.

Tanner JM, Whitehouse RH and Healy MJR. A New System for Estimating Skeletal Maturity from Hand and Wrist, with Standards Derived from a 
Study of 2.600 healthy british children. Paris: Centre International de L' Enfance, 1962.

Tanner JM, Whitehouse RH, Cameron N, Marshall WA, Healy MJR, Goldstein H. Assessment of skeletal maturity and prediction of adult height (TW2 method). New York: Academic Press, 1975.

Tanner JM. Fetus into man. Harvard: Harvard University Press, 1978.

Taranger J, Hägg U. The timing and duration of adolescent growth. Acta Odontol Scand. 1980;38:57-67.

Ten Cate AR. Oral histology. Mosby, 2003.

Thompson GW, Popovich F. Relationship of craniofacial changes and skeletal age increments in females. Hum Biol. 1973;45:595-603.

Thompson GW, Anderson DL, Popovich F. Sexual dimorphism in dentition mineralization. Growth. 1975;39:289-301.

Tofani MI. Mandibular growth at puberty. Am J Orthod. 1972;62:176-95. van der Linden F. Facial growth and facial orthopedics. Chicago: Quintessence Publishing, 1986.

Von Bremen J, Pancherz H. Efficiency of early and late class II division 1 treatment. Am J Orthod Dentofacial Orthop. 2002;121:31-7.

West KS and McNamara JA Jr. Changes in the craniofacial complex from adolescence to midadulthood: A cephalometric study. Am J Orthod Dentofacial Orthop. 1999;115:521-32. 
Winer BJ. Statistical Principles in Experimental Design, 2nd ed. New York: McGraw-Hill, 1971. 
APPENDIX 
Table A-1. Demographic, skeletal, dental, and cephalometric data for all patients.

\begin{tabular}{|c|c|c|c|c|c|c|c|c|c|c|c|c|}
\hline Sex & Pre-Tx Age & Tx Duration & $\mathrm{C} 2$ & $\mathrm{C} 3$ & $\mathrm{C} 4$ & LL3 & LR3 & $\Delta S-N$ & $\Delta S-G n$ & $\Delta$ S-Go & $\Delta S-\mathrm{A} \mathrm{Pt}$ & $\triangle \mathrm{S}-\mathrm{B} \mathrm{Pt}$ \\
\hline Female & 8.67 & 4.67 & 1 & 1 & 1 & 11 & 11 & 4.30 & 9.20 & 7.60 & 6.30 & 5.90 \\
\hline Male & 12.50 & 4.33 & 1 & 2 & 1 & 11 & 11 & 2.20 & 13.80 & 14.50 & 2.00 & 6.50 \\
\hline Female & 10.42 & 2.58 & 1 & 1 & 1 & 13 & 13 & 3.00 & 8.10 & 0.00 & 2.40 & 4.90 \\
\hline Male & 12.42 & 2.33 & 2 & 1 & 1 & 12 & 12 & 2.50 & 5.60 & 1.90 & 1.20 & 4.00 \\
\hline Female & 12.08 & 4.08 & 2 & 2 & 2 & 13 & 13 & 3.00 & 9.00 & 4.90 & 1.50 & 3.70 \\
\hline Male & 11.58 & 3.83 & 2 & 2 & 2 & 10 & 10 & 2.50 & 10.20 & 10.10 & 3.50 & 5.80 \\
\hline Female & 13.75 & 1.08 & 5 & 5 & 5 & 13 & 13 & -0.50 & 3.10 & -1.20 & 0.10 & -1.70 \\
\hline Male & 14.83 & 5.17 & 4 & 4 & 4 & 12 & 12 & 2.70 & 8.20 & 6.10 & 2.10 & 2.70 \\
\hline Female & 12.67 & 3.42 & 6 & 6 & 6 & 12 & 12 & -3.40 & -3.40 & -5.00 & -3.30 & -5.00 \\
\hline Male & 12.67 & 5.08 & 1 & 1 & 1 & 11 & 12 & 4.40 & 10.90 & 9.30 & 4.10 & 7.00 \\
\hline Male & 12.92 & 2.50 & 2 & 1 & 1 & 11 & 10 & 3.80 & 14.70 & 13.70 & 3.60 & 9.00 \\
\hline Female & 14.08 & 3.25 & 4 & 4 & 4 & 13 & 13 & 1.10 & 3.50 & 5.50 & 2.00 & 4.10 \\
\hline Female & 54.75 & 2.42 & 6 & 6 & 6 & 13 & 13 & 0.50 & -0.70 & -0.80 & -3.00 & -3.00 \\
\hline Female & 27.00 & 4.17 & 6 & 6 & 6 & 13 & 13 & -0.30 & -0.10 & -0.80 & -2.20 & -1.40 \\
\hline Female & 11.25 & 1.08 & 4 & 4 & 4 & 13 & 13 & 0.50 & 3.40 & 1.20 & 0.30 & 3.00 \\
\hline Female & 12.00 & 1.83 & 3 & 3 & 3 & 13 & 13 & 1.60 & 9.70 & 6.80 & 2.00 & 2.70 \\
\hline Female & 14.17 & 2.50 & 5 & 5 & 5 & 13 & 13 & 0.20 & 3.40 & 3.70 & 1.30 & 1.50 \\
\hline Female & 12.17 & 7.67 & 2 & 1 & 1 & 12 & 12 & 0.70 & 18.70 & 12.00 & 0.00 & 12.00 \\
\hline Female & 13.83 & 3.92 & 5 & 5 & 5 & 13 & 13 & 0.80 & 2.80 & 7.40 & -0.20 & -0.30 \\
\hline Female & 11.42 & 2.00 & 2 & 2 & 2 & 12 & 13 & 1.70 & 3.90 & 4.60 & 1.10 & 4.30 \\
\hline Female & 30.25 & 2.92 & 6 & 6 & $\mathrm{NP}$ & 13 & 13 & 4.90 & 10.00 & 4.20 & 9.90 & 6.40 \\
\hline Male & 13.25 & 3.42 & 3 & 3 & 3 & 11 & 11 & 2.00 & 12.80 & 8.80 & 3.90 & 3.30 \\
\hline Female & 12.58 & 5.33 & 2 & 2 & 2 & 10 & 11 & 0.60 & 5.20 & 6.20 & -0.20 & 0.50 \\
\hline Female & 14.67 & 0.92 & 5 & 5 & 5 & 12 & 12 & 2.30 & 4.00 & 1.30 & 0.80 & 0.70 \\
\hline Female & 11.67 & 1.83 & 5 & 5 & 5 & 11 & 11 & 2.00 & 7.60 & 9.30 & 5.80 & 6.00 \\
\hline Male & 14.50 & 4.00 & 3 & 3 & 3 & 13 & 13 & -0.70 & 6.70 & 6.20 & 2.20 & 1.00 \\
\hline Male & 13.75 & 4.08 & 2 & 2 & 2 & na & 12 & 3.20 & 13.70 & 12.20 & 1.10 & $4.2 Q$ \\
\hline
\end{tabular}


Table A-1 (continued)

\begin{tabular}{|c|c|c|c|c|c|c|c|c|c|c|c|c|}
\hline Sex & Pre-Tx Age & Tx Duration & $\mathrm{C} 2$ & $\mathrm{C} 3$ & $\mathrm{C} 4$ & LL3 & LR3 & $\Delta \mathrm{S}-\mathrm{N}$ & $\Delta S-G n$ & $\Delta$ S-Go & $\Delta \mathrm{S}-\mathrm{A} \mathrm{Pt}$ & $\Delta \mathrm{S}-\mathrm{B} \mathrm{Pt}$ \\
\hline Female & 13.42 & 3.42 & 5 & 4 & 4 & 12 & 13 & 2.40 & 8.80 & 7.10 & -0.70 & 1.80 \\
\hline Male & 14.58 & 4.42 & 4 & 4 & 3 & 13 & 13 & 1.90 & 5.10 & 5.10 & -1.70 & 3.50 \\
\hline Female & 11.08 & 1.75 & 1 & 1 & $\mathrm{NP}$ & 13 & 13 & -1.20 & 8.10 & 5.50 & -2.50 & 6.50 \\
\hline Female & 12.92 & 3.17 & 1 & 2 & 3 & 13 & 12 & 1.70 & 6.10 & 3.80 & 2.50 & 2.20 \\
\hline Male & 11.50 & 4.58 & 2 & 2 & 2 & 12 & 12 & 6.10 & 17.00 & 13.50 & 7.10 & 11.30 \\
\hline Male & 13.25 & 3.75 & 1 & 1 & 1 & 11 & 12 & 5.80 & 16.50 & 8.30 & 5.80 & 8.00 \\
\hline Female & 11.92 & 1.83 & 3 & 3 & 3 & 13 & 13 & 2.40 & 4.20 & 1.30 & 2.00 & 0.90 \\
\hline Female & 9.00 & 8.00 & 5 & 4 & 4 & 9 & 8 & 2.40 & 11.00 & 8.20 & 5.50 & 8.10 \\
\hline Female & 11.83 & 3.50 & 3 & 3 & 3 & NA & NA & 1.50 & 10.00 & 9.20 & 2.40 & 6.60 \\
\hline Female & 15.42 & 2.50 & 6 & 6 & 6 & 13 & 13 & -1.20 & -1.40 & -2.80 & -0.60 & -3.20 \\
\hline Male & 13.25 & 5.50 & 3 & 3 & 3 & 13 & 13 & 3.10 & 16.70 & 10.50 & 5.60 & 9.40 \\
\hline Male & 12.08 & 2.58 & 2 & 2 & 1 & 12 & 12 & 3.90 & 10.40 & 16.80 & -0.30 & 5.40 \\
\hline Female & 14.67 & 3.83 & 5 & 5 & 5 & 13 & 13 & -4.10 & 7.40 & 6.20 & 1.20 & 6.80 \\
\hline Female & 31.50 & 2.25 & 6 & 6 & 6 & 13 & 13 & 1.20 & -0.20 & -1.30 & 1.40 & -2.10 \\
\hline Female & 12.33 & 4.33 & 5 & 5 & 5 & 12 & 12 & 0.20 & 2.90 & 4.40 & 0.10 & 0.60 \\
\hline Male & 12.33 & 5.92 & 2 & 2 & 2 & 12 & 12 & 2.40 & 20.50 & 19.30 & 6.20 & 11.80 \\
\hline Male & 13.58 & 2.92 & 4 & 4 & 3 & 13 & 13 & 4.50 & 10.80 & 10.20 & 1.00 & 7.00 \\
\hline Male & 13.33 & 2.50 & 3 & 3 & 3 & 12 & 12 & 1.40 & 10.20 & 5.90 & 6.30 & 3.10 \\
\hline Male & 13.00 & 3.67 & 2 & 2 & 2 & 13 & 12 & 3.30 & 15.10 & 16.70 & 5.60 & 9.80 \\
\hline Female & 23.92 & 3.25 & 6 & 6 & 6 & 13 & 13 & 4.10 & 9.90 & 9.70 & 5.60 & 2.80 \\
\hline Female & 11.00 & 1.83 & 2 & 2 & 2 & 13 & 13 & 2.50 & 6.70 & 5.30 & 3.60 & 5.70 \\
\hline Female & 12.92 & 2.00 & 2 & 2 & 2 & 13 & 13 & 3.90 & 8.40 & 9.40 & 2.00 & 4.10 \\
\hline Male & 12.50 & 3.00 & 5 & 5 & 5 & 12 & 12 & 0.30 & 7.80 & 7.20 & -1.40 & 2.70 \\
\hline Male & 14.83 & 3.25 & 2 & 2 & 2 & 11 & 11 & 5.10 & 10.80 & 4.70 & 1.60 & 3.50 \\
\hline Male & 10.00 & 7.25 & 2 & 2 & 2 & 10 & 10 & 10.30 & 19.70 & 16.80 & 6.90 & 13.50 \\
\hline Female & 43.00 & 3.17 & 6 & 6 & 6 & 13 & 13 & -1.60 & 0.30 & -0.90 & -2.00 & -4.30 \\
\hline Male & 10.42 & 4.08 & 1 & 1 & $\mathrm{NP}$ & 12 & 13 & 3.50 & 10.20 & 5.80 & 1.80 & $9.7 q$ \\
\hline
\end{tabular}


Table A-1 (continued)

\begin{tabular}{|c|c|c|c|c|c|c|c|c|c|c|c|c|}
\hline Sex & Pre-Tx Age & Tx Duration & $\mathrm{C} 2$ & $\mathrm{C} 3$ & $\mathrm{C} 4$ & LL3 & LR3 & $\Delta \mathrm{S}-\mathrm{N}$ & $\Delta S-G n$ & $\Delta$ S-Go & $\Delta \mathrm{S}-\mathrm{A} \mathrm{Pt}$ & $\Delta S-B$ Pt \\
\hline Female & 17.00 & 3.00 & 6 & 6 & 6 & 13 & 13 & 3.80 & 9.60 & -2.50 & 4.20 & 1.80 \\
\hline Male & 14.67 & 3.58 & 4 & 4 & 4 & 12 & 12 & 1.20 & 4.60 & 2.20 & 1.60 & -0.30 \\
\hline Female & 10.00 & 6.75 & 1 & 1 & 1 & 9 & 10 & 1.50 & 12.00 & 8.70 & 5.10 & 6.80 \\
\hline Female & 13.75 & 2.75 & 4 & 3 & 3 & 13 & 13 & 0.20 & 2.70 & 4.40 & 0.60 & 1.30 \\
\hline Male & 11.33 & 2.42 & 5 & 4 & 4 & 13 & 13 & 2.40 & 6.60 & 0.50 & 0.10 & 3.70 \\
\hline Female & 14.25 & 3.58 & 5 & 4 & 4 & 13 & 13 & -0.10 & 4.20 & 5.00 & -0.90 & 3.20 \\
\hline Male & 14.25 & 1.42 & 3 & 3 & 3 & 13 & 13 & 1.80 & 5.60 & 3.60 & 2.90 & 2.90 \\
\hline Male & 14.50 & 2.67 & 6 & 6 & 6 & 13 & 13 & 1.90 & 4.70 & 4.30 & 1.60 & 5.30 \\
\hline Female & 13.50 & 2.33 & 5 & 5 & 5 & 13 & 13 & 2.00 & 2.90 & 4.10 & -0.40 & 0.60 \\
\hline Male & 12.00 & 1.67 & 3 & 3 & 3 & 13 & 13 & 4.00 & 9.50 & 5.40 & 3.80 & 4.70 \\
\hline Male & 12.92 & 2.92 & 2 & 2 & 2 & 12 & 12 & 3.60 & 9.20 & 7.90 & 4.30 & 5.40 \\
\hline Female & 12.33 & 2.33 & 3 & 3 & 3 & 11 & 12 & -0.40 & 3.60 & -0.40 & 1.60 & -0.60 \\
\hline Female & 13.83 & 2.33 & 5 & 5 & 5 & 13 & 13 & 1.60 & 4.60 & 4.70 & -2.90 & -0.30 \\
\hline Male & 16.00 & 3.67 & 4 & 4 & 4 & 13 & 13 & 2.20 & 7.50 & 10.50 & 4.20 & 5.60 \\
\hline Female & 13.67 & 4.08 & 4 & 4 & 4 & 12 & 12 & 0.70 & 3.90 & 5.30 & 0.20 & 2.00 \\
\hline Female & 10.58 & 4.17 & 3 & 3 & 3 & 11 & 11 & 2.50 & 12.80 & 9.20 & 4.60 & 6.40 \\
\hline Female & 13.00 & 3.92 & 3 & 3 & 3 & 13 & 13 & 0.50 & 6.10 & 7.00 & 3.10 & 6.20 \\
\hline Male & 14.33 & 3.08 & 4 & 4 & 4 & 12 & 12 & 1.10 & 9.70 & 10.60 & 3.60 & 6.00 \\
\hline Male & 12.33 & 4.92 & 3 & 3 & 2 & 12 & 12 & 6.90 & 15.90 & 12.50 & 3.30 & 5.90 \\
\hline Female & 12.50 & 3.83 & 4 & 4 & 4 & 12 & 12 & 2.30 & 6.30 & 1.50 & -1.00 & 3.60 \\
\hline Male & 22.08 & 3.50 & 2 & 2 & 2 & 11 & 12 & 5.30 & 11.00 & 9.00 & 5.70 & 6.30 \\
\hline Female & 12.83 & 3.08 & 5 & 5 & 5 & 13 & 13 & 1.20 & 4.70 & 7.10 & 0.30 & 1.80 \\
\hline Male & 13.33 & 4.17 & 4 & 4 & 4 & 13 & 13 & 4.30 & 7.90 & 7.40 & 4.40 & 5.10 \\
\hline Male & 13.25 & 5.33 & 2 & 2 & 2 & 11 & 12 & 5.70 & 15.50 & 10.40 & 6.70 & 12.50 \\
\hline Female & 13.75 & 2.33 & 5 & 5 & 5 & 13 & 13 & 0.00 & 0.20 & 0.40 & 0.60 & 1.40 \\
\hline Male & 11.83 & 3.58 & 2 & 2 & 2 & 12 & 12 & 3.80 & 14.10 & 8.40 & 1.60 & 10.80 \\
\hline Male & 14.08 & 5.50 & 3 & 3 & 3 & 12 & 13 & 5.90 & 12.90 & 9.40 & 2.80 & 4.49 \\
\hline
\end{tabular}


Table A-1 (continued)

\begin{tabular}{|c|c|c|c|c|c|c|c|c|c|c|c|c|}
\hline Sex & Pre-Tx Age & Tx Duration & $\mathrm{C} 2$ & $\mathrm{C} 3$ & $\mathrm{C} 4$ & LL3 & LR3 & $\Delta \mathrm{S}-\mathrm{N}$ & $\Delta S-G n$ & $\Delta$ S-Go & $\Delta \mathrm{S}-\mathrm{A} \mathrm{Pt}$ & $\Delta S-B \mathrm{Pt}$ \\
\hline Female & 10.42 & 2.25 & 2 & 2 & 2 & 12 & 12 & 0.30 & 3.20 & 2.90 & 0.90 & 2.00 \\
\hline Female & 12.50 & 1.83 & 4 & 4 & 4 & 13 & 12 & 2.90 & 7.60 & 1.70 & 1.20 & 2.50 \\
\hline Male & 12.92 & 3.33 & 2 & 1 & 1 & 13 & 13 & 3.10 & 16.00 & 11.60 & 7.10 & 10.30 \\
\hline Female & 15.92 & 2.42 & 5 & 5 & 5 & 13 & 13 & 1.20 & -0.50 & -1.70 & -0.20 & -0.20 \\
\hline Male & 13.58 & 2.25 & 3 & 2 & 2 & 13 & 13 & 7.40 & 21.00 & 17.80 & 10.60 & 13.10 \\
\hline Male & 9.75 & 5.17 & 1 & 1 & 1 & 9 & 9 & 4.10 & 19.90 & 11.50 & 8.90 & 14.70 \\
\hline Female & 12.33 & 4.58 & 5 & 5 & 5 & 12 & 13 & 3.70 & 6.20 & 4.20 & 1.90 & -1.50 \\
\hline Male & 16.67 & 3.25 & 6 & 5 & 5 & 13 & 13 & 3.60 & 10.30 & 10.10 & 6.10 & 8.70 \\
\hline Female & 10.83 & 1.75 & 4 & 4 & 4 & 11 & 11 & 2.40 & 6.60 & 6.60 & 2.60 & 6.70 \\
\hline Female & 12.92 & 1.75 & 2 & 2 & 2 & 13 & 13 & 2.40 & 9.10 & 5.50 & 2.50 & 4.70 \\
\hline Male & 13.08 & 3.33 & 5 & 5 & 5 & 13 & 13 & 4.30 & 7.80 & 7.20 & 2.70 & 3.60 \\
\hline Female & 12.92 & 4.58 & 3 & 3 & 3 & 11 & 11 & 0.60 & 7.00 & 8.20 & 1.70 & -1.40 \\
\hline Female & 12.25 & 2.58 & 2 & 2 & 2 & 13 & 13 & 5.10 & 14.40 & 12.60 & 6.50 & 9.00 \\
\hline Female & 9.67 & 3.58 & 4 & 4 & 4 & 11 & 11 & 2.20 & 10.80 & 8.20 & 3.10 & 7.30 \\
\hline Female & 13.75 & 2.67 & 5 & 5 & 5 & 12 & 11 & 0.20 & 2.40 & 2.40 & -5.30 & 4.00 \\
\hline Female & 14.42 & 1.50 & 4 & 4 & 4 & 12 & 13 & -1.50 & 0.70 & -0.80 & 1.80 & 2.10 \\
\hline Male & 14.00 & 1.75 & 2 & 1 & 1 & 12 & 12 & 3.50 & 10.10 & 8.50 & -0.20 & 8.10 \\
\hline Female & 13.08 & 1.50 & 3 & 3 & 3 & 13 & 13 & 0.70 & 4.80 & 3.00 & 1.80 & 0.30 \\
\hline Female & 13.92 & 4.00 & 4 & 4 & 4 & 13 & 13 & 2.70 & 10.20 & 7.90 & -0.30 & 4.70 \\
\hline Female & 11.17 & 3.75 & 3 & 3 & 3 & 12 & 11 & 1.70 & 8.60 & 3.90 & 2.20 & 2.50 \\
\hline Male & 11.33 & 1.67 & 2 & 2 & 2 & 12 & 12 & 0.90 & 5.40 & 1.30 & 2.00 & -0.70 \\
\hline Male & 14.50 & 1.92 & 1 & 1 & 1 & 12 & NA & 1.10 & 8.10 & 5.90 & 5.90 & 4.20 \\
\hline Female & 10.17 & 1.92 & 2 & 2 & 2 & 12 & 12 & 2.00 & 9.30 & 8.60 & -0.30 & 5.60 \\
\hline Male & 13.33 & 3.42 & 2 & 2 & 1 & 12 & 12 & 4.90 & 12.00 & 9.60 & 4.50 & 6.60 \\
\hline Male & 11.00 & 3.50 & 2 & 2 & 2 & 11 & 10 & 2.00 & 9.90 & 5.60 & -0.60 & 9.80 \\
\hline Female & 11.33 & 2.42 & 3 & 3 & 3 & 12 & 12 & 3.80 & 9.20 & 9.80 & 3.40 & 8.90 \\
\hline Male & 13.58 & 2.92 & 2 & 1 & 1 & 11 & 11 & 2.50 & 9.30 & 8.80 & 0.30 & 7.29 \\
\hline
\end{tabular}


Table A-1 (continued)

\begin{tabular}{|c|c|c|c|c|c|c|c|c|c|c|c|c|}
\hline Sex & Pre-Tx Age & Tx Duration & $\mathrm{C} 2$ & $\mathrm{C} 3$ & $\mathrm{C} 4$ & LL3 & LR3 & $\Delta \mathrm{S}-\mathrm{N}$ & $\Delta S-G n$ & $\Delta$ S-Go & $\Delta \mathrm{S}-\mathrm{A} \mathrm{Pt}$ & $\Delta S-B$ Pt \\
\hline Female & 9.25 & 1.33 & 2 & 1 & 1 & 11 & 10 & 5.80 & 19.90 & 16.90 & 9.40 & 17.20 \\
\hline Male & 12.67 & 3.00 & 2 & 2 & 2 & 12 & 11 & 1.40 & 9.70 & 9.40 & 2.40 & 5.00 \\
\hline Male & 13.42 & 1.67 & 4 & 4 & 3 & 12 & 12 & 2.20 & 13.00 & 10.50 & -0.40 & 10.50 \\
\hline Female & 12.42 & 3.50 & 4 & 4 & 4 & 13 & 13 & -0.30 & 0.20 & 3.30 & 1.70 & -1.10 \\
\hline Male & 13.92 & 1.83 & 2 & 2 & 2 & 12 & 13 & 3.60 & 8.30 & 7.50 & 3.10 & 5.70 \\
\hline Female & 12.08 & 4.67 & 5 & 5 & 5 & 13 & 13 & 2.40 & 2.00 & -0.40 & -0.60 & -1.40 \\
\hline Female & 9.83 & 3.33 & 2 & 2 & 2 & 13 & 13 & 2.90 & 6.30 & 5.10 & 0.00 & 3.20 \\
\hline Male & 12.83 & 3.67 & 1 & 2 & 2 & 12 & 12 & 2.50 & 9.00 & 8.50 & 0.10 & 6.00 \\
\hline Female & 30.67 & 4.42 & 6 & 6 & 6 & 13 & 13 & -0.10 & 0.30 & 4.10 & -2.40 & -2.80 \\
\hline Male & 12.00 & 3.25 & 3 & 3 & 3 & 12 & 12 & 3.30 & 15.60 & 13.40 & 3.50 & 8.70 \\
\hline Female & 11.08 & 3.33 & 3 & 3 & 3 & 13 & 13 & 4.20 & 2.40 & 1.00 & 1.10 & -1.50 \\
\hline Male & 14.08 & 3.50 & 3 & 3 & $\mathrm{NP}$ & 13 & 13 & 4.80 & 11.50 & 13.10 & 3.50 & 9.30 \\
\hline Female & 12.83 & 1.83 & 2 & 2 & 2 & 13 & 13 & -0.80 & 3.80 & 3.60 & -1.10 & 2.50 \\
\hline Male & 11.00 & 4.17 & 2 & 2 & 2 & 12 & 12 & 3.50 & 10.10 & 7.70 & 2.20 & 6.40 \\
\hline Male & 13.08 & 2.50 & 3 & 3 & 3 & 12 & 13 & 1.90 & 11.70 & 12.60 & 3.80 & 6.40 \\
\hline Female & 21.42 & 2.83 & 6 & 6 & 6 & 13 & 13 & -0.20 & 0.90 & 2.40 & 3.10 & -0.30 \\
\hline Female & 13.83 & 4.67 & 3 & 3 & 2 & 13 & 13 & 0.90 & 5.10 & 4.70 & 2.70 & -1.70 \\
\hline Female & 9.58 & 2.50 & 1 & 1 & 1 & 10 & 10 & 2.60 & 7.30 & 1.90 & 0.10 & 3.60 \\
\hline Female & 15.00 & 3.42 & 6 & 6 & 5 & 13 & 13 & -0.30 & 0.70 & 1.40 & -3.40 & -0.20 \\
\hline Female & 13.17 & 2.42 & 6 & 6 & 6 & 13 & 13 & 1.80 & 2.80 & -0.50 & -1.60 & -0.50 \\
\hline Female & 13.67 & 4.08 & 5 & 5 & $\mathrm{NP}$ & 13 & 13 & 1.50 & 3.20 & 4.50 & 0.00 & 3.80 \\
\hline Male & 17.83 & 2.58 & 5 & 5 & 5 & 13 & 13 & 0.90 & 3.70 & 3.80 & 2.90 & 3.30 \\
\hline Female & 14.83 & 2.00 & 6 & 6 & 6 & 13 & 13 & 2.10 & 5.00 & 1.10 & 3.40 & 1.90 \\
\hline Female & 10.08 & 3.67 & 4 & 4 & 4 & 13 & 12 & -0.50 & 4.60 & -2.30 & -0.80 & 1.00 \\
\hline Female & 11.50 & 4.08 & 3 & 3 & 2 & 11 & 10 & 4.60 & 14.60 & 10.60 & 8.00 & 9.30 \\
\hline Male & 12.92 & 3.75 & 3 & 3 & 3 & 13 & 13 & 4.70 & 12.90 & 10.60 & 2.10 & 5.30 \\
\hline Female & 12.17 & 1.92 & 2 & 2 & 2 & 13 & 13 & 2.10 & 7.00 & 7.40 & -3.00 & 6.79 \\
\hline
\end{tabular}


Table A-1 (continued)

\begin{tabular}{|c|c|c|c|c|c|c|c|c|c|c|c|c|}
\hline Sex & Pre-Tx Age & Tx Duration & $\mathrm{C} 2$ & $\mathrm{C} 3$ & $\mathrm{C} 4$ & LL3 & LR3 & $\Delta S-N$ & $\Delta \mathrm{S}-\mathrm{Gn}$ & $\Delta$ S-Go & $\Delta S-\mathrm{A} \mathrm{Pt}$ & $\triangle \mathrm{S}-\mathrm{B} \mathrm{Pt}$ \\
\hline Male & 13.83 & 2.50 & 5 & 4 & 5 & 13 & 13 & 3.20 & 6.60 & 8.30 & 4.40 & 1.50 \\
\hline Male & 15.92 & 2.67 & 5 & 5 & 5 & NA & 13 & 0.60 & 1.10 & 4.70 & -0.50 & 0.30 \\
\hline Male & 13.50 & 3.25 & 4 & 4 & 4 & 13 & 12 & 3.10 & 8.80 & 10.00 & 1.90 & 4.20 \\
\hline Female & 13.17 & 1.75 & 2 & 2 & 1 & 12 & 12 & 1.80 & 6.30 & 3.50 & 2.20 & 2.00 \\
\hline Female & 14.08 & 1.83 & 6 & 5 & 6 & 13 & 13 & 1.40 & 4.30 & -0.50 & -4.00 & 4.20 \\
\hline Female & 12.42 & 1.92 & 4 & 3 & 3 & 13 & 13 & -1.20 & 0.20 & -2.10 & -4.60 & -1.40 \\
\hline Female & 12.17 & 3.17 & 3 & 3 & 3 & 11 & 12 & 0.10 & 5.20 & 1.10 & 2.60 & 0.70 \\
\hline Male & 10.92 & 4.50 & 2 & 2 & 2 & NA & NA & 2.40 & 9.10 & 5.50 & 3.00 & 3.20 \\
\hline Male & 12.67 & 2.33 & 1 & 1 & 1 & 13 & 13 & 3.50 & 12.60 & 8.30 & 5.30 & 9.20 \\
\hline Male & 14.92 & 3.67 & 4 & 4 & 4 & 13 & 13 & 1.70 & 2.50 & 4.30 & -0.10 & 0.60 \\
\hline Female & 10.75 & 2.75 & 2 & 2 & 2 & 10 & 10 & 5.90 & 11.00 & 10.70 & 7.10 & 10.30 \\
\hline Male & 13.92 & 2.92 & 3 & 3 & 3 & 12 & 12 & 4.50 & 14.60 & 11.50 & 7.80 & 12.00 \\
\hline Female & 12.92 & 3.33 & 5 & 5 & 5 & 13 & 13 & 5.30 & 7.20 & 7.60 & 2.90 & 0.40 \\
\hline Female & 11.00 & 2.50 & 4 & 4 & 4 & 13 & 13 & 0.20 & 3.60 & 4.10 & 0.90 & 2.30 \\
\hline Male & 10.50 & 2.00 & 5 & 5 & 4 & 12 & 12 & 1.70 & 5.50 & -1.40 & -0.40 & 1.20 \\
\hline Male & 11.33 & 3.42 & 3 & 3 & 3 & 11 & 10 & 4.50 & 13.90 & 9.00 & 5.80 & 8.80 \\
\hline Male & 13.92 & 1.83 & 2 & 1 & 1 & 13 & 13 & 2.40 & 1.80 & 1.00 & 1.80 & -1.10 \\
\hline Female & 23.25 & 2.25 & 6 & 6 & 6 & 13 & 13 & -0.40 & 0.30 & 3.30 & 0.10 & 0.60 \\
\hline Female & 32.83 & 2.50 & 6 & 6 & 6 & 13 & 13 & -0.30 & 0.70 & 2.70 & -1.70 & 0.40 \\
\hline Male & 12.25 & 2.50 & 1 & 1 & 1 & 0 & 0 & 5.50 & 16.30 & 11.90 & 3.00 & 8.40 \\
\hline Female & 13.67 & 4.00 & 6 & 6 & 6 & 13 & 13 & -1.30 & 1.70 & -0.60 & 1.10 & -1.10 \\
\hline Female & 13.92 & 2.83 & 6 & 6 & 6 & 13 & 13 & -1.80 & 0.10 & 3.10 & -1.30 & -1.60 \\
\hline Female & 47.25 & 2.33 & 6 & 6 & 6 & 13 & 13 & 0.10 & 0.10 & -1.60 & -2.70 & -1.40 \\
\hline Female & 13.08 & 2.42 & 6 & 6 & 6 & 13 & 13 & 0.20 & 2.00 & -2.70 & -1.40 & -0.60 \\
\hline Male & 13.50 & 2.75 & 1 & 1 & 1 & 12 & 12 & 4.10 & 17.60 & 10.10 & 3.70 & 9.60 \\
\hline Male & 12.75 & 2.50 & 1 & 1 & 1 & 11 & 11 & 5.20 & 12.20 & 8.10 & 3.90 & 3.90 \\
\hline Female & 24.00 & 2.08 & 6 & 6 & 6 & 13 & 13 & 3.40 & 1.20 & 2.20 & -0.70 & -1.09 \\
\hline
\end{tabular}


Table A-1 (continued)

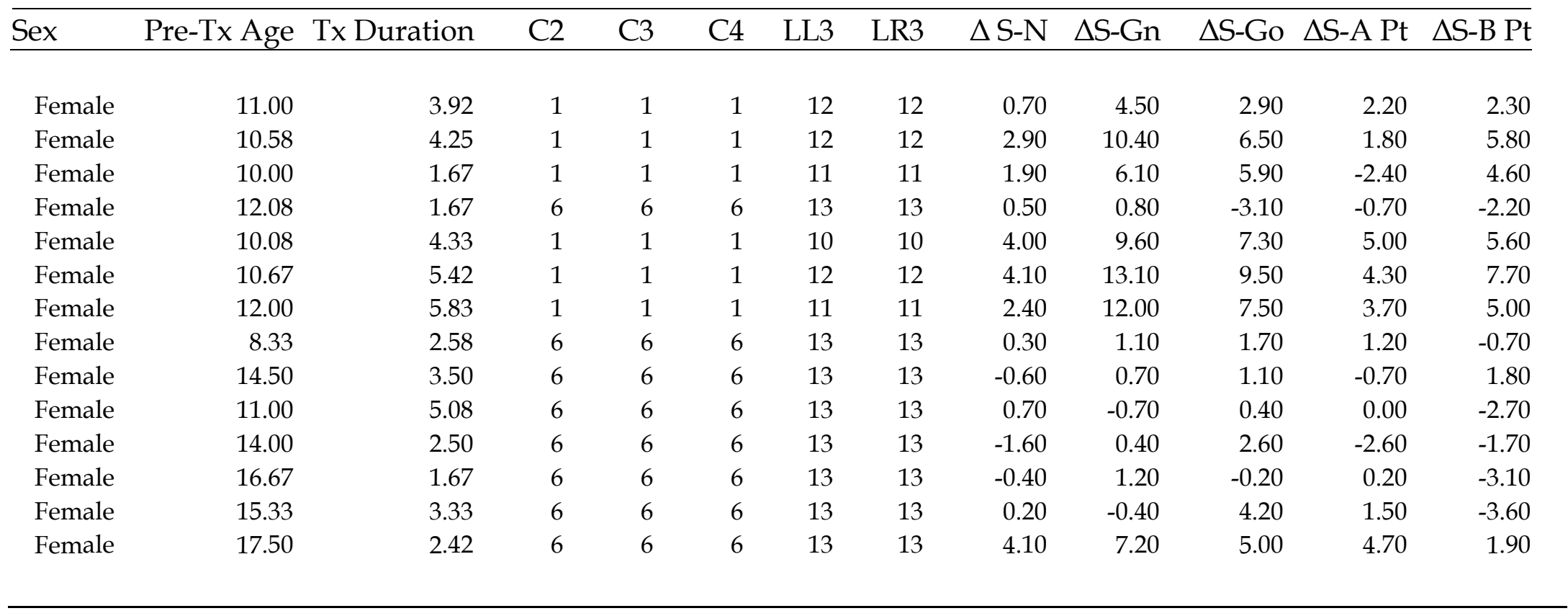


Charles Allen Chance was born in Knoxville, Tennessee, on July 11, 1976. His family resided in Knoxville until his father, who worked for Tennessee Valley Authority, was transferred to Johnson City, Tennessee, in 1979. In 1980 they moved back to Knoxville until his father was transferred again to Chattanooga, Tennessee, in 1984. During the summer of 1988, the family made one last move back to Knoxville where his family currently lives. Allen attended The University of Tennessee, Knoxville, where he received a Bachelor of Science in Chemistry. After undergraduate study, he attended The University of Tennessee College of Dentistry in Memphis, Tennessee, where he received the Doctor of Dental Surgery degree May 2003, with High Honors. After this, he studied as a graduate student in the Department of Orthodontics at The University of Tennessee, Memphis, and received his Master of Dental Science in May, 2006. Allen plans to move to East Tennessee to practice orthodontics. 